\title{
WestVirginiaUniversity
}

THE RESEARCH REPOSITORY @ WVU

Graduate Theses, Dissertations, and Problem Reports

2005

\section{Gallium nitride light-emitting diodes and a study of etching techniques}

Smiti Bhattacharya

West Virginia University

Follow this and additional works at: https://researchrepository.wvu.edu/etd

\section{Recommended Citation}

Bhattacharya, Smiti, "Gallium nitride light-emitting diodes and a study of etching techniques" (2005).

Graduate Theses, Dissertations, and Problem Reports. 4134.

https://researchrepository.wvu.edu/etd/4134

This Thesis is protected by copyright and/or related rights. It has been brought to you by the The Research Repository @ WVU with permission from the rights-holder(s). You are free to use this Thesis in any way that is permitted by the copyright and related rights legislation that applies to your use. For other uses you must obtain permission from the rights-holder(s) directly, unless additional rights are indicated by a Creative Commons license in the record and/ or on the work itself. This Thesis has been accepted for inclusion in WVU Graduate Theses, Dissertations, and Problem Reports collection by an authorized administrator of The Research Repository @ WVU. For more information, please contact researchrepository@mail.wvu.edu. 


\title{
GALLIUM NITRIDE LIGHT EMITTING DIODES AND A STUDY OF ETCHING TECHNIQUES
}

\author{
by
}

Smiti Bhattacharya

Thesis submitted to the College of Engineering and Mineral Resources at West Virginia University

in partial fulfillment of the requirements

for the degree of

Master of Science

in

Electrical Engineering

Approved by

Dimitris Korakakis, Ph. D., Committee Chairperson

Lawrence A. Hornak, Ph. D.

Charter Stinespring, Ph. D.

Lane Department of Computer Science and Electrical Engineering

Morgantown, West Virginia

2005

Keywords: Gallium Nitride, Light Emitting Diode, Laser Ablation

Copyright 2005 Smiti Bhattacharya 


\section{ABSTRACT \\ Gallium Nitride Light Emitting Diodes and a Study of Etching Techniques}

\section{Smiti Bhattacharya}

In the recent years Light Emitting Diodes of impressive longevity and high efficiency have been produced. Gallium Nitride in particular is used in the manufacture of Blue Light Emitting Diodes because it is a direct band gap semiconductor which can be alloyed with AlN and InN allowing band gap energies to range from $1.9 \mathrm{eV}$ to $6.2 \mathrm{eV}$, which allows the emission of short wavelengths like that of blue light. A new structure for a GaN blue LED has been proposed. The difficulty faced in wet etching $\mathrm{GaN}$ resulted in the study of viable dry etching techniques. This study has looked into the Reactive Ion Etching of Gallium Nitride in Sulphur Hexafluoride. The use of Laser Ablation as an alternative method of etching $\mathrm{GaN}$ has been studied in detail. N-type contacts have been deposited on the etched surface and their specific contact resistivities have been measured for different samples under different conditions. 


\section{Acknowledgements}

I would like to express my appreciation towards my advisor Dr. Dimitris Korakakis for his constant guidance, support and encouragement through the course of my research. I would also like to extend my appreciation towards my committee members Dr. Lawrence A Hornak and Dr. Charter Stinespring for their invaluable insights and guidance. Many thanks to Dr. Kolin Brown, for his guidance while training me in the use of various lab equipment and his valuable discussions and suggestions. I would also like to thank Mr. James Lenke, Mr. Trust Razunguzwa, for their help in teaching me how to use the Oxford Copper Vapor Laser and their patience in answering my many questions. I also extend my sincere appreciation towards Mr. Livieu Magean and Steve Carpenter for the many hours that they have sat with me analyzing samples under the Scanning Electron Microscope.

I express my sincere thanks towards my colleagues Sridhar Kuchibhatla, Lavanya Turlapati, John P Harmon, Kalyan Reddy Kasarla, and Timothy Cornell and all my friends in the lab for their help and encouragement. 


\section{$\underline{\text { Dedication }}$}

It is with tremendous love and pride that I dedicate this work to my parents Mrs. Joyeeta Bhattacharya and Dr. Jayant Lal Bhattacharya without whose incessant support and encouragement I wouldn't have been able to come this far.

I would also like to extend my sincere appreciation towards all my friends for their belief in my abilities and for being my family away from home! 


\section{TABLE OF CONTENTS}

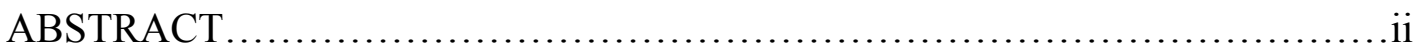

ACNKOWLEDGEMENTS ..................................................

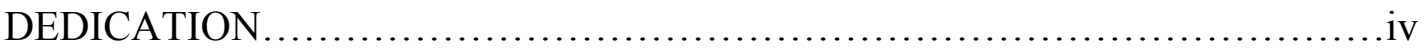

TABLE OF CONTENTS.......................................................

TABLE OF FIGURES......................................................iii

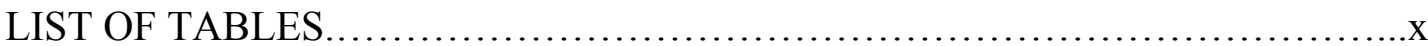

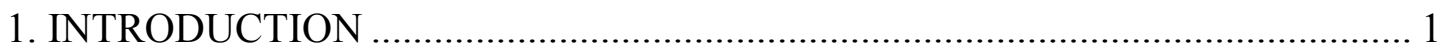

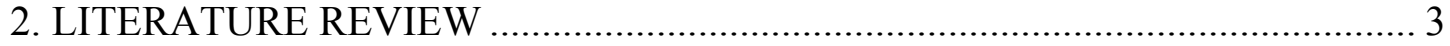

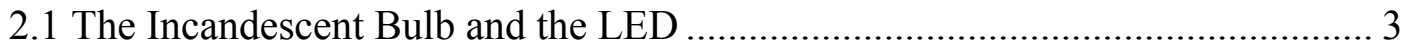

2.2 Use of $\mathrm{GaN}$ for Light Emitting Diodes.......................................................... 4

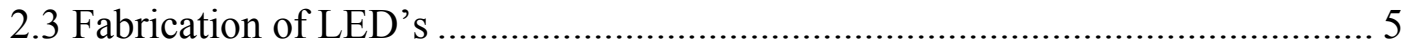

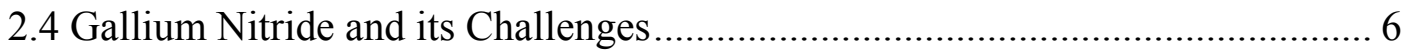

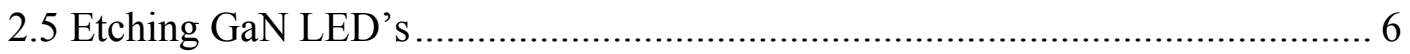

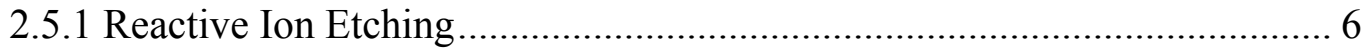

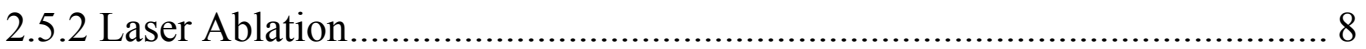

2.6 Principles involved in Light Emitting Diodes .............................................. 9

2.6.1 Radiative and Non Radiative Recombination........................................... 9

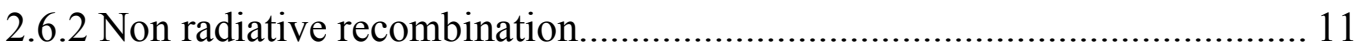

2.6.3 Current Voltage Characteristics ............................................................... 12

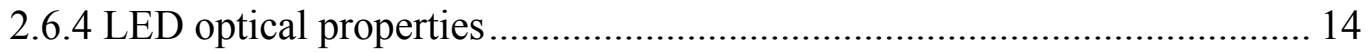

2.6.5 Light Escape Cone ………………………….................................. 15

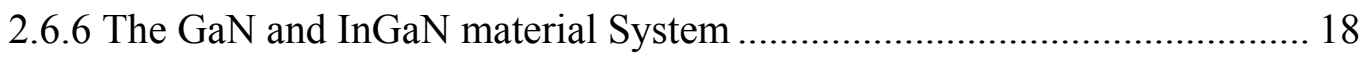

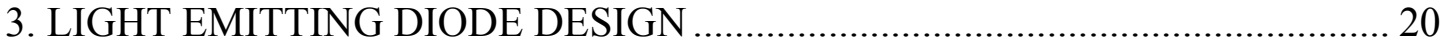

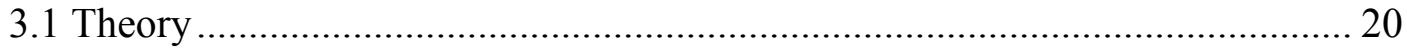

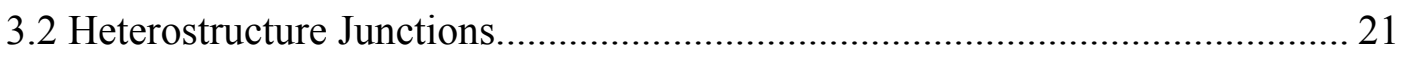

3.3 Heterostructure Junctions and device Resistance ............................................ 22

3.4 Thickness of the Active region in the quantum wells...................................... 23 
3.5 Solution to the Schrödinger's wave equation 24

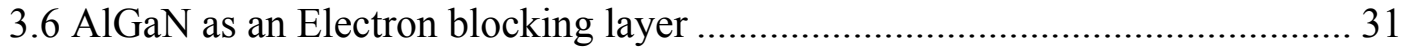

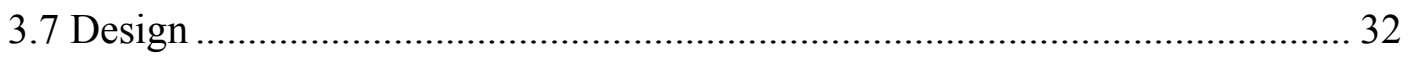

3.7.1 Calculation of width of $\mathrm{AlGaN}$ barrier ............................................... 34

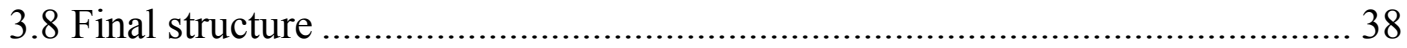

4. REACTIVE ION ETCHING PROCESS AND EXPERIMENTAL RESULTS .... 40

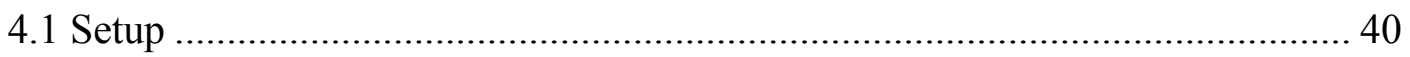

4.1.1 Apparatus and Chemicals used ........................................................... 40

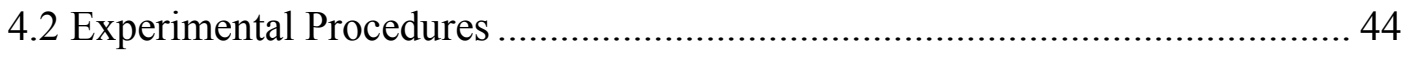

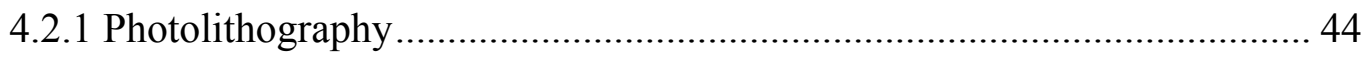

4.2.2 Calculation of the Etch Rates of $\mathrm{SiO}_{2}$ and the PhotoResist .................... 50

4.2.3 Determination of the etch rates of $\mathrm{SiO}_{2}$, Photoresist, and determining its variation with different parameters effecting the etch rates............................ 51

4.2.4 Determining the Etch Rate of Gallium Nitride ..................................... 52

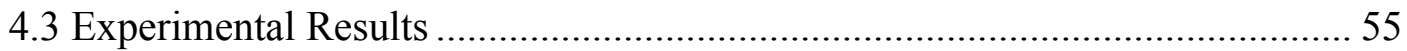

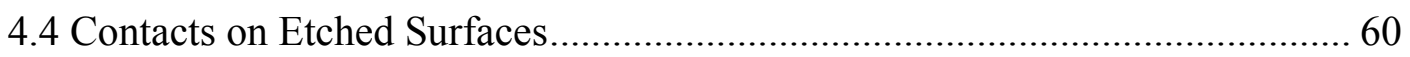

\section{LASER ABLATION OF GALLIUM NITRIDE AND EXPERIMENTAL}

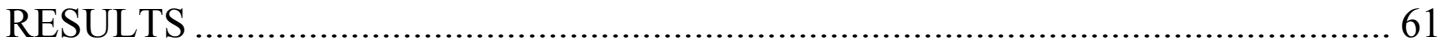

5.1 Algorithm for performing Ablation on GaN using a Copper Vapor Laser....... 63

5.1.1 Choosing an appropriate Mask for the System ...................................... 63

5.1.2 Load the sample onto the table and perform the focus test to choose the focus.

5.1.3 Write a program to perform the ablation in the desired fashion with the

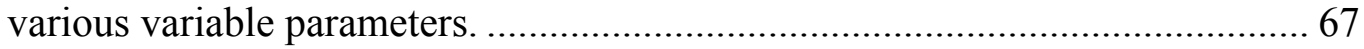

5.1.4 Vary the parameters to attain the desired ablation................................ 67

5.1.5 Treat the sample with $\mathrm{HCl}$ before observing under the SEM.................. 72

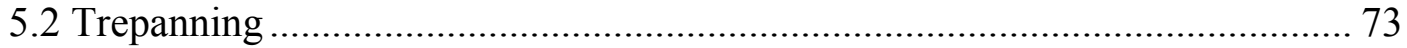

5.3 Deposition of Contacts on the Ablated Gallium Nitride.............................. 76

5.4 Proposed Laser Ablation for deposition of Metal Contacts ............................ 79

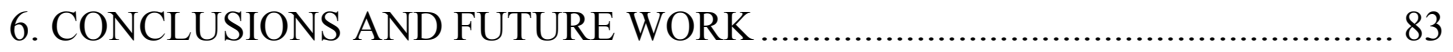

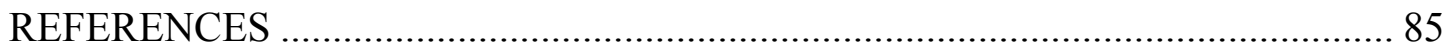


APPENDIX A: SOLUTION TO THE 1- DIMENSION TIME INDEPENDENT

SCHRODINGER WAVE EQUATION USING MATLAB .................................. 90

APPENDIX B: MATLAB PROGRAM TO CALCULATE THE WIDTH OF THE

AlGaN BARRIER

APPENDIX C: MATLAB PROGRAM TO CALCULATE THE OVERFLOW

CURRENT OF A LIGHT EMITTING DIODE

APPENDIX D: PROGRAM TO DETERMINE THE FOCUS OF THE LASER ..... 97

APPENDIX E: PROGRAM TO ABLATE A SAMPLE OF GALLIUM NITRIDE TO

DEPOSIT CONTACTS

APPENDIX F: PROGRAM TO ABLATE LINES IN GaN VARYING THE SPEED

OF ABLATION

APPENDIX G: PROGRAM TO ABLATE LED

APPENDIX H: PROTOCOL FOR HCl CLEANING

APPENDIX I: PROTOCOL FOR BUFFERED OXIDE ETCH FOR ETCHING

SILICON DIOXIDE.

APPENDIX J: PROTOCOL FOR TREATING LASER ABLATED GaN WITH

TRANSETCH-n.

APPENDIX K: ETCH RATES OF SILICON DIOXIDE AND PHOTORESIST UNDER DIFFERENT CONDITIONS

APPENDIX L: TABLE 13 SPECIFIC CONTACT RESISTIVITY AND SHEET

RESISTANCE OBTAINED FOR DIFFERENT SAMPLES 


\section{LIST OF FIGURES}

Table 1: Theoretical Wavelength Vs Well Thickness for a constant Indium Mole

fraction of 0.18

Table 2: Table showing the Overflow Current Densities for various Indium Mole Fractions and their corresponding Wavelength, Well thickness and Energy level

Table 3: Table listing the values of the thickness of $\mathrm{Al}_{\mathrm{x}} \mathrm{Ga}_{(1-\mathrm{x})} \mathrm{N}$ and the corresponding Mole fraction taking into consideration parabolic grading............................. 36

Table 4: Table showing the Process Recipe for the PECVD system......................... 43

Table 5: Table showing the Process Recipe for the PECVD system......................... 43

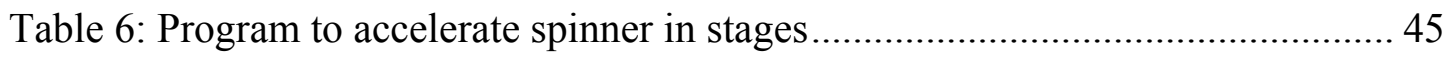

Table 7: Etch Rates of Photoresist and $\mathrm{SiO}_{2}$ obtained at $\mathrm{ICP}=125 \mathrm{~W}, \mathrm{RF}=200 \mathrm{~W}$ and

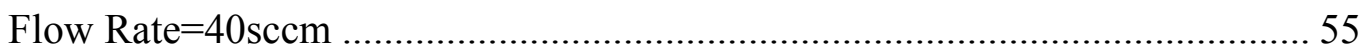

Table 8: Etch Rates of Photoresist and $\mathrm{SiO}_{2}$ obtained at $\mathrm{RF}=230 \mathrm{~W}$; ICP=230W;

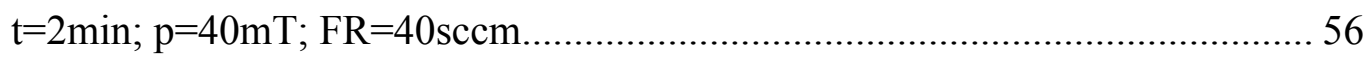

Table 9: Etch Rates of Photoresist and $\mathrm{SiO}_{2}$ obtained $\mathrm{RF}=220 \mathrm{~W} ; \mathrm{ICP}=250 \mathrm{~W} ; \mathrm{t}=2 \mathrm{~min}$;

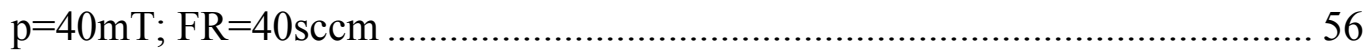

Table 10: Etch Rates of Photoresist and $\mathrm{SiO}_{2}$ obtained $\mathrm{RF}=220 \mathrm{~W}$; ICP=220W;

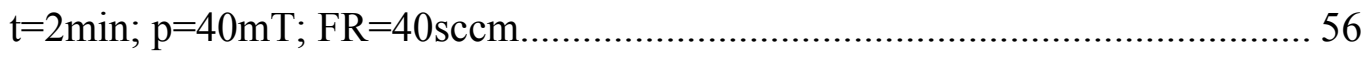

Table 11: Etch Rates of Photoresist and $\mathrm{SiO}_{2}$ obtained RF=220W; ICP=200W;

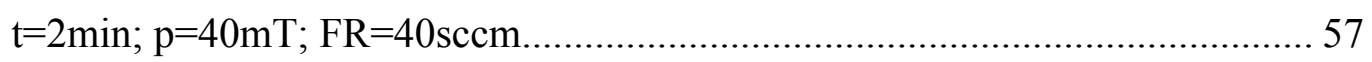

Table 12: Final etch rates of Silicon Dioxide and Photoresist................................ 57

Table 13: Etch rates of $\mathrm{SiO}_{2}$ and Photoresist under $\mathrm{RF}=220 \mathrm{~W} ; \mathrm{t}=2 \mathrm{~min} ; \mathrm{p}=10 \mathrm{mT}$;

$\mathrm{FR}=65 \mathrm{sccm}$

Table 14: Etch rates of $\mathrm{SiO}_{2}$ and Photoresist under $\mathrm{RF}=220 \mathrm{~W} ; \mathrm{ICP}=250 \mathrm{~W} ; \mathrm{t}=2 \mathrm{~min}$;

$\mathrm{FR}=40 \mathrm{sccm}$ 108

Table 15: Etch rates of $\mathrm{SiO}_{2}$ and Photoresist under $\mathrm{RF}=220 \mathrm{~W} ; \mathrm{ICP}=250 \mathrm{~W} ; \mathrm{t}=2 \mathrm{~min}$;

$\mathrm{FR}=65 \mathrm{sccm}$ 108

Table 16: Etch rates of $\mathrm{SiO}_{2}$ and Photoresist under $\mathrm{RF}=220 \mathrm{~W} ; \mathrm{ICP}=250 \mathrm{~W} ; \mathrm{t}=2 \mathrm{~min}$; $\mathrm{p}=30 \mathrm{mT}$ 108 
Table 17: Etch rates of $\mathrm{SiO}_{2}$ and Photoresist under $\mathrm{RF}=220 \mathrm{~W} ; \mathrm{ICP}=250 \mathrm{~W} ; \mathrm{t}=2 \mathrm{~min}$;

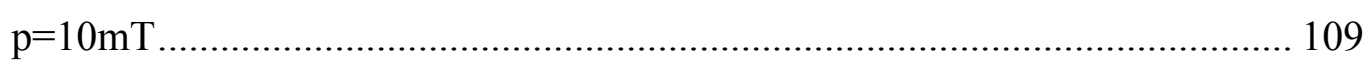

Table 18: Specific Contact Resistivity and Sheet Resistance obtained for GaN samples under different conditions ........................................................... 110 


\section{LIST OF TABLES}

Table 1: Theoretical Wavelength Vs Well Thickness for a constant Indium Mole

fraction of 0.18

Table 2: Table showing the Overflow Current Densities for various Indium Mole Fractions and their corresponding Wavelength, Well thickness and Energy level

Table 3: Table listing the values of the thickness of $\mathrm{Al}_{\mathrm{x}} \mathrm{Ga}_{(1-\mathrm{x})} \mathrm{N}$ and the corresponding Mole fraction taking into consideration parabolic grading............................. 36

Table 4: Table showing the Process Recipe for the PECVD system........................ 43

Table 5: Table showing the Process Recipe for the PECVD system........................ 43

Table 6: Program to accelerate spinner in stages.................................................. 45

Table 7: Etch Rates of Photoresist and $\mathrm{SiO}_{2}$ obtained at $\mathrm{ICP}=125 \mathrm{~W}, \mathrm{RF}=200 \mathrm{~W}$ and

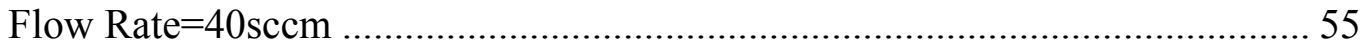

Table 8: Etch Rates of Photoresist and $\mathrm{SiO}_{2}$ obtained at $\mathrm{RF}=230 \mathrm{~W}$; ICP=230W;

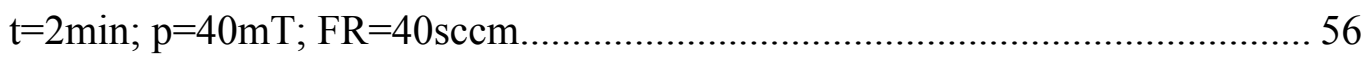

Table 9: Etch Rates of Photoresist and $\mathrm{SiO}_{2}$ obtained $\mathrm{RF}=220 \mathrm{~W} ; \mathrm{ICP}=250 \mathrm{~W} ; \mathrm{t}=2 \mathrm{~min}$;

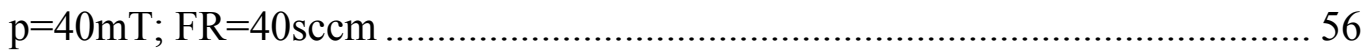

Table 10: Etch Rates of Photoresist and $\mathrm{SiO}_{2}$ obtained RF=220W; ICP=220W;

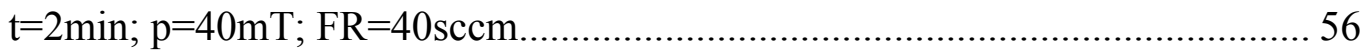

Table 11: Etch Rates of Photoresist and $\mathrm{SiO}_{2}$ obtained $\mathrm{RF}=220 \mathrm{~W}$; ICP=200W;

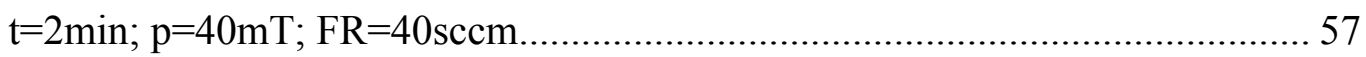

Table 12: Final etch rates of Silicon Dioxide and Photoresist................................ 57

Table 13: Etch rates of $\mathrm{SiO}_{2}$ and Photoresist under $\mathrm{RF}=220 \mathrm{~W} ; \mathrm{t}=2 \mathrm{~min} ; \mathrm{p}=10 \mathrm{mT}$;

$\mathrm{FR}=65 \mathrm{sccm}$

Table 14: Etch rates of $\mathrm{SiO}_{2}$ and Photoresist under $\mathrm{RF}=220 \mathrm{~W} ; \mathrm{ICP}=250 \mathrm{~W} ; \mathrm{t}=2 \mathrm{~min}$;

$\mathrm{FR}=40 \mathrm{sccm}$ 108

Table 15: Etch rates of $\mathrm{SiO}_{2}$ and Photoresist under $\mathrm{RF}=220 \mathrm{~W} ; \mathrm{ICP}=250 \mathrm{~W} ; \mathrm{t}=2 \mathrm{~min}$;

$\mathrm{FR}=65 \mathrm{sccm}$ 108

Table 16: Etch rates of $\mathrm{SiO}_{2}$ and Photoresist under $\mathrm{RF}=220 \mathrm{~W} ; \mathrm{ICP}=250 \mathrm{~W} ; \mathrm{t}=2 \mathrm{~min}$; $\mathrm{p}=30 \mathrm{mT}$ 
Table 17: Etch rates of $\mathrm{SiO}_{2}$ and Photoresist under $\mathrm{RF}=220 \mathrm{~W} ; \mathrm{ICP}=250 \mathrm{~W} ; \mathrm{t}=2 \mathrm{~min}$;

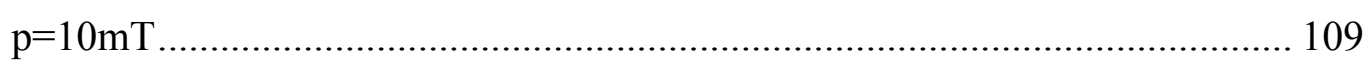

Table 18: Specific Contact Resistivity and Sheet Resistance obtained for GaN samples under different conditions ........................................................... 110 


\section{INTRODUCTION}

Solid State lighting is of interest in today's economy because of the huge savings they result in terms of power. Till the early nineties, the lack of efficient blue Light Emitting Diodes (LED) prevented the production of commercial solid state white light, this however changed with the demonstration of the blue LED in 1994 by Shuji Nakamura. Other applications of Light Emitting Diodes are in full color displays and traffic signals. The major advantage in solid state lighting lies in the principle behind the operation of the LED. Whereas in conventional lighting techniques like the incandescent bulb $90 \%$ of the energy given is lost as heat this is not the case in LED's where the light is produced by the radiative recombination of electrons and holes.

Gallium Nitride $(\mathrm{GaN})$ is a suitable material for the manufacture of Blue LED's because it is a direct bandgap semiconductor. This is an advantage over Silicon Carbide which used to be used as a material for blue LED's. The Blue LED's produced however, had a low efficiency because of its indirect bandgap. Along with this it may be alloyed with $\mathrm{InN}$ and $\mathrm{AlN}$ to allow bandgap energies ranging from $1.9 \mathrm{eV}$ to $6.2 \mathrm{eV}$ [Kim, 1999]. This gives one the ability to tailor the device to emit visible light over the entire spectrum.

Upon growing a device in order to make it working, one needs to deposit $\mathrm{p}$ and $\mathrm{n}$ type of contacts on the $\mathrm{p}$ and $\mathrm{n} \mathrm{GaN}$ regions respectively. In order to be able to deposit contacts on the $\mathrm{n} \mathrm{GaN}$ layer it becomes essential to be able to etch the Gallium Nitride. This makes a study of etching techniques essential. Since $\mathrm{GaN}$ is very inert in nature, wet etching becomes difficult. This leads to the study of viable dry etch techniques.

Often in the Industry Inductively Coupled Plasma etching of GaN takes place in Chlorine plasma. These result in the formation of volatile Chloride products which are easily removed from the surface increasing the ease of etch. Chloride bi products however are often toxic and corrosive in nature making it important to study the 
Reactive Ion Etching (RIE) in other gases whose bi-products are not noxious in nature. Sulphur Hexafluoride is one such gas whose bi products are $\mathrm{GaF}_{3}$ and $\mathrm{NF}_{3}$.

An alternative dry etch technique for Gallium Nitride is known as Laser Ablation. Laser Ablation proves itself to be a versatile technique to etch $\mathrm{GaN}$ as it is not limited by the use of a mask. Also the etch rate does not depend on the removal of non volatile materials from the surface. Another advantage is that the bi-products are not toxic in nature.

Any kind of etching be it Reactive Ion etching or Laser Ablation cause damage to the surface due either ion bombardment or thermal effects respectively. It is therefore essential to study how the etch effects the surface and in turn how this effects properties of metal contacts such as for example the Specific Contact Resistivity. 


\section{LITERATURE REVIEW}

The recent years have seen the production of Light Emitting Diodes of impressive longevity and high efficiency. Due to these factors, the market of Gallium Nitride Chips has grown to a worth greater than $\$ 1.2$ billion. This began with the creation of the Blue Gallium Nitride Light Emitting Diode in 1994 by Nichia researcher Shuji Nakamura.

Lighting by LED's finds commercial use in many applications such as traffic and railway signaling and outdoor displays. Although statistics reveal that LED's available now are around 100 times more expensive than the ordinary incandescent bulb, they are also 100 times more efficient. It is also possible to produce a wide range of colors of light by mixing light emitted from LED's of different wavelength. [Zorpette, 2002]

\subsection{The Incandescent Bulb and the LED}

An incandescent bulb by nature is a resistor. It produces light by thermal radiation when a wire filament is heated to white heat by passing electricity through it. Most incandescent lamps waste $90 \%$ of the power that they consume on heat. From an economical standpoint, hundreds of Giga watts of power are wasted on producing unwanted heat.

The operation of an LED on the other hand involves an entirely different principle. A light emitting diode is in essence nothing but a p-n junction. The ' $n$ ' part comprising of a material doped heavily with electrons and the ' $p$ ' type, a material comprising of a large number of positively charged electron deficiencies called holes. On the application of a voltage, the electrons and holes recombine in an 'active region' emitting energy in the form of a photon of light. In order to efficiently "trap" the emitted photons, present day devices implement what is called a 'quantum well' structure in the design of the diode. The basic principle involved in a quantum well is a structure so thin that it is almost two dimensional in nature. Under such conditions 
the electrons and holes are compelled to exhibit Quantum Mechanical properties. Under such situations they are supposedly more likely to emit and absorb photons.

Just like the incandescent bulb, an LED exhibits some resistance and therefore heat. A large issue faced in the design of Light Emitting Diodes is the internal quantum efficiency of the device. A low efficiency may be caused when the electrons and holes do recombine but the recombination results in lattice vibrations instead of a photon being emitted. In addition, the photons that are emitted may be lost by absorption in various defects and impurities in the crystal resulting in the production of heat.

\subsection{Use of GaN for Light Emitting Diodes}

Gallium Nitride is a III-V semiconductor with a direct band gap of about $3.4 \mathrm{eV}$. It's advantage stems from the fact that it may be alloyed along with $\mathrm{InN}$ and $\mathrm{AlN}$ allowing band gap energies to range from $1.9 \mathrm{eV}$ to $3.4 \mathrm{eV}$ and $3.4 \mathrm{eV}$ to $6.2 \mathrm{eV}$ respectively [Kim, 1999][Turlapati, 2004]. This allows material systems to be fabricated with light emission in the short wavelength range. This makes $\mathrm{GaN}$ a suitable semiconductor in the manufacture of Blue Light Emitting diodes. 


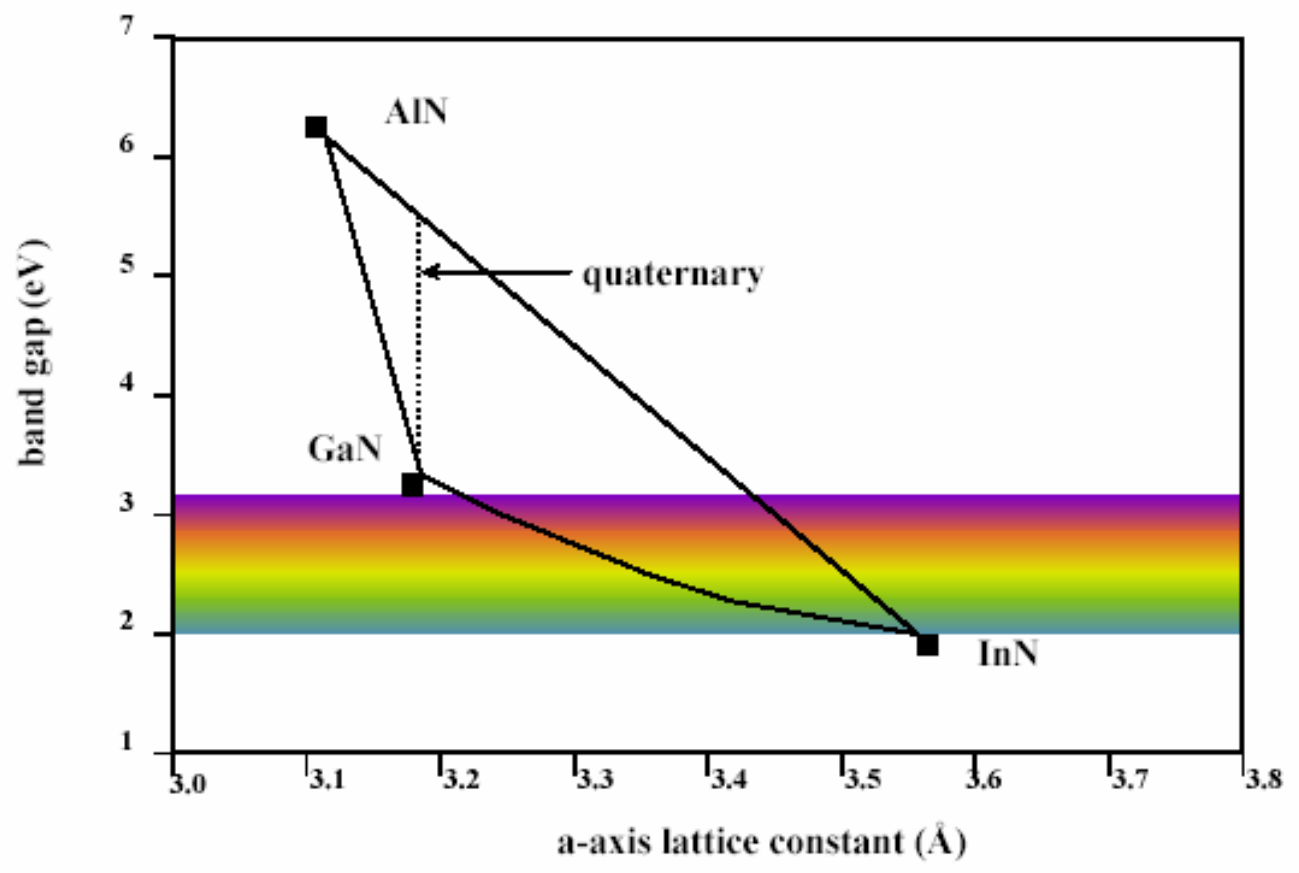

Figure 2.1 Band gap Vs Lattice Constant for group III Nitrides

\subsection{Fabrication of LED's}

Fabricating more efficient devices begins with their growth. The device most popularly used for the growth of LED's is the Metal Organic Chemical Vapor Deposition System. Shuji Nakamura proposed the two-flow MOCVD method [Nakamura, 1999] which is also popularly used. In order to grow the different layers of the devices, the substrate is placed in the chamber and heated to a temperature of $900-1100^{\circ} \mathrm{C}$. The reactant gases are then introduced into the system in such a way that they react with each other in order to produce the layers that comprise the device. The major requirements for the gases are that they ought to have a high vapor pressure so that their flow may be easily controlled in the growth chamber. They must also react producing the required molecules and no contaminating molecules.

The various layers of the device are grown by varying the temperature, pressure and flow of the reacting gases. An LED may have many layers including several layers of the Multiple Quantum Well whose thickness is in the range of 3-4nm. 


\subsection{Gallium Nitride and its Challenges}

The major problem faced in the manufacture of GaN LED's is that GaN has not yet been manufactured in bulk crystal form. Hence other substrates are required to be used to grow the devices such as Silicon and Sapphire. This results in a lattice mismatch between the substrate and the Gallium Nitride which produces dislocations which convert the photons to heat in the device.

Various process techniques are being researched to reduce the number of defect dislocations in the device. An improvement in the growth techniques of these devices promises a future growth aiming at values such as $751 \mathrm{~m} / \mathrm{W}$ in $2007,1501 \mathrm{~m} / \mathrm{W}$ in 2012 and $2001 \mathrm{~m} / \mathrm{W}$ in 2020 [Zorpette, 2002]. One such technique is the growth of Epitaxially Laterally Overgrown Substrates (ELOG). It was found that the growth of GaN on an ELOG substrate as opposed to growth over a conventional Sapphire or Silicon substrate produced a lower density of threading dislocations [Nakamura, 1999].

\subsection{Etching GaN LED’s}

\subsubsection{Reactive Ion Etching}

Developing devices based on III-V materials such as GaN, require a high fidelity and low damage pattern transfer process. Wet Etching on Nitrides is not so easy because of their high chemical inertness and their high bond strength. Even though wet etching has been made possible using hot Phosphoric Acid, pattern transfer of very small features is not very accurate especially for features on devices such as Light Emitting Diodes and Laser Diodes.

Since GaN possesses properties such as high mechanical strength and chemical inertness, there is a lot of attention towards the etching techniques of III-V compounds. Dry etching is made a little complicated by the inert chemical nature and strong bond energy of group III nitrides compared to other compound 
semiconductors. For example $\mathrm{GaN}$ has a bond energy of $8.92 \mathrm{eV} /$ atom as compared to GaAs which has bond energy of 6.2eV/atom [Tripathy, 2001]. Highly anisotropic, nanoscale features cannot be resolved without the control over dry etches. However these techniques are known to cause excessive lattice damage.

High density plasma etching techniques such as Inductively Couple Plasma (ICP) and magnetron Reactive Ion Etching lead to higher etch rates. These techniques lead to ion bombardment damage of the surface and increase in the surface roughness at higher ICP and RF powers. The ICP etching techniques provide low damage, still maintaining a high etch rate. During etching, the breaking of the III-nitrogen bond is crucial in obtaining a high etch rate along with the volatility of the etch products. Plasma induced damage often degrades the electrical and optical properties of the GaN based semiconductors [Tripathy, 2001].

For example, during ion enhanced dry etching, point defects and defect clusters are induced into the sample which may affect the device characteristics. In all RIE plasmas, a high ion bombardment is required to break the III-N bond. Therefore the etch rates are relatively low with the fastest rate obtained in the chlorine based plasmas [Rong, 2001]. ICP etch rates of $\mathrm{GaN}$ in $\mathrm{Cl}_{2} / \mathrm{H}_{2} / \mathrm{Ar}$ ICP generated plasmas were found to be as high as 6900 angstroms per minute [Im, 2000]. The principal behind the use of chlorides and bromides is that their derivatives formed with $\mathrm{Ga}$ are volatile making their removal easy from the surface.

In the above process however, hydrogen can diffuse into the $\mathrm{GaN}$ at 85 degrees centigrade and although the reactivation of dopants can be achieved at 400-500 degrees centigrade, $\mathrm{H}$ does not leave $\mathrm{GaN}$ till 800 degrees forming electrically neutral complexes with the dopants. Another disadvantage of the use of $\mathrm{Cl}$ is the highly corrosive nature of the by products of the reaction apart from its being toxic. SF6 however is a less corrosive and noxious gas. Although $\mathrm{GaF}_{3}$ is non volatile, the nitrogen forms volatile NF3 when it reacts with fluorine. In addition, the physical 
sputtering from the accelerated ions plays an additional role to help remove any non volatile products of from the etch [Basak, 1997].

\subsubsection{Laser Ablation}

Laser Ablation is an additional means for processing GaN based technology. Laser processing is sometimes more suitable because of material properties of Nitrides such as chemical inertness and stability. Laser processing has been applied to such areas of processing as Laser Annealing, surface processing and laser lift off.

Laser ablation may either be done by using Femto or Nanosecond systems. Machining using long wavelength lasers such as these involve free or seed electrons. These free electrons are accelerated in the lasers field and may free bound electrons via impact ionization as shown below [G. Rice, 2003]. The material is therefore removed by thermal ablation.

Seed electron accelerated

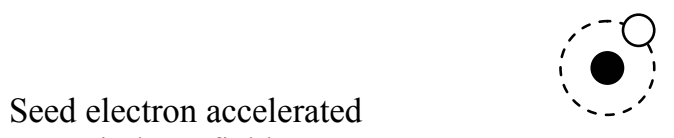
in laser field

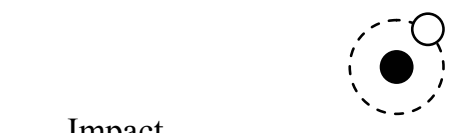

Exponential growth of
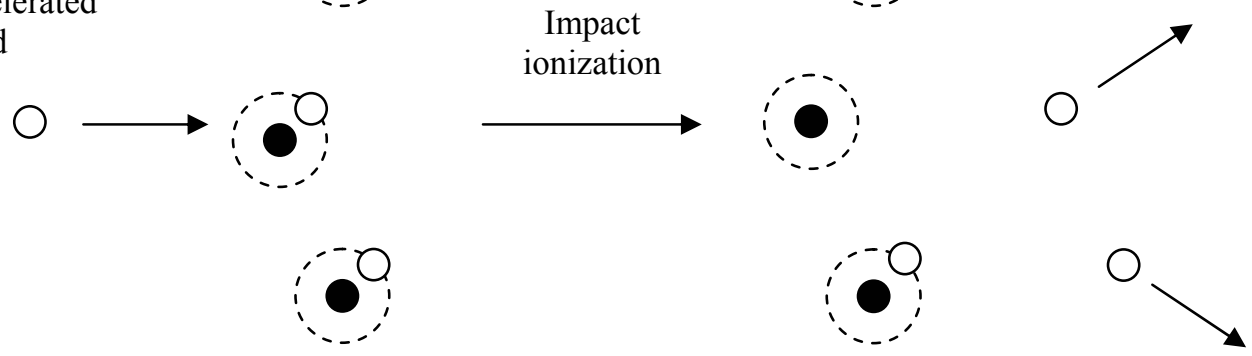
free electron density

Figure 2.2: Exponential growth of free electron density

When the exponential growth of this free electron reaches a critical value of around $10^{18}-10^{20}$ electrons $/ \mathrm{cm}^{3}$ then a significant amount of optical absorption occurs leading to an irreversible breakdown of the lattice structure in the material, or in other words the ablation. In most materials, free electrons are supplied by either intentional doping or metallic impurities. This value may vary from site to site making the ablation statistical in nature [G. Rice, 2003]. However Nanosecond laser machining could be a 
valuable as a cheaper bench top alternative to the more expensive femtosecond laser systems.

The Copper Vapor laser is a Nanosecond laser of wavelength $255 \mathrm{~nm}$. The Copper Vapor Laser has been industrially proven to be a favourable source of micromachining. This laser operates with a high average power and pulse rate, which makes it suitable for machining materials in a controllable way. It has also been reported that high repetition rate pulsed lasers increase the penetration efficiency over that obtained with continuous wave lasers with similar power [Gu, 2003].

Literature shows that the Current-Voltage characteristics of both GaN LED's fabricated by laser etching and commercial ICP etching are almost identical. This indicates that the laser etching technology is a good alternative to device fabrication. In addition, it may be carried out in air instead of vacuum and generates no chemical waste, making it a great choice for the high throughput and low environment impact production of nitride based devices [Yang, 2002].

\subsection{Principles involved in Light Emitting Diodes}

\subsubsection{Radiative and Non Radiative Recombination}

The electrons and holes in a semiconductor recombine either radiatively or nonradiatively. Radiative recombination results in the emission of a photon. Since non radiative recombination can not be eliminated completely it becomes important to maximize the radiative and minimize the non radiative recombination. The recombination rate is proportional to not only the electrons but also the of hole concentration [Schubert, 2003]. That is

$$
R \alpha n p \text {. }
$$

Where:

$\mathrm{n}=$ concentration of electrons 
$\mathrm{p}=$ concentration of holes

$\mathrm{R}=$ Rate of recombination

Upon using proportionality constant the recombination rate per unit time per unit volume can be written as [Schubert, 2003]

$$
R=-\frac{d n}{d t}=-\frac{d p}{d t}=B n p
$$

This equation is called the Bimolecular Rate Equation and the proportionality constant $\mathrm{B}$ is called the bimolecular recombination coefficient having typical values of $10^{-11}-10^{-9} \mathrm{~cm}^{-3} / \mathrm{s}$ for III-V compounds.

When a semiconductor is subjected to a low level of photo excitation, the carrier lifetime is given as [Schubert, 2003]:

$$
\Gamma=\left[B\left(n_{0}+p_{0}\right)\right]^{-1}
$$

Where:

$\Gamma=$ Carrier lifetime (seconds)

$\mathrm{n}_{\mathrm{o}}=$ carrier density of electrons in thermal equilibrium

$\mathrm{p}_{\mathrm{o}}=$ carrier density of holes in thermal equilibrium

For a semiconductor of a specific doping type this equation reduces to [Schubert, 2003]

$$
\begin{aligned}
& t_{n}=\frac{1}{B p_{0}}=\frac{1}{B N_{a}} \\
& t_{p}=\frac{1}{B n_{0}}=\frac{1}{B N_{d}}
\end{aligned}
$$

Where:

$t_{n}=$ minority carrier life time of electrons 
$t_{p}=$ minority carrier lifetime of holes that is the mean time between generation and recombination of a minority carrier.

$\mathrm{N}_{\mathrm{a}}=$ Acceptor concentration

$\mathrm{N}_{\mathrm{d}}=$ Donor concentration

For high level excitation the time constant is given by the equation [Schubert, 2003]:

$$
\Gamma(t)=t+\frac{1}{B \Delta\left(n_{0}\right)}
$$

Quantum wells are useful for confining free carriers into a narrow quantum well by means of two barrier regions. The recombination rate in the quantum well may be given as [Schubert, 2003]:

$$
R=B *\left(\frac{n_{2 d}}{L_{Q W}}\right) *\left(\frac{P_{2 d}}{L_{Q W}}\right)
$$

This equation indicates that as the length of the quantum well decreases the recombination rate increases [Schubert, 2003].

The luminescence intensity is proportional to the recombination rate and the decay of carriers in a semiconductor may be measured by the decay in the luminescence after a short optical excitation pulse. Lower the carrier lifetime the higher the recombination rate of the carriers. Doping the active region or injecting a high concentration of carriers into the active region may reduce the carrier lifetime. Heterostructures are used to confine free carriers into the well region to obtain high carrier concentrations and short carrier lifetimes [Schubert, 2003].

\subsubsection{Non radiative recombination}

In semiconductors there are two basic types of recombination, Radiative recombination in which one photon of energy equal to the band gap energy of the 
semiconductor is emitted and non radiative recombination in which the energy of the electron is converted to phonons or lattice vibrations. Therefore the energy of the electron is converted into heat. Unwanted non radiative mechanisms occur due to various defects in the crystal such as dislocations and foreign atoms. In a compound semiconductor these defects may be due to interstitials and vacancies. These defects have energy levels that are different from the useful substitution semiconductor atoms. Often these defects cause several energy levels within the forbidden gap of the semiconductor [Schubert, 2003].

Another form of non radiative recombination is called Auger Recombination and involves two carriers of the same type for the recombination process. This kind of recombination reduces luminescence only at a very high injection current due its dependence on the cubic carrier concentration, at a lower carrier concentration however the effect of this recombination may be disregarded.

\subsubsection{Current Voltage Characteristics}

From the Shockley equation for the current under forward bias conditions it may be seen that the current strongly increases when the applied voltage approaches the diffusion voltage $V_{d}$. The voltage at which the current strongly increases is called the threshold voltage $V_{t h}$. The threshold voltage can be written as [Schubert, 2003]:

$$
V_{t h}=V_{d}=\frac{E_{g}}{e}
$$

Where:

$\mathrm{V}_{\text {th }}=$ Threshold voltage

$\mathrm{V}_{\mathrm{d}}=$ Diffusion voltage

InGaN $/ \mathrm{GaN}$ diodes usually have a very high ideality factor $\mathrm{n}_{\text {ideal }}=6.0$. The following equation is used to describe the I-V characteristics of an ideal diode [Schubert, 2003]. 


$$
\left.I=I_{s} * e^{\left(e V / n_{\text {ideal }} * K^{*} T\right.}\right)
$$

$\mathrm{K}=$ Boltzmann constant

$\mathrm{I}_{\mathrm{s}}=$ Ideal saturation current

$\mathrm{T}=$ Absolute temperature

The theory of conservation of energy dictates that the forward voltage should be either equal to or larger than the band gap energy. The diode voltage is given as [Schubert, 2003].

$$
V=\frac{h v}{e}=\frac{E_{g}}{e}
$$

There are several causes for this voltage not to be equal to the drive voltage.

Firstly: If the diode has additional resistances such as follows, a voltage drop may occur

a. Series resistance wherein an additional drop of $\mathrm{IR}_{\mathrm{s}}$ occurs

b. Contact resistance

c. Resistance caused by abrupt heterostructures

d. Bulk resistance occurring in materials with a low carrier concentration.

Secondly: The energy may be lost when the electron is injected into a quantum well. The energy that is lost may be written as $\Delta \mathrm{E}_{\mathrm{c}}-\mathrm{E}_{\mathrm{o}}$ where $\mathrm{E}_{\mathrm{o}}$ is the lowest energy state in the quantum well. This energy is lost in the form of a phonon or lattice vibration or heat. Non-adiabatic injection of carriers occurs in semiconductors with a large band discontinuity for example group III-V nitride materials. Experimentally it was found that the diode voltage could be slightly lower than the minimum value that can be calculated. 


\subsubsection{LED optical properties}

There are various efficiencies that may be defined for an LED namely [Schubert, 2003]:

Internal quantum efficiency $=\frac{P_{\text {int }} /(h v)}{I / e}$

Where:

$\mathrm{P}_{\mathrm{int}}=$ optical power emitted from the active region and $\mathrm{I}$ is the injection current.

The extraction efficiency $=\frac{P /(h v)}{P_{\text {int }} /(h v)}$

Where:

$\mathrm{P}=$ power emitted into free space.

The extraction efficiency may be a huge limitation for a high performance LED.

The external quantum efficiency $=\frac{P /(h v)}{I / e}$

This is a measure of the number of useful light particles injected into the system.

The power efficiency is defined as $=\mathrm{P} / \mathrm{IV}$ where IV is the power supplied to the LED. Emission in an LED occurs through the process of "Spontaneous Emission" as opposed to "Stimulated Emission" that occurs in Lasers.

According to the law of conservation of energy the energy of the photon is given by the difference between the energy of the electron and that of hole [Schubert, 2003]:

$$
h v=E_{e}-E_{h} \sim E_{g}
$$


The emission wavelength of an LED can be attained by choosing a semiconductor material with the appropriate band gap. Calculations indicate that the momentum of the carrier is much larger in magnitude than the photon momentum, and therefore the electron momentum can not change significantly during the transition from the conduction to the valence band. Hence only 'vertical' transitions are made wherein the electrons combine with holes of the same momentum. From calculations the maximum emission intensity occurs at [Schubert, 2003]:

$$
E=E_{g}+\frac{1}{2 K T}
$$

and the FWHM of the emission is $\Delta E=1.8 K T$ [Schubert, 2003]

\subsubsection{Light Escape Cone}

If the light ray is almost at right angles in incidence, then it can escape from the semiconductor, on the contrary light which is at a critical angle suffers from total internal reflection which reduces the total external efficiency especially for LED comprising of high refractive index materials. The light escape angle is given by the equation [Schubert, 2003]:

$$
\theta_{c} \cong n_{\text {air }} / n_{s}
$$

Where:

$\mathrm{n}_{\mathrm{s}}=$ refractive index of the semiconductor

$\mathrm{n}_{\text {air }}=$ refractive index of air

The value of ns is usually very high for semiconductors. This angle forms the basis of the light emitting cone. Light emitted outside the cone gets totally internally reflected. 
The ratio of the escape power to the power generated in the source is given by [Schubert, 2003]:

$$
\frac{P_{\text {escape }}}{P_{\text {source }}}=\frac{1}{4}\left(\frac{n_{\text {air }}}{n_{s}}\right)^{2}
$$

This is a significant problem in an LED design because the refractive index is quite high and only a small percent of light gets emitted.

The temperature dependence on the luminous intensity for an LED is given by the the equation [Schubert, 2003]:

$$
I=10 K * e^{\left(-T / T_{1}\right)}
$$

Where:

$\mathrm{T}_{1}=$ Characteristic temperature

$\mathrm{T} 1$ is the characteristic temperature and normally a high value is desired because it implies small temperature dependence. Blue LEDs have the highest characteristic temperature because they have the deepest wells so that the carrier confinement is very effective in the InGaN/GaN structures. The decrease in the intensity with temperature may be due to several reasons such as non radiative recombination in deep levels, surface recombination and carrier loss over heterostructure barriers.

In order to improve the internal efficiency of an LED one must either increase the radiative recombination or reduce non radiative recombination. The bimolecular rate equation shows that the rate of radiative recombination increases with carrier concentration, hence it is important for the region where recombination is occurring to have a high carrier concentration. It is in such as situation that a double heterostructure shows its advantages. A double heterostructure consists of an active region confined by two confinement layers whose band gap is larger than that of the active layer. The condition being that the band edge discontinuities $\Delta \mathrm{Ec}$ and $\Delta \mathrm{Ev}$ 
should be much larger than $\mathrm{kT}$ to avoid the escape of carriers into the confinement layer. In the case of a homojunction structure, on the application of a forward bias the minority carriers diffuse over their diffusion length, this wide distribution of carriers leads to a low carrier concentration especially towards the end of the "diffusion tail". DH structures may be used for both the "bulk" and "active region" in a quantum well.

The active region in a quantum well provides additional carrier confinement in a narrow well region improving the internal quantum efficiency. A situation to be considered while using quantum wells is that the size of the barrier should be thin enough to allow the homogeneous distribution of carriers in the quantum well. If the active layer is too thick, it looses the functionality of a heterostructure and behaves like a homojunction and if it is too thin then the carriers can overflow at a high injection level.

Another issue to be dealt with is that the light that is trapped in the semiconductor will eventually be reabsorbed by a defect in the substrate, the active region or another absorbing layer. Absorption by the substrate and metallic contacts normally lowers the extraction efficiency. On the other hand if the electron-hole pair may re-emit a photon or recombine non radiatively. In order to increase the extraction efficiency all the semiconductor layers except for the active region should have a bandgap energy larger than the energy of the photon. But semiconductors do absorb below bandgap light, but with a lower absorbption coefficient. Most below bandgap transitions are phonon assisted transition. Mechanisms causing potential fluctuations eading to local variations in the semiconductor band edge such as random dopant variation, local variation in the chemical composition of an alloy, result in the below bandgap transitions. Since the confinement regions in an LED are not only thin but also have band gap energies much higher than that of the active region, they can be considered "transparent" to the photons emitted. Under high current injection conditions, the Fermi levels of the carriers rises into the conduction and valence band thus making the active region almost transparent for near bandgap emission. In order to reduce losses, the active region should have a high internal efficiency to make the re- 
emission of the absorbed photons likely. A current-spreading layer is used to spread the current injected into the active region where the recombination occurs, to regions which are not covered by the top electrode. Often a current blocking layer is used to block the current from entering the active region from the top contact. This is a way of increasing the extraction efficiency by decreasing the amount of light obstructed by the opaque metal contact [Schubert, 2003].

\subsubsection{The GaN and InGaN material System}

InGaN/GaN blue LED's became commercially available in the late 1990's. One of their greatest advantages of these is that inspite of the high threading dislocation density of the order of $10^{7}-10^{9} \mathrm{~cm}^{-2}$, caused due to the lattice mismatch between the most commonly used Sapphire substrates and $\mathrm{GaN}$ and $\mathrm{InGaN}$ epitaxial films. The cause of this is still not clearly understood and is speculated to be due to the small diffusion lengh of holes and low electrical activity of dislocations in $\mathrm{GaN}$ and $\mathrm{InGaN}$ which allows high radiative efficiencies.

It has been postulated that the In variation in the InGaN quantum well leads the carriers to be trapped in localized potential minima which eventually recombine radiatively. As they are trapped in the local minima they are prevented from reaching any dislocations. Hence, the optical properties of III-V nitrides are less affected by dislocations than those of III-V aresenides and III-V phosphides. The bandgap energy of InGaN may be varied to emit light over the entire visible spectrum by varying the In compostion. However it is more suitable for shorter wavelengths and therefore blue and UV light as it becomes increasingly harder to incorporate a high concentration of In atoms into the system due to re evaporation. Prior to 2002 the band gap of InN was thought to be $1.9 \mathrm{eV}$ but later on measurements indicated an energy of $0.7-0.8 \mathrm{eV}$. Also with an increasing temperature a blue shift is observed [Schubert, 2003].

The forward voltage of Green LED's was observed to be slightly lower than that of Blue LED's this might be because of the loss of energy of the carrier in phonon 
vibrations as they are injected from the GaN barrier into the In richer active region. This energy is supplied by the external voltage, hence explaining a higher external voltage. The series resistance of Blue and Green InGaN/GaN LED's are also higher because of the, "lateral" resistance in the n-type buffer layer for devices grown on sapphire substrates, the polarization effects occurring in the nitride family materials, low $\mathrm{p}$-type conductivity and high $\mathrm{p}$ contact resistance. The low $\mathrm{p}$ type resistance is due to the high activation energy of the acceptors in $\mathrm{GaN}$ and InGaN, therefore only a very few number of acceptors are activated. It is also observed that with an increasing temperature the forward voltage decreases for blue and green LED's because of an increase in the acceptor activation occurring at a higher temperature thus increasing the conductivity and decreasing the resistivity. Another reason is a decrease in the band gap energy. 


\section{LIGHT EMITTING DIODE DESIGN}

\subsection{Theory}

When a $\mathrm{p}$ and $\mathrm{n}$ type of a particular material are brought together their fermi levels align at equilibrium. A diagram of the resulting homojunction under zero bias is shown below [Schubert, 2003].

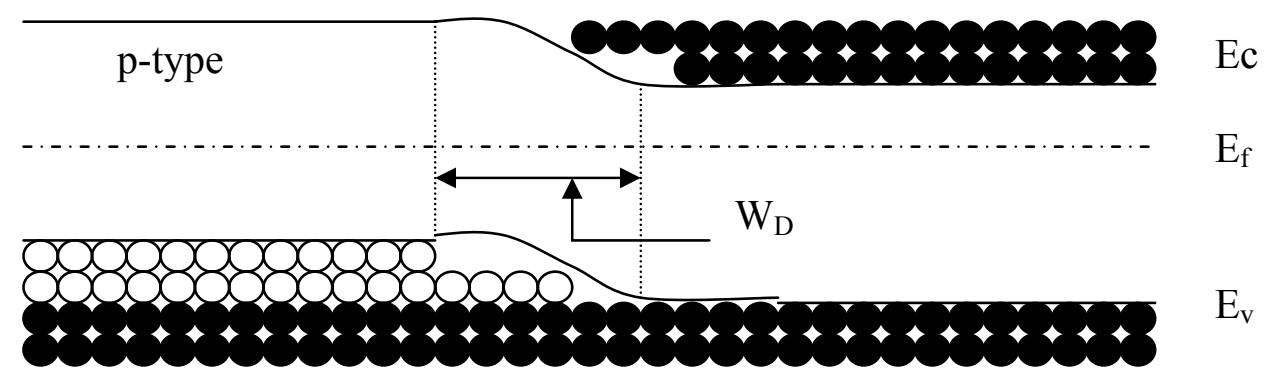

Figure 3.1: Band diagram of a homojunction under zero bias conditions

Upon providing a forward bias to this structure, the minority carriers distribute themselves over a large distance as shown in the figure below. The probability with which an electron may recombine with a hole depends directly on the hole and electron concentration. Therefore the recombination rate is proportional to the product of the electron and hole concentrations. The resulting equation from the previous chapter is given by [Schubert, 2003]:

$$
R=B n p
$$

From equation (3.1), it can be seen that the rate of radiative recombination is proportional to the concentration of carriers. Therefore if the carriers could be confined in one region wherein recombination could take place the rate of recombination would increase significantly. This is the basic concept employed in the use of a heterojunction structure. The band diagram of a heterostructure under a forward bias condition is given in the figure below [Schubert, 2003]. 


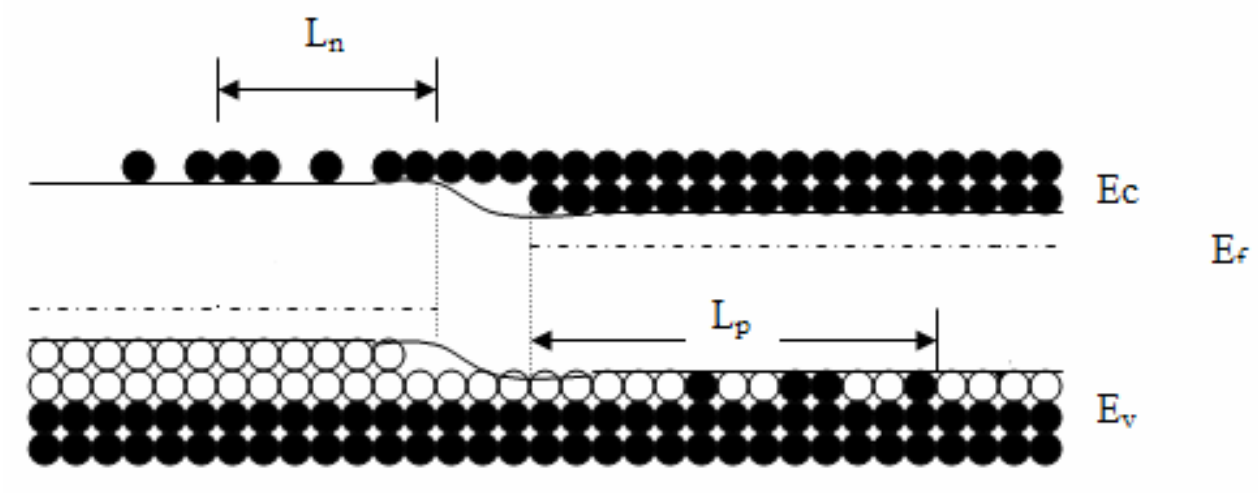

Figure 3.2: Band diagram of heterostructure under a forward bias condition

\subsection{Heterostructure Junctions}

A Heterostructure junction comprises of two semiconductors differing in their band gap energies. The semiconductor with smaller band gap energy forms the active region and that with a larger bandgap forms the barrier region. The carriers that are injected into the active region are confined in that region by the barriers surrounding it. Therefore the thickness of the region where the carriers recombine is given not by the diffusion length of the carriers but by the thickness of the active region.

As an example of the advantage, an assumption is made that the thickness of the active region is much less than that of the diffusion length of the carriers. Hence whereas the magnitude of the diffusion lengths is around 1-20 $\mu \mathrm{m}$, the active region's thickness may range from 0.01 to $1.0 \mu \mathrm{m}$. Therefore the carriers in the active region of a double heterostructure have a higher concentration than in a homojunction where they are distributed over several diffusion lengths. Therefore, from the Bimolecular Rate Equation, it is clear that in the active region the radiative recombination rate increases and decreases the recombination lifetime. Hence the design of high efficiency LED employs the services of double heterostructures and quantum wells [Schubert, 2003]. 


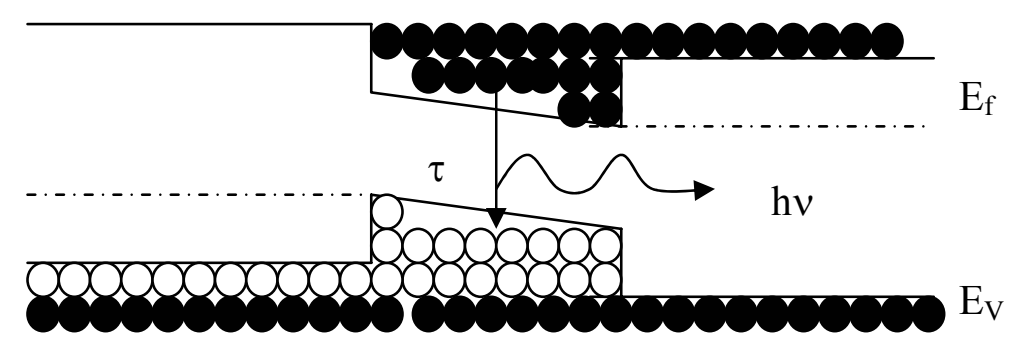

Figure 3.3: Band diagram of a double hetrostructure Quantum Well

\subsection{Heterostructure Junctions and device Resistance}

Heterostructures help in increasing the efficiency of the LED by confining the carriers to the active region and not allowing them to diffuse over a long distance. They also serve as a wave-guiding layer in LED's, which are required to be edge emitting. However there are certain issues associated with a heterostructure.

The major problem associated with a heterostructure is the resistance that is caused by the heterostructure interface. The band diagram of a heterostructure is given below [Schubert, 2003].

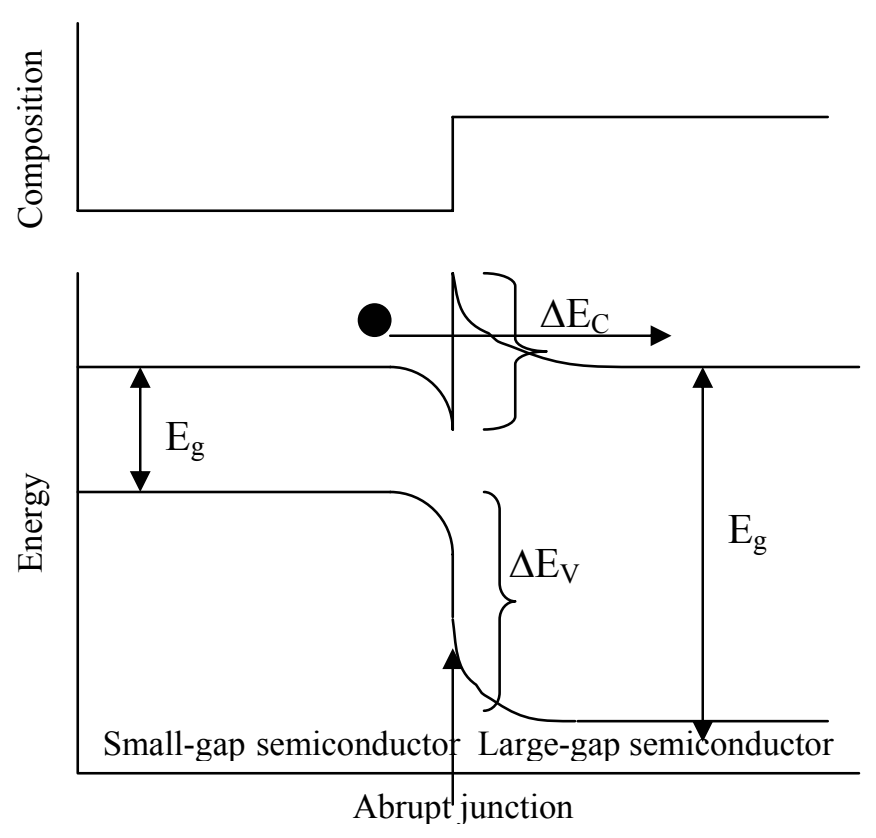

Figure 3.4: Band diagram of a heterostructure 
In this diagram, both of the semiconductors are assumed to be of $\mathrm{n}$ type. The carriers from the large band gap semiconductor diffuse into the small band gap material where they occupy lower energy states in the conduction band. As a result of the transfer of electrons from the conduction band, the electron donors are positively ionized and similarly the acceptors in the lower bandgap semiconductor are negatively ionized. As a result a charged depletion layer is created and the potential leads to a band bending shown in the figure above.

The charges traveling from one semiconductor to the other need to overcome this barrier by tunneling or thermal emission over the barrier, this leads to a resistance which has a negative effect on the device performance. For example the thermal power that is produced due to the resistance leads to a heating of the active region and ultimately reduces the overall radiative efficiency. This issue is addressed further on in this chapter.

\subsection{Thickness of the Active region in the quantum wells}

As discussed above radiative recombination is increased with the use of heterostructures. Hence in order to increase the efficiency of Blue LED's quantum wells are used. This section focuses on the thickness of the active region in the quantum well.

The free carriers in the active region are distributed according to the Fermi Dirac distribution, resulting in some carriers having a higher energy than the height of the confining barrier, allowing some of the carriers to escape into the barrier region. This overflow is a loss mechanism. As the density of the injection current increases, the probability for carrier overflow increases to a point where an increase in the injection current density does not increase the carrier concentration in the active region and the optical intensity saturates. Since at high injection current densities, carrier overflow 
occurs even if the barriers are sufficiently high, the leakage at low current densities may be neglected.

The current density at which the active region overflows is given by the following equation [Schubert, 2003]:

$$
J_{\text {Overflow }}=\left[\frac{m^{*}\left(\Delta E_{C}-E\right)_{0}}{\pi(h / 2 \pi)^{2}}\right]^{2} \frac{e B}{W_{Q W}}
$$

Where:

$\mathrm{m}^{*}=$ effective mass of the electron

$\Delta \mathrm{E}_{\mathrm{C}}=$ discontinuity in the conduction band

$\mathrm{E}_{0}=$ is the minimum energy level in the active region

$\mathrm{H}=$ planks constant

$$
B=3.0 * 10^{-10} \frac{\mathrm{cm}^{-3}}{S(300 \mathrm{~K} / T)^{3 / 2}\left(E_{g} / 1.5 \mathrm{eV}\right)^{2}}
$$

$\mathrm{W}_{\mathrm{QW}}=$ width of the quantum well

Hence the goal is to maximize the overflow current by choosing a quantum well width of a reasonable thickness.

\subsection{Solution to the Schrödinger's wave equation}

The infinite well problem is more accurate for getting the discrete energy states in a quantum well especially for the ground state $(\mathrm{n}=1)$. For a more accurate solution one must deal with the finite potential step problem. This forces one to examine the region outside the well where the wave function has a finite value as shown in the figure 3.5. 


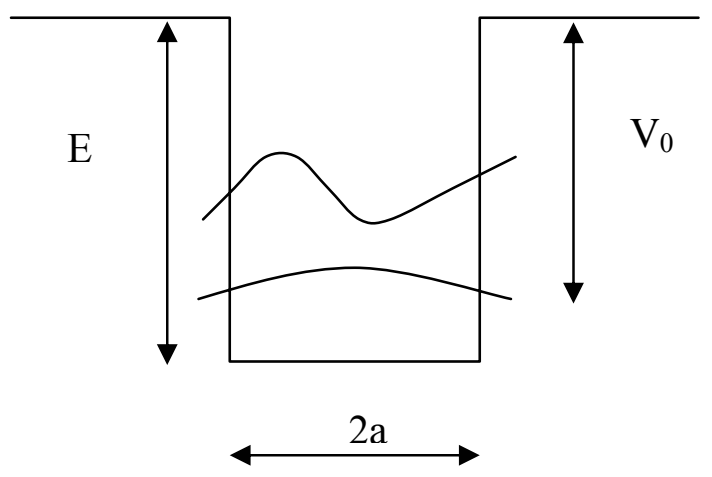

Figure 3.5: Figure of a finite barrier quantum well

In this case the Schrödinger's equation has a finite value and the equation for the barrier region is as follows [Singh, 1993]:

$$
\frac{d^{2} \Psi}{d x^{2}}=-\frac{8 \pi^{2} m}{h^{2}}[E-V(x)] \varphi(x) \text { for }|x| \geq a
$$

Where:

$\varphi(x)=$ wave function

$m=$ mass

$h=$ Planks constant

$E=$ total energy of particle

$V(x)=$ potential energy function of the particle

The solutions inside the well have the form

$$
\begin{gathered}
\psi(x)=A \sin (\alpha x)+B \cos (\alpha x) \\
\alpha=\sqrt{\frac{2 m E^{*} 4^{*} \pi^{2}}{2 h^{2}}}
\end{gathered}
$$

Likewise the solution outside the well has the form 


$$
\begin{aligned}
& \psi(x)=C \exp (-\beta x)+D \exp (\beta x) \\
& \beta=\sqrt{\frac{2 m\left(V_{0}-E\right) * 4^{*} \pi^{2}}{h^{2}}}
\end{aligned}
$$

Imposing the boundary conditions that at $\mathrm{x}= \pm a, \psi$ and $d \psi / d x$ are continuous. This corresponds to saying that the electron probability and current do not suffer a discontinuity at the boundary. The conditions give:

$$
\begin{aligned}
A \sin (\alpha a)+B \cos (\alpha a) & =C \exp (-\beta a) \\
\alpha A \cos (\alpha a)-\alpha B \sin (\alpha a) & =-C \beta \exp (-\beta a) \\
-A \sin (\alpha a)+B \cos (\alpha a) & =D \exp (-\beta a) \\
\alpha A \cos (\alpha a)+\alpha B \sin (\alpha a) & =\beta D \exp (-\beta a)
\end{aligned}
$$

This yields the following results for non trivial solutions

$$
\begin{aligned}
& y_{1}=\alpha \tan (\alpha a) \\
& \& y_{2}=\beta
\end{aligned}
$$

The energy levels are obtained by numerically or graphically solving these transcendental equations [Singh, 1993]. In this case they have been solved by graphically solving them. The solution is obtained when $\mathrm{f}(\mathrm{E})=0$, where:

$$
f(E)=y 1-y 2
$$

A program was written to solve this equation in MATLAB. The details of the program are given in the appendix A. 
The simulation accepts a value for the indium mole fraction and gives as an output,

- The possible wavelength emission at different active region thickness and

- The energy of the first level in the quantum well.

The aim of this research is to design a blue LED emitting in the region of $460 \mathrm{~nm}$. From the simulation, upon giving a value of 0.18 for the indium mole fraction, it was seen that the wavelength of $461 \mathrm{~nm}$ would be emitted for a well thickness of $4 \mathrm{~nm}$. The plots generated for Well thickness Vs Eo and Wavelength Vs Well thickness are given below. Table 1 gives the values of well thickness versus the emission wavelength at an Indium mole fraction of 0.18 .

Table 1: Theoretical Wavelength Vs Well Thickness for a constant Indium Mole fraction of 0.18

\begin{tabular}{|c|c|}
\hline Wavelength (nm) & Well Thickness (nm) \\
\hline 419.9 & 2 \\
\hline 433.6 & 2.5 \\
\hline 444.8 & 3 \\
\hline 453.8 & 3.5 \\
\hline 461.0 & 4 \\
\hline 466.9 & 4.5 \\
\hline 471.7 & 5 \\
\hline 475.7 & 5.5 \\
\hline 479.0 & 6 \\
\hline 481.8 & 6.5 \\
\hline 484.2 & 7 \\
\hline 486.3 & 7.5 \\
\hline 488.0 & 8 \\
\hline 489.5 & 8.5 \\
\hline
\end{tabular}




\begin{tabular}{|c|c|}
\hline 490.9 & 9 \\
\hline 492.0 & 9.5 \\
\hline 493.1 & 10 \\
\hline
\end{tabular}

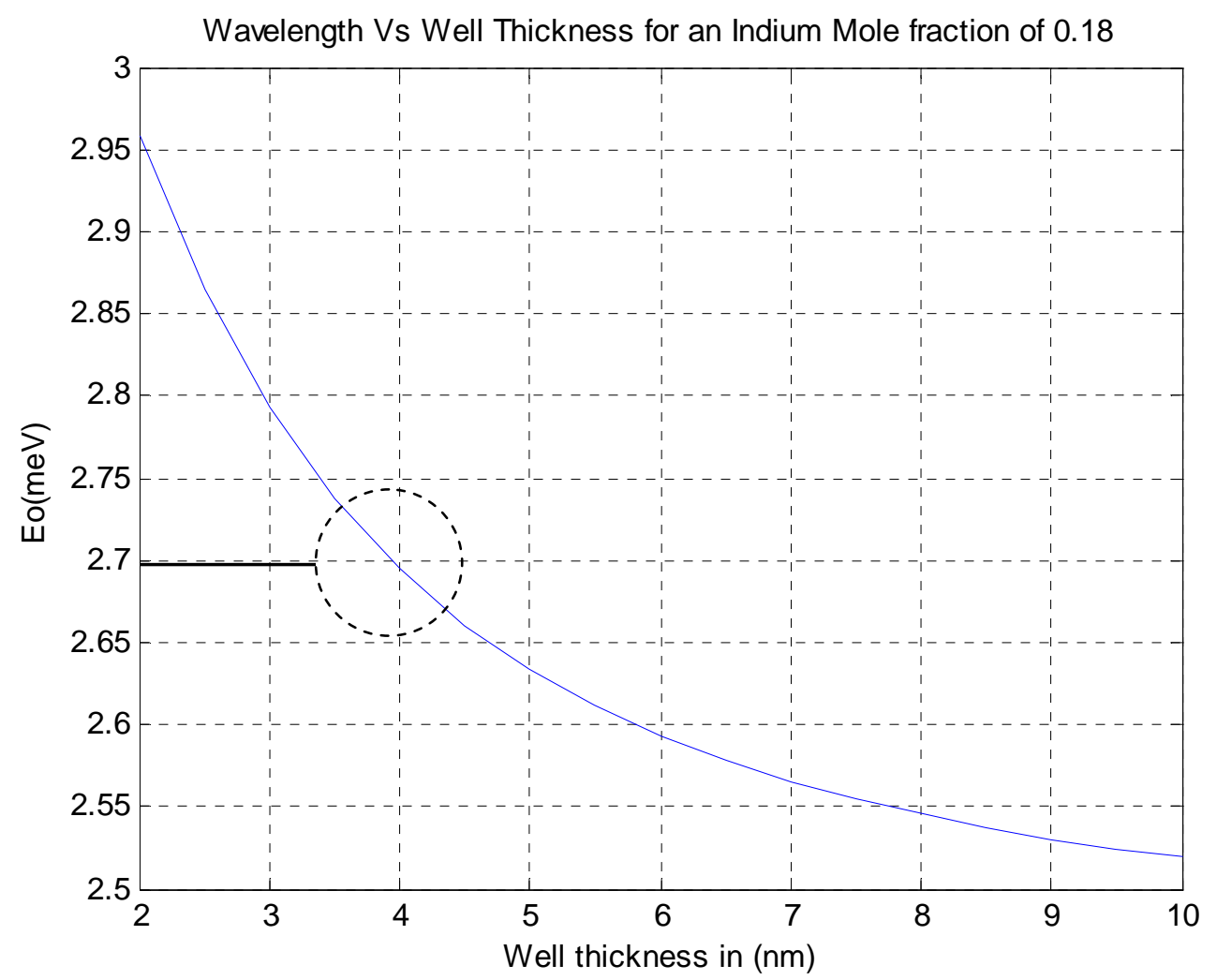

Figure 3.6: Plot showing the first discrete energy level Vs the Well thickness generated from the solution to Schrodingers $1 D$ Time Independent wave equation 


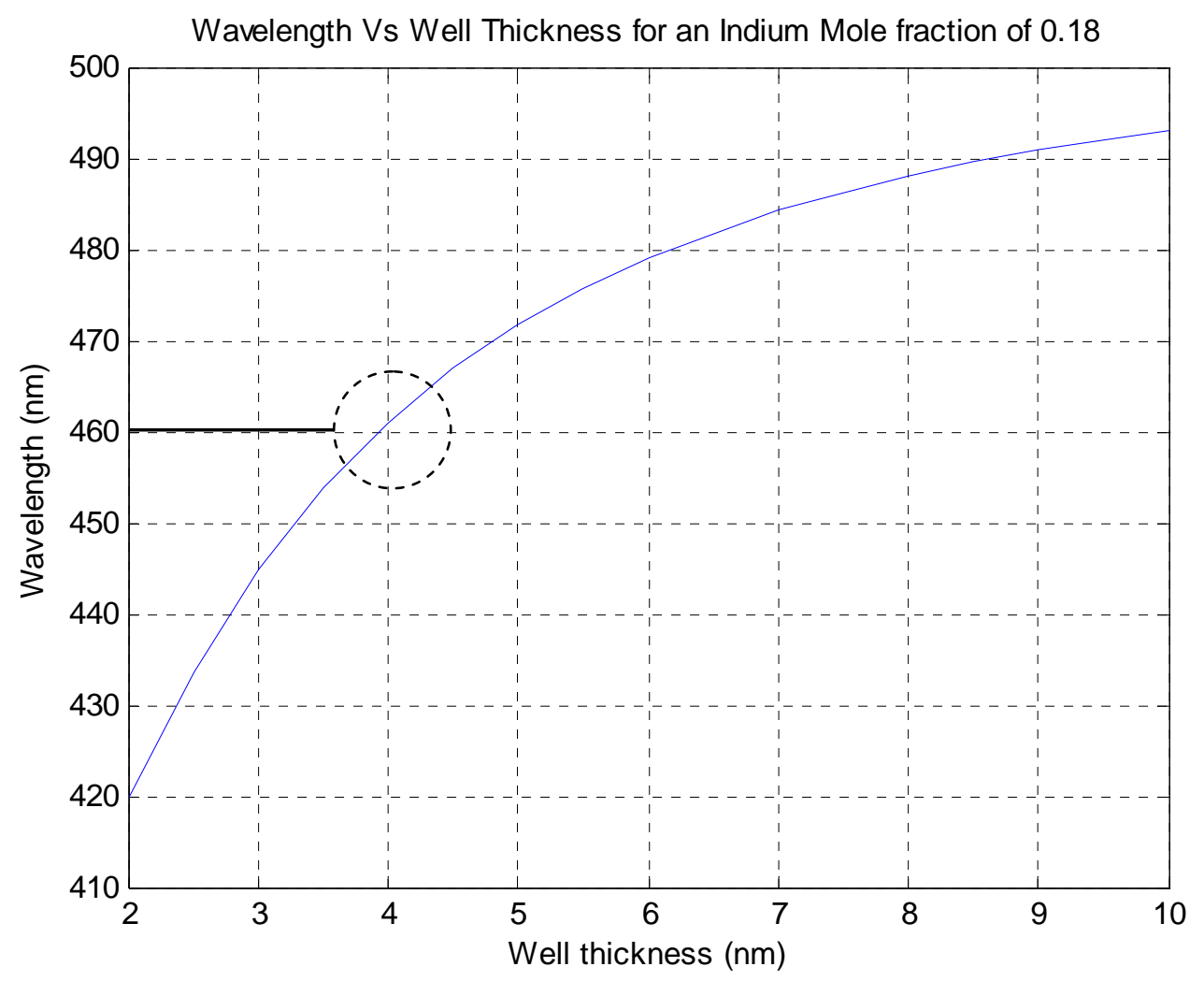

Figure 3.7: Plot showing predicted Wavelength Vs Well thickness for an Indium Mole fraction of 0.18

The simulation is run for various values of indium mole fraction and the value of Eo for each case is noted down. Using equation 3.2, a program was written in MATLAB to compute the value of the overflow current giving as an input the indium mole fraction, Eo and active layer thickness. The details of the program are given in the appendix. The values of the indium mole fraction, emission wavelength, active layer thickness, Eo and overflow current density in $\mathrm{A} / \mathrm{cm}^{2}$ are tabulated in Table 2. 
Table 2: Table showing the Overflow Current Densities for various Indium Mole Fractions and their corresponding Wavelength, Well thickness and Energy level

\begin{tabular}{|c|c|c|c|c|}
\hline $\begin{array}{c}\text { Mole } \\
\text { Fraction }\end{array}$ & $\begin{array}{c}\text { Wavelength } \\
(\mathbf{n m})\end{array}$ & $\begin{array}{c}\text { Well } \\
\text { thickness } \\
(\mathbf{n m})\end{array}$ & Eo (meV) & J (A/cm^2) \\
\hline 0.13 & 448.6 & 10 & 2.7692 & 137149.4 \\
\hline 0.14 & 457.0 & 10 & 2.7180 & 154078.4 \\
\hline 0.15 & 459.9 & 7.5 & 2.7008 & 228339.3 \\
\hline 0.16 & 459.1 & 5.5 & 2.7058 & 342899.2 \\
\hline 0.17 & 459.0 & 4.5 & 2.7064 & 457868.2 \\
\hline $\mathbf{0 . 1 8}$ & 461.0 & $\mathbf{4 . 0}$ & $\mathbf{2 . 6 9 4 5}$ & $\mathbf{5 5 8 8 1 2 . 4}$ \\
\hline 0.19 & 461.0 & 3.5 & 2.6943 & 688429 \\
\hline
\end{tabular}

A plot showing the variation of the overflow current with the change in the Indium Mole fraction is given below.

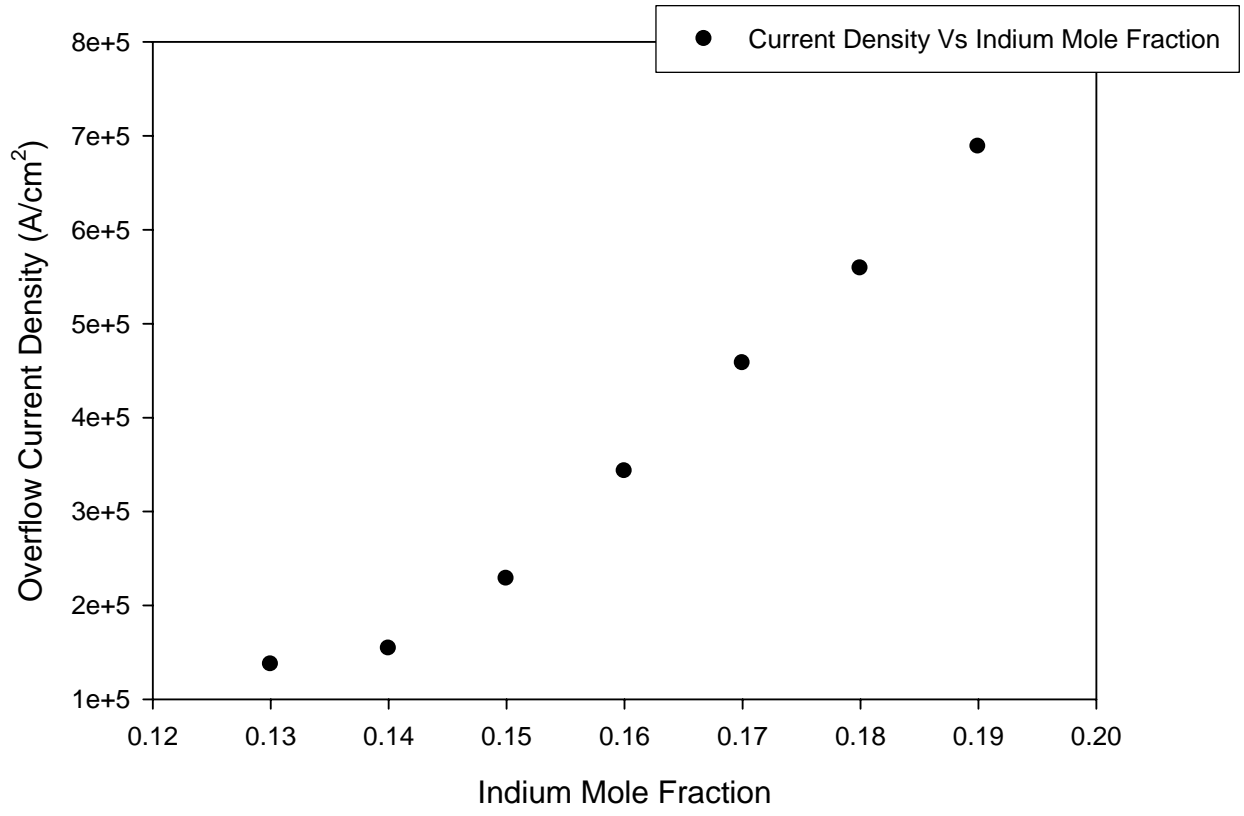

Figure 3.8: Plot showing Overflow Current Density Vs Indium mole fraction for wavelengths centered on $460 \mathrm{~nm}$ 
Since the Overflow Current Density is defined as Current density at which the active region overflows [Schubert, 2003], it is in the interest of the design to have as high an Overflow Current Density as possible.

From the plot it can be seen that the maximum overflow current is seen to increase with an increase in the indium mole fraction from 0.13 to 0.19 . The mole fraction of 0.18 is chosen as opposed to that of 0.19 as there is not a large difference in the Overflow Current Density and a lower value of Indium Mole fraction is taken to avoid possible accumulation effects of quantum dots caused by high Indium concentration.

\subsection{AlGaN as an Electron blocking layer}

Literature indicates that the band discontinuity in a heterostructure can be completely removed by grading the chemical composition of the semiconductor near the region of the heterostructure. The band diagram of such a graded heterostructure is given in the figure below. It can be seen that there is no spike in the conduction band impeding the flow of the electrons. It has been shown that the resistance of the heterostructure is comparable to the bulk material resistance and therefore additional resistance introduced by the heterostructure can be removed by parabolic grading [Schubert, 2003].

The concentration of the ionized charges in the $\mathrm{p}$ large-bandgap material will be that

of the donor concentration and assuming this to be $\mathrm{N}_{\mathrm{D}}$ and a constant through the heterostructure, the solution to the Poisson's equation yields an electrostatic potential to be as follows [Schubert, 2003]:

$$
\phi=\frac{e N_{D} x^{2}}{2 \varepsilon}
$$

Where:

$\mathrm{N}_{\mathrm{D}}=$ Donor concentration 
$\mathrm{x}=$ special co-ordinate

$\varepsilon=$ dielectric constant of $\mathrm{p}$ large bandgap material

The potential has a parabolic shape and this may be seen from the quadratic variation of the spatial coordinate ' $x$ '. In order to compensate the parabolic shape of the depletion layer, the composition of the semiconductor is varied parabolically as well resulting in an overall flat potential, assuming that a parabolic variation of the chemical composition results in a parabolic variation of the bandgap energy. In other words, we assume that the band gap energy varies linearly with the chemical composition of the semiconductor.

Assuming that the conduction band discontinuity is given by $\Delta \mathrm{E}$ and the structure is uniformly doped with a concentration of $\mathrm{N}_{\mathrm{D}}$, when the potential created in the depletion region is equals $\Delta \mathrm{E} / \mathrm{e}$, the electrons no longer transfer to the small bandgap material. From equation (3.2) the thickness of the depletion region may be calculated to be

$$
W_{D}=\sqrt{\frac{2 \varepsilon \Delta E}{e^{2} N_{D}}}
$$

Where:

$\mathrm{W}_{\mathrm{D}}=$ Thickness of the depletion region

$\varepsilon=$ Dielectric constant of the material

$\mathrm{N}_{\mathrm{D}}=$ Donor concentration

$\Delta \mathrm{E}=$ difference in the conduction or valence band gaps

\subsection{Design}

In the case of $\mathrm{InGaN} / \mathrm{GaN}$ blue light emitting diodes, a p-AlGaN electron-blocking layer is used to reduce the leakage of carriers out of the active region of the device. The electron leakage current is larger than that of the holes in III-V semiconductors because the diffusion constant of electrons is larger than that of holes. AlGaN is 
considered to be a good choice for a blocking layer due to its high band gap energy given by the equation [Chang, 2003]:

$$
\mathrm{E}_{\mathrm{g}}=x \mathrm{E}_{\mathrm{g}, \mathrm{AlN}}+(1-x) \mathrm{E}_{\mathrm{g}, \mathrm{GaN}^{-}}-x(1-x) \mathrm{x} 1.0
$$

Where:

$x=$ the mole fraction of the $\mathrm{Al}$ in the semiconductor.

The figure below shows the energy band diagram of the pAlGaN-GaN interface.

The figure indicates that there is a barrier to the flow of holes created in the AlGaN$\mathrm{GaN}$ interface. This is due to the depletion of holes in the $\mathrm{AlGaN}$ doped region. The potential spike is created due to the accumulation of holes in the AlGaN layer impeding the flow of holes injected from the $\mathrm{p}-\mathrm{GaN}$ region.

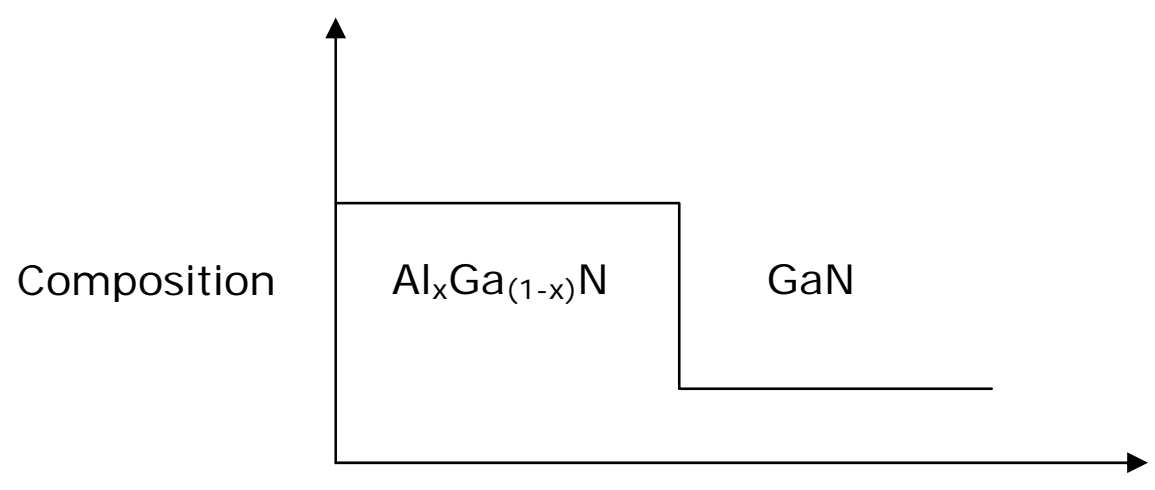

(a)
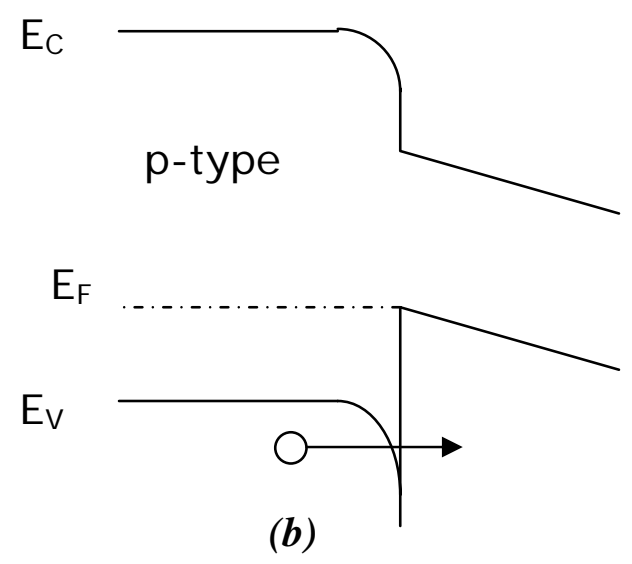

Figure 3.9: (a) Diagram showing a sharp compositional variation of Al in AlGaN and (b) The corresponding Energy Band Diagram of the p-AlGaN-GaN interface 
In order to reduce the resistance caused by this spike the p-AlGaN is compositionally graded, so that the hole flow is not impeded at all.

\subsubsection{Calculation of width of AlGaN barrier}

A program was written in MATLAB to calculate the width of the barrier from equation (3.16), given the $\mathrm{Al}$ mole fraction ' $x$ ' in the $\mathrm{AlGaN}$ and the doping concentration. From the literature it was seen that a doping concentration's varied from a range of typically $10^{17}$ to $10^{19} \mathrm{~cm}^{-3}$ [Dang, 1999][Polyakov, 2001]. The mole fraction of the $\mathrm{Al}$ is seen to vary from a value of 0.1 to 0.3 .

The plot below is made for the mole fraction of $\mathrm{Al}$ versus the thickness calculated for the $\mathrm{AlGaN}$ layer for a constant mole fraction and doping concentration.

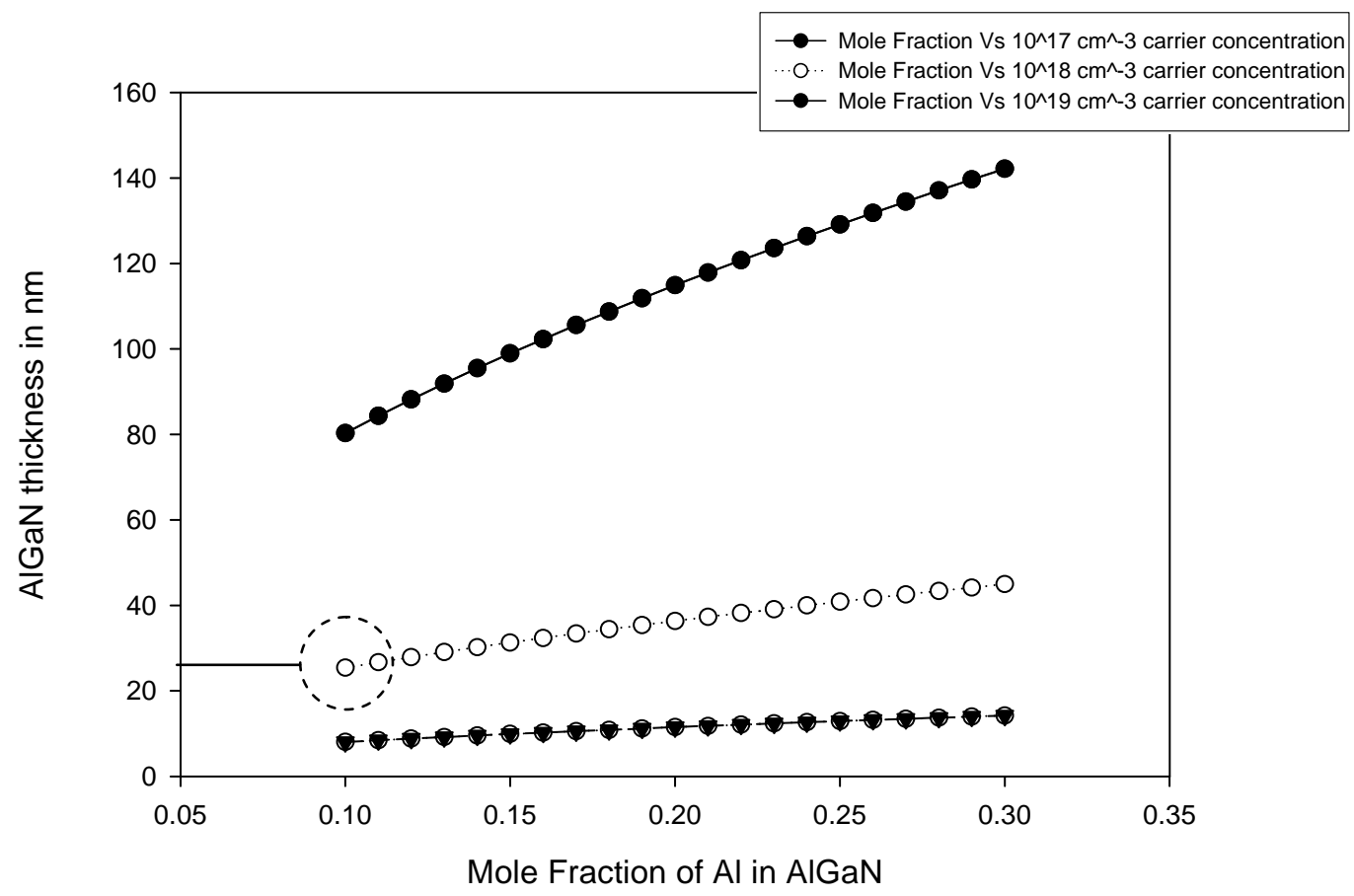

Figure 3.10: Plot for Al mole fraction Vs AlGaN thickness calculated for a constant carrier concentration. 
From the above plot it is seen that the least thickness of $\mathrm{Al}$ is obtained for a maximum carrier concentration of the order of $10^{19} \mathrm{~cm}^{-3}$ and an Al mole fraction of 0.1. Although the trend seen is counter intuitive, the linear relation might be explained by the fact that from equation (3.16) the dependence of $\mathrm{W}_{\mathrm{D}}$ on $\mathrm{N}_{\mathrm{D}}$ is greater than that of the mole fraction ' $\mathrm{x}$ '.

Literature indicated that AlGaN p type doping was more easily attainable at lower concentrations. Therefore the AlGaN thickness at a doping concentration of $10^{18} \mathrm{~cm}^{-3}$ and $\mathrm{Al}$ mole fraction 0.1 is chosen. From the MATLAB program, this value was found to be $25.38 \mathrm{~nm}$.

\subsubsection{Grading the Mole fraction of Al parabolically}

As was shown above, in order to reduce the resistance caused by the discontinuity in the band structure the $\mathrm{Al}$ mole fraction is to be varied parabolically. The focus of this section is to calculate the gradation of the $\mathrm{Al}$ mole fraction.

The equation of a parabola is given by the equation:

$$
y=a x^{2}+c
$$

From the calculations of the simulations above, the minimum value for the grading thickness was taken to be $25.38 \mathrm{~nm}$, which is rounded to $25 \mathrm{~nm}$. In order to grade this value, it is split to 25 layers of $1 \mathrm{~nm}$ thickness each and the mole fraction is varied from a minimum of ' 0 ' to a maximum of ' 0.1 ' by solving the equation using Microsoft Excel. The plot below shows the values obtained as a result of this parabolic grading. 


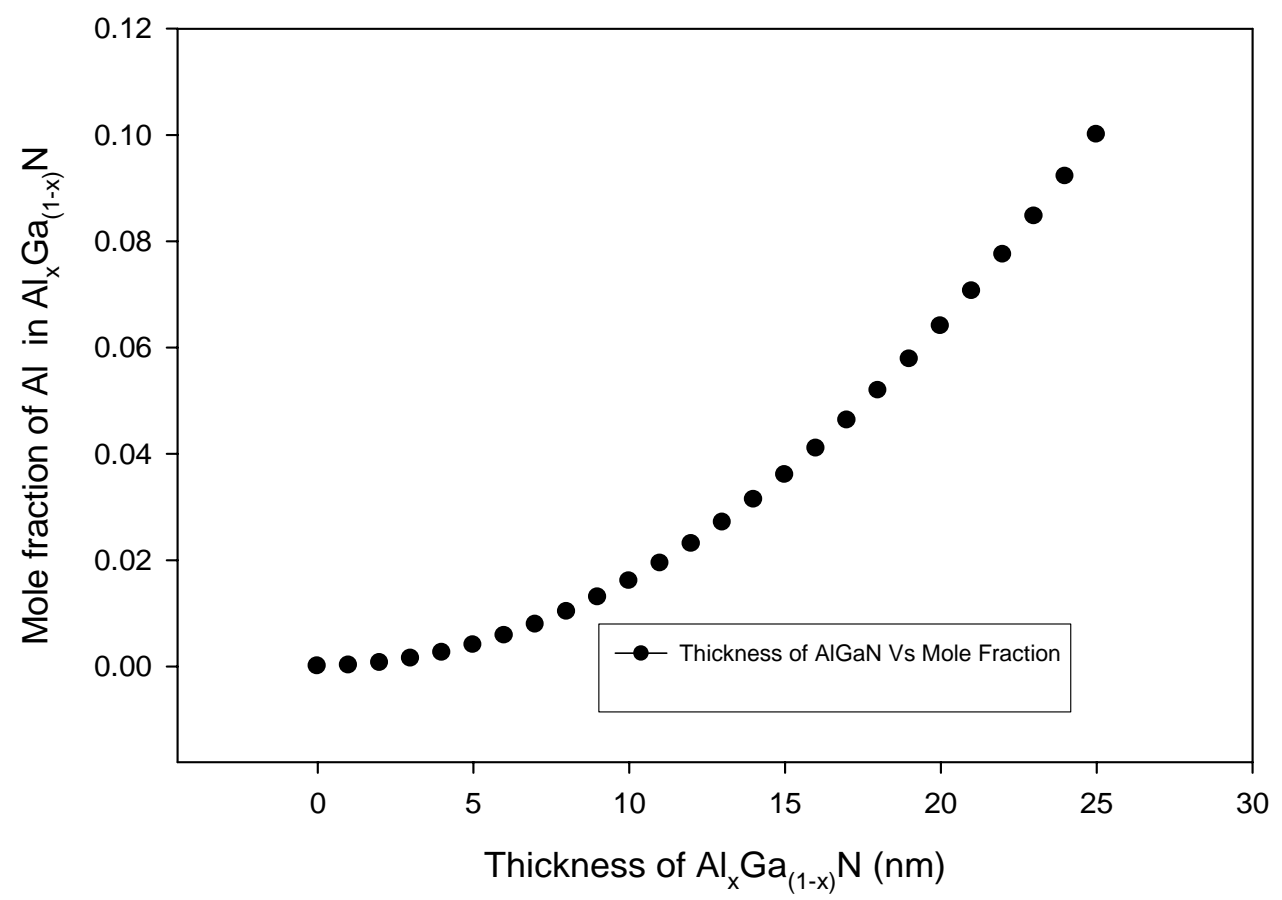

Figure 3.11: Plot showing the variation of $A$ in $A l_{x} G a_{(1-x)} N$ versus the thickness of $A l_{x} G a_{(1-x)} N$

The values of the graded mole fraction are given with the thickness in the following table.

Table 3: Table listing the values of the thickness of $\mathrm{Al}_{\mathrm{x}} \mathrm{Ga}_{(1-\mathrm{x})} \mathrm{N}$ and the corresponding Mole fraction taking into consideration parabolic grading

\begin{tabular}{|c|c|}
\hline $\begin{array}{c}\mathbf{A l}_{\mathbf{x}} \mathbf{G a}_{(1-\mathrm{x})} \mathbf{N} \\
\text { thickness in nm }\end{array}$ & Mole fraction \\
\hline 0.0000 & 0.0000 \\
\hline 1.0000 & $1.6 \times 10^{-4}$ \\
\hline 2.0000 & $6.4 \times 10^{-4}$ \\
\hline 3.0000 & $1.44 \times 10^{-3}$ \\
\hline 4.0000 & $2.56 \times 10^{-3}$ \\
\hline 5.0000 & $4.0 \times 10^{-3}$ \\
\hline 6.0000 & $5.76 \times 10^{-3}$ \\
\hline 7.0000 & $7.84 \times 10^{-3}$ \\
\hline 8.0000 & 0.0102 \\
\hline 9.0000 & 0.0130 \\
\hline \multicolumn{2}{|c}{} \\
\hline
\end{tabular}




\begin{tabular}{|l|l|}
\hline 10.0000 & 0.0160 \\
\hline 11.0000 & 0.0194 \\
\hline 12.0000 & 0.0230 \\
\hline 13.0000 & 0.0270 \\
\hline 14.0000 & 0.0314 \\
\hline 15.0000 & 0.0360 \\
\hline 16.0000 & 0.0410 \\
\hline 17.0000 & 0.0462 \\
\hline 18.0000 & 0.0518 \\
\hline 19.0000 & 0.0578 \\
\hline 20.0000 & 0.0640 \\
\hline 21.0000 & 0.0706 \\
\hline 22.0000 & 0.0774 \\
\hline 23.0000 & 0.0846 \\
\hline 24.0000 & 0.0922 \\
\hline 25.0000 & 0.1000 \\
\hline
\end{tabular}

Upon grading the mole fraction of $\mathrm{Al}$ in the $\mathrm{p}$-AlGaN layer parabolically as calculated above, the expected energy band diagram of the $\mathrm{p}-\mathrm{AlGaN}-\mathrm{GaN}$ interface is shown below.

Composition $\mathrm{x}$

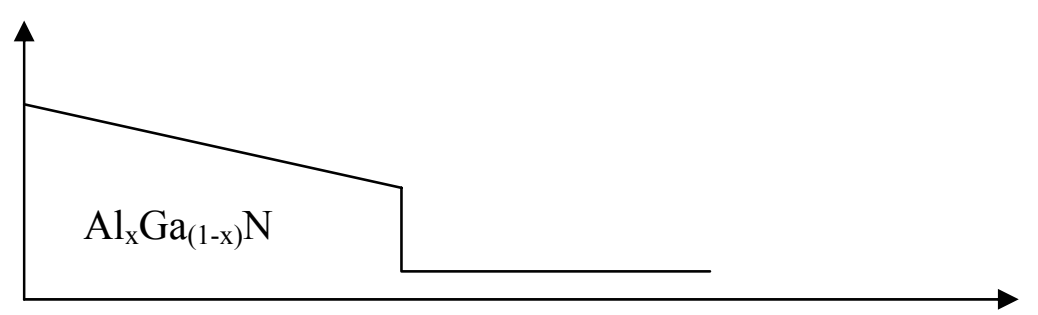

(a)

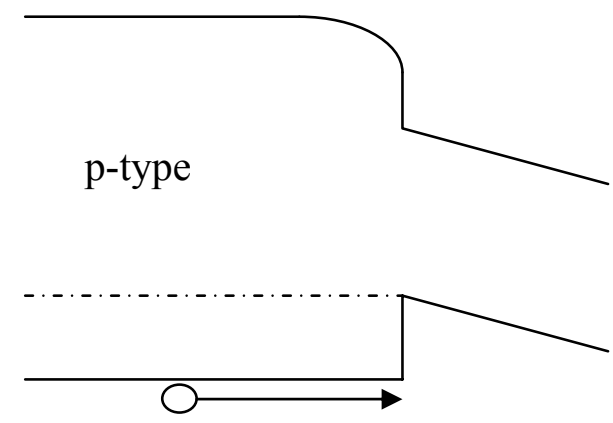

(b)

Figure 3.12: (a) Diagram showing a compositional grading of Al in $p$ - AlGaN and (b) The corresponding Energy Band Diagram of the p-AlGaN-GaN interface 
Experimental Results prove that when the number of Quantum Wells increases above 6, the Photoluminescence peak decreases [Cheong, 2001]. Therefore an optimum number of 5 quantum wells are decided upon. It is also observed that with increasing barrier thickness from 45 to $170 \AA$ the PL intensity increases and the crystal quality of the barriers increase with an increasing thickness. The PL intensity was seen to increase rapidly until 65 Angstroms and then saturate [Cheong, 2001]. Therefore in order to obtain a high PL efficiency the barrier thickness should be greater than 65 angstroms. Henceforth a value of $7 \mathrm{~nm}$ is decided upon. From the literature the values of $\mathrm{p}-\mathrm{GaN}$ and $\mathrm{n}-\mathrm{GaN}$ are taken to be $0.5 \mu \mathrm{m}$ and $3 \mu \mathrm{m}$.

\subsection{Final structure}

The diagram and Energy band diagrams of the final structure are given below.

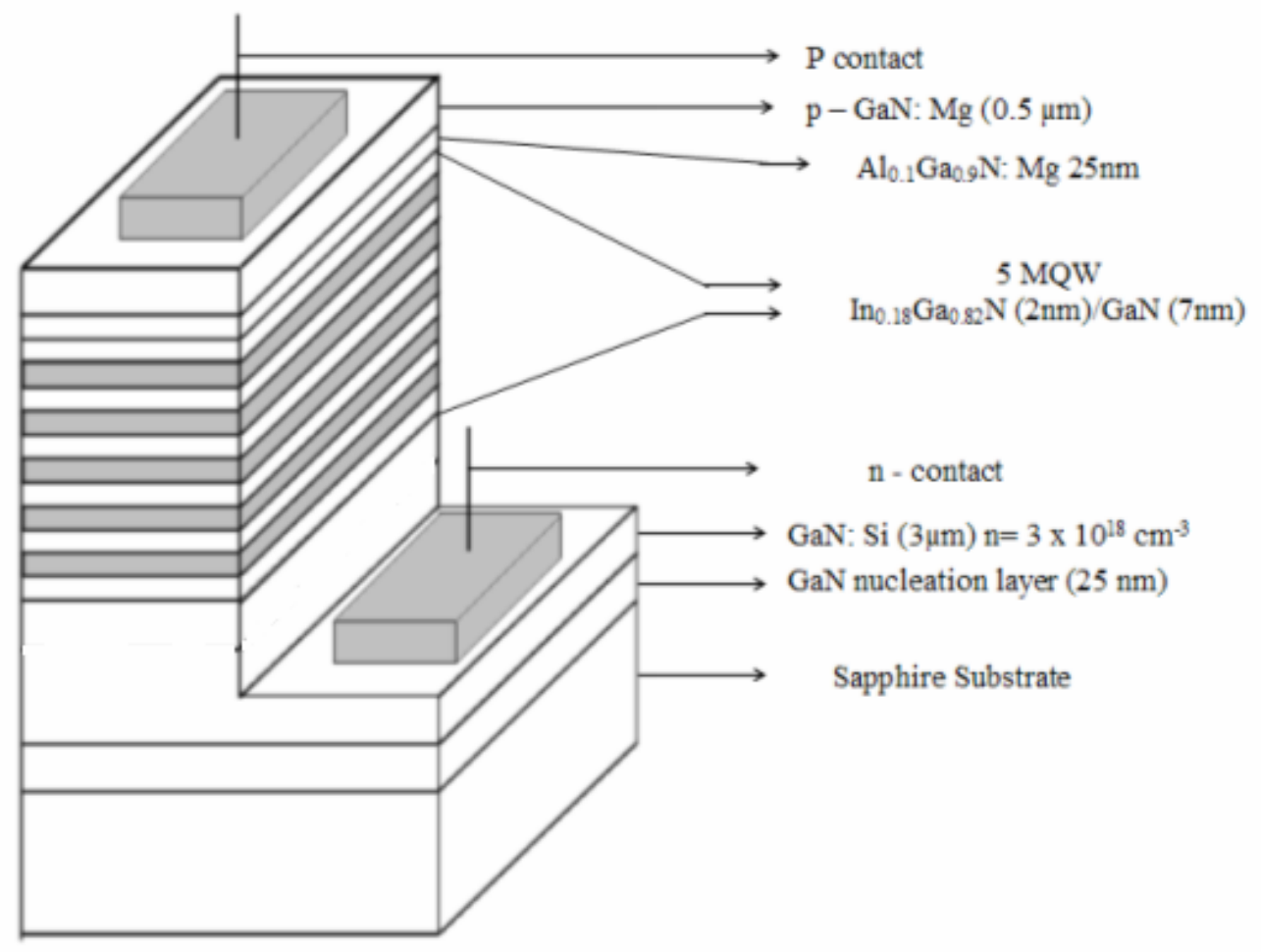

Figure 3.13: Structure of the Designed InGaN/GaN Light Emitting Diode 


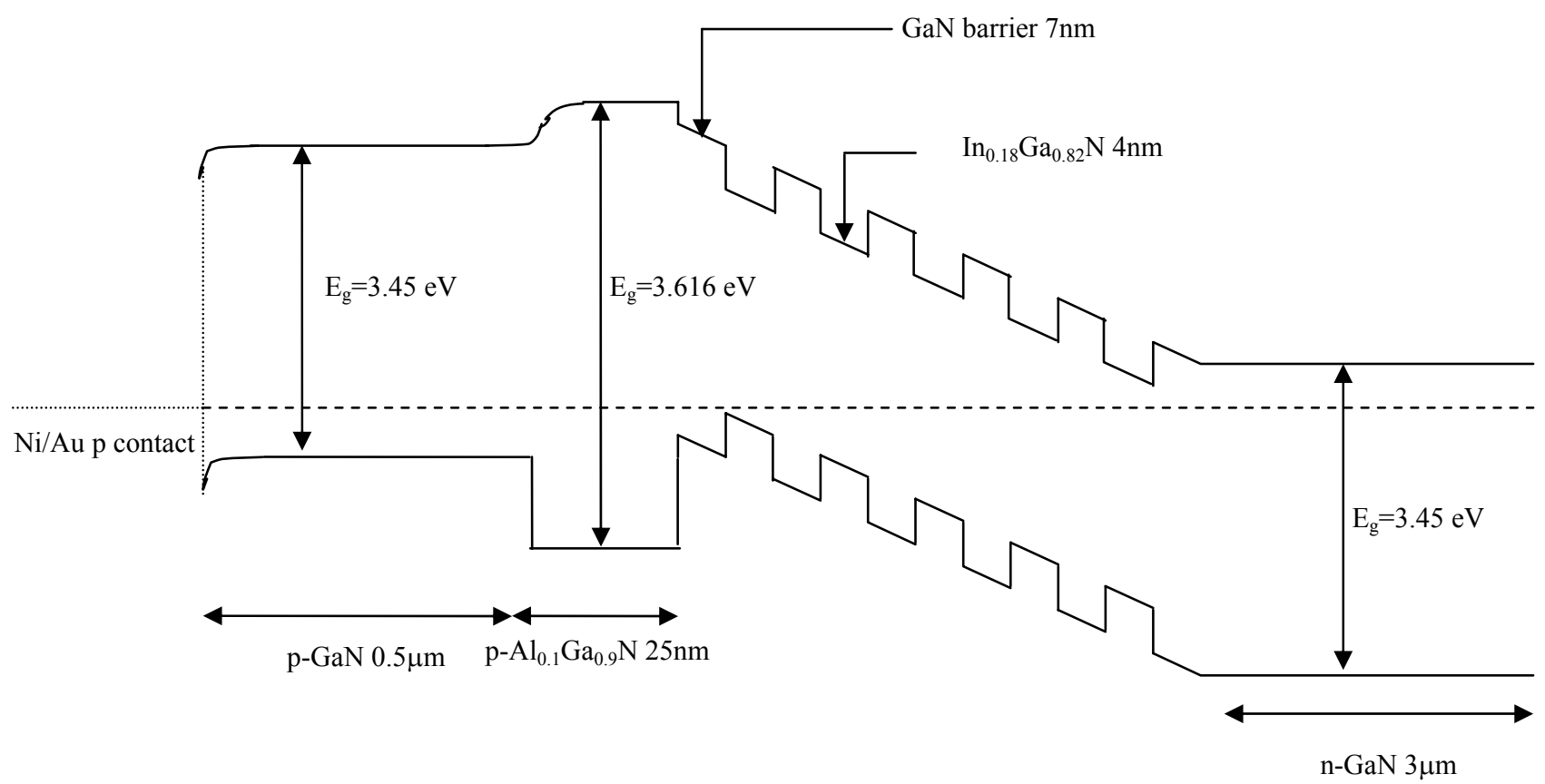

Figure 3.14: Energy band diagram of the proposed Light Emitting Diode structure 


\section{REACTIVE ION ETCHING PROCESS AND EXPERIMENTAL RESULTS}

\subsection{Setup}

In order to Determine the etch rate of the different compounds the samples were initially cleaned and mounted on a larger substrate. Photolithography was then performed on these samples and then they were etched under various conditions. A list of the apparatus used is given in this chapter, which is then followed by the experimental recipes and procedures used.

\subsubsection{Apparatus and Chemicals used}

The various apparatus that were used in the experimental setup include:

- Karl Suss MA6 Aligner

- Spinner

- Soda Lime Mask

- Alpha Step

- Optical Microscope

- Baking Oven

- Hot Plate

- Oxford Plasmalab80 PECVD system

- Oxford Plasmalab 80 RIE system

The Different reagents used included:

- AZ 312 MIF Developer

- $\quad$ AZ 5214 photo resist

- Acetone \& Methanol 
- $5 \%$ Silane

- Nitrous Oxide

- SF6

Karl Suss MA6 Aligner: This was used to expose a photo resist coated surface with $\mathrm{UV}$ light of a wavelength of $320 \mathrm{~nm}$. The power of the light was found to be $1.22 \mathrm{~W} / \mathrm{s}$. A photograph of the aligner is given below.

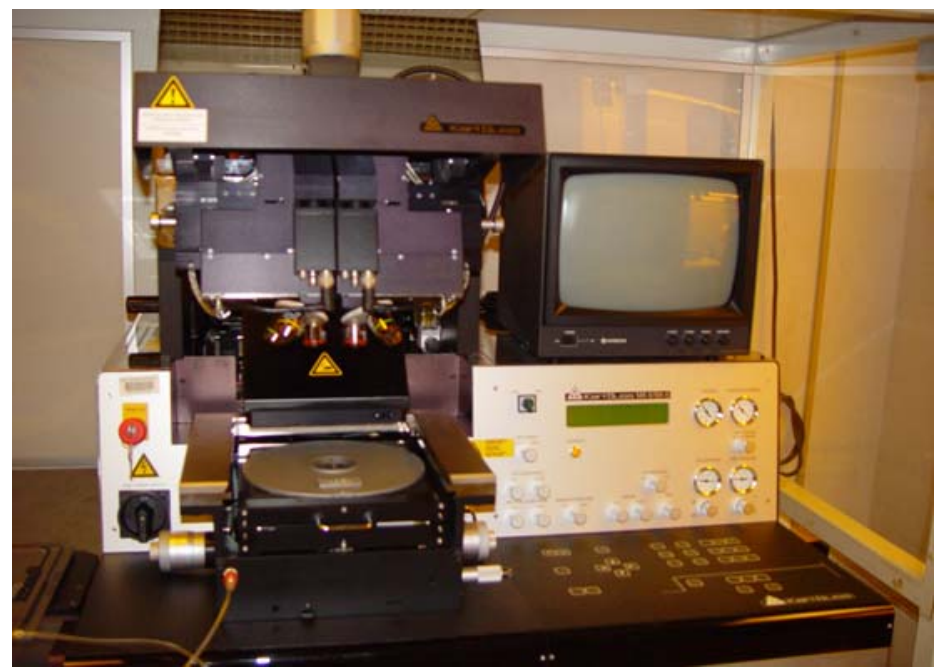

Figure 4.1: KarlSuss MA6/BA6 Aligner

(Property of West Virginia University Micro/ Nanosystem Fabrication Laboratory)

Spinner: The spinner served to coat the sample with the Photo Resist and could rotate with speeds upto 5000rpm. The vacuum that it created was in the range of 22.27. Spinning the Photo Resist was done in two stages. Initially the spinner was allowed to rotate 2000rpm, and then it gradually reached the desired value.

Soda Lime Mask: A Soda Lime Mask with a pattern comprising of lines of thickness of range 50microns was used to pattern the substrate. This mask was created previously using the LEdit software.

Alpha Step: The Alpha Step was used to measure the height of the Photo resist spun on the sample and later on the etch depth of the sample after removing it from the 
Reactive Ion Etching System. This system reads features upto a size of 5-10nm in dimension. A stylus force in the range of 4-9mg was used for the photo resist.

Optical Microscope: An optical microscope of magnifications ranging from 40x, $10 \mathrm{x}, 15 \mathrm{x}$ was used to observe any processed samples.

Baking oven: The oven was used to dehydrate samples. It was maintained at a constant temperature of 100 degrees centigrade.

Hot Plate: A hot plate was used to soft bake the samples at various stages of the process. The temperature range of this varies from 0 to 200 degrees centigrade with an accuracy of about one degree centigrade.

Oxford Plasmalab 80 PECVD system: The PECVD system was used to grow Silicon Dioxide on Silicon and Gallium Nitride samples. The process recipe used to execute the growth of Silicon Dioxide is given below. The system was kept cool with a continuous supply of water. The pressure was controlled with a throttle valve and an automatic pressure control unit.

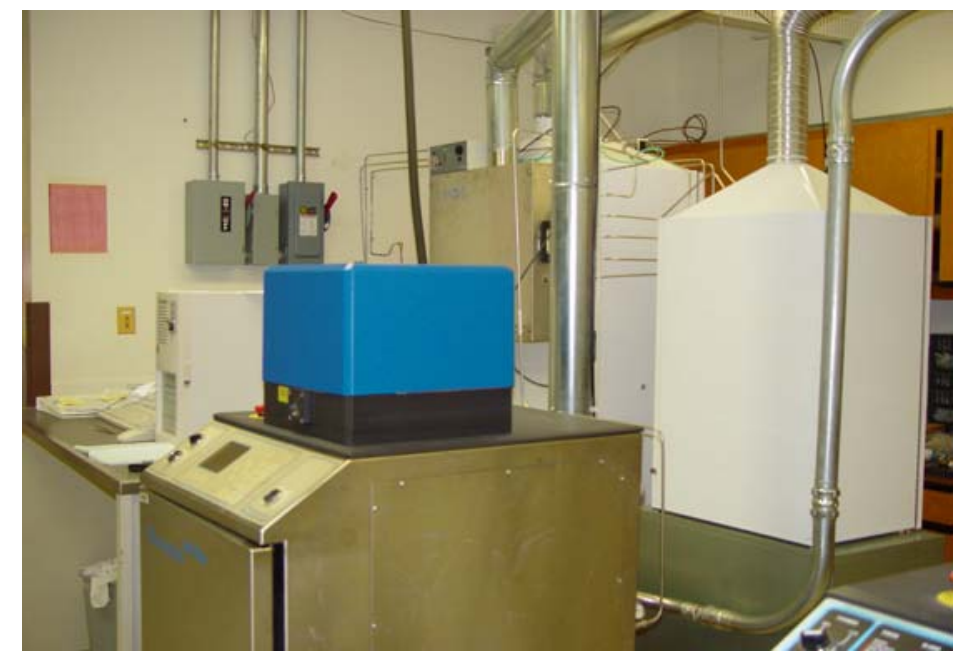

Figure 4.2: Oxford Plasmalab 80 plus PECVD system (Property of West Virginia University Micro/ Nanosystem Fabrication Laboratory) 
Table 4: Table showing the Process Recipe for the PECVD system

\begin{tabular}{|l|l|l|}
\hline 1 & Base Pressure & Pumping to base pressure \\
\hline 2 & Process & $0: 10: 00 ; 10$ minute pumping \\
\hline 3 & Process & $0: 02: 00 ;$ Filling process line with gas \\
\hline 4 & Process & $0: 15: 00 ;$ Silicon Dioxide Deposition \\
\hline 5 & Chamber Vent & Chamber Vent \\
\hline
\end{tabular}

Oxford Plasmalab 80 RIE system: This system was used to etch the samples. It comprises of a throttle valve and an automatic pressure control system wherein the pressure of the system can go down to the tens of milli Torr range. A process recipe was written in order to vary different parameters such as gas flow rate, chamber pressure, RF and ICP powers. The process recipe used to execute the etching of $\mathrm{SiO}_{2}$ and Photo Resist is given below.

Table 5: Table showing the Process Recipe for the PECVD system

\begin{tabular}{|l|l|l|}
\hline 1 & Base Pressure & Pumping down to base pressure $\left(5 \times 10^{-6}\right.$ milli bar $)$ \\
\hline 2 & Process & $00: 00: 30 ; \mathrm{SF}_{6}=40 \mathrm{sccm} ; \mathrm{icp}=150 \mathrm{~W} ; \mathrm{rf}=230 \mathrm{~W}$ \\
\hline 3 & Chamber Vent & Chamber Vent \\
\hline
\end{tabular}




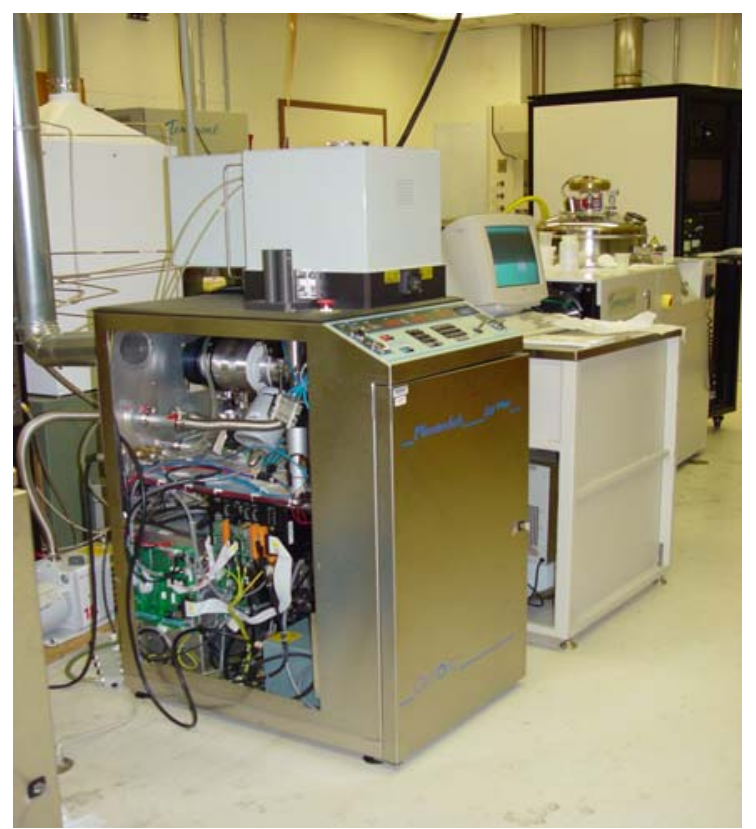

Figure 4.3: Oxford Plasmalab 80 plus RIE system.

(Property of West Virginia University Micro/ Nanosystem Fabrication Laboratory)

\subsection{Experimental Procedures}

In this chapter the experimental procedure and different process steps are explained in detail. It begins with a discussion of the Photolithography procedures, PECVD and then the RIE processes.

\subsubsection{Photolithography}

Silicon Dioxide was used as a hard mask material. Hence the first step would be to characterize the etch rates of the Photo resist and the Silicon Dioxide. This was done by developing a step like structure. 


\subsubsection{Developing a Step like Structure}

In order to determine the etch rates of both the Silicon Dioxide and the Photo resist under the same etch conditions an innovative step like structure was grown onto the substrate. The following process was undertaken.

- A 6 inch silicon wafer was cleaved on its edge and the sample was cleaned by putting it an Acetone and thereafter Methanol bath for a period of five minutes each.

- Upon removing the sample from Methanol, they were dried using Nitrogen gas.

- The dried samples were hard baked at a constant temperature of 100degrees centigrade in an oven for 30 minutes.

- Upon cooling, the wafer was loaded into a PECVD system in order to deposit Silicon Dioxide. The process recipe used to grow the Silicon Dioxide is given in table IV above. Above a 15 minute deposition a speckle pattern was seen to form on the grown Silicon Dioxide, therefore 15 minutes of deposition was decided upon to be the optimal deposition time.

- Upon growing the Silicon Dioxide the wafer was ready to have the Photoresist step pattern, patterned onto it.

In order to achieve the step structure in the photo resist, the AZ 5124 photoresist was spun on the wafer at a speed of 2000 rotations per minute; the program to achieve this on the spinner is given below. The spinner is programmed to accelerate gradually in three stages.

Table 6: Program to accelerate spinner in stages

\begin{tabular}{|c|c|c|}
\hline & & RPM \\
\hline Seconds & $00: 00$ & 400 \\
\hline Acceleration & 04 & 360 \\
\hline
\end{tabular}




\begin{tabular}{|c|c|c|}
\hline Seconds & $00: 55$ & 2000 \\
\hline Acceleration & 015 & 1350 \\
\hline Seconds & 0 & 0 \\
\hline Acceleration & 011 & 990 \\
\hline
\end{tabular}

This sample was then soft baked for 45 seconds on a hot plate at 90 degrees centigrade and left to cool for three minutes.

The step like structure was achieved by a two-step exposure procedure.

- The sample was loaded onto the chuck of the Karl Suss Aligner and exposed initially for a time period of 75 seconds.

- The sample was then taken and developed for 30seconds. Upon developing, the sample is dried thoroughly in Nitrogen gas. The dried sample is then loaded onto the chuck of the Aligner. Using the microscope, the semideveloped pattern can be easily seen on the monitor. The mask pattern is aligned with the developed so that a slight overlap takes place.

- This time the sample is exposed to UV light for another 155 seconds. The exposed sample is then unloaded and developed for one minute and dried thoroughly in Nitrogen gas.

The sample was then examined under the alpha step and it was observed that the desired step like structure was attained. The Alpha step profile of the sample is given in figure 4.4. 


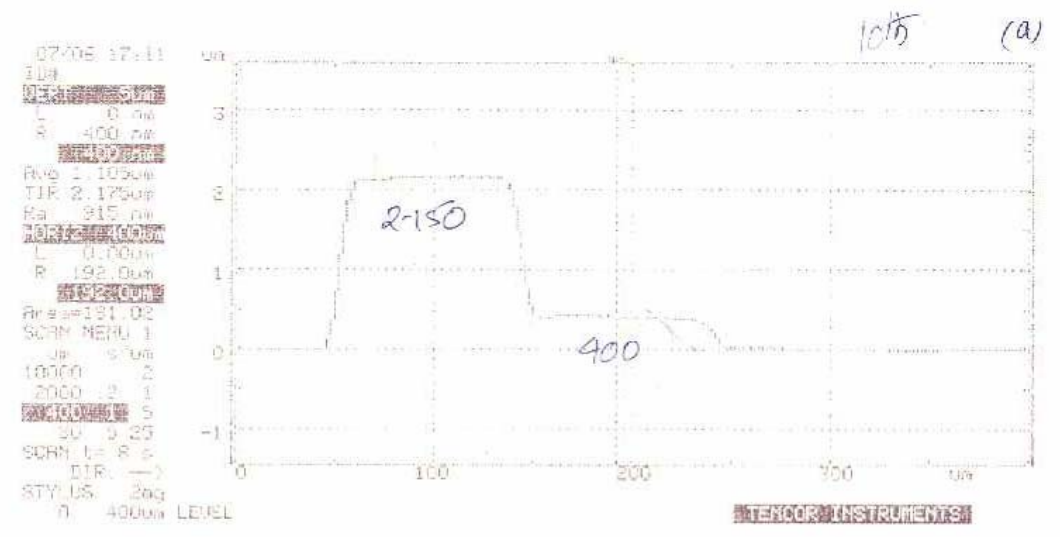

Figure 4.4: Alpha step profile of a step like structure

The figure below shows diagrammatically the step like structure. The height of the second step as shown below is given as " $h_{3}$ ".

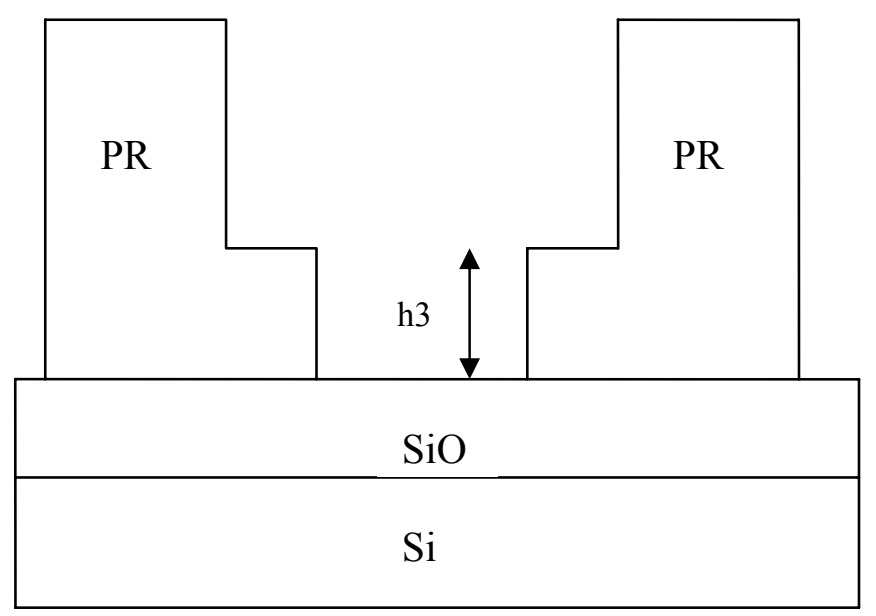

Figure 4.5: Step like structure shown diagrammatically

The sample is then loaded into the RIE system and etched with $\mathrm{SF}_{6}$ for a total time ' $\mathrm{T}$ '. In the course of this time there will be a point, $\mathrm{t}$ where the etch will look as follows, 


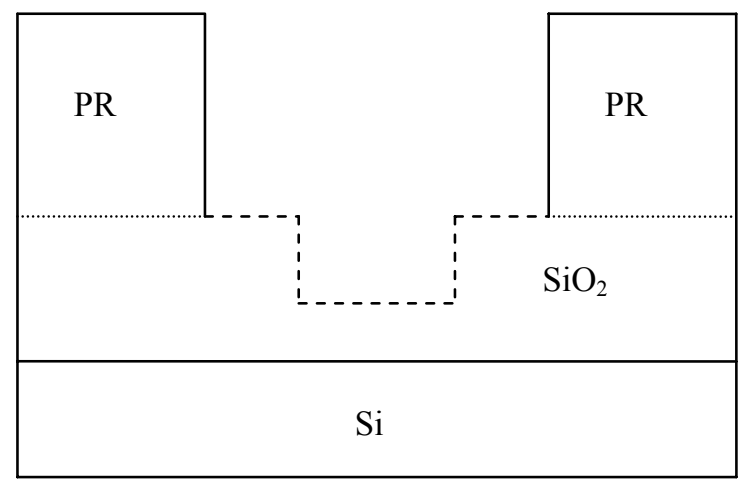

Figure 4.6: Etched structure after a time 't' seconds

Upon etching it for the complete time ' $\mathrm{T}$ 'minutes, the structure will look as follows,

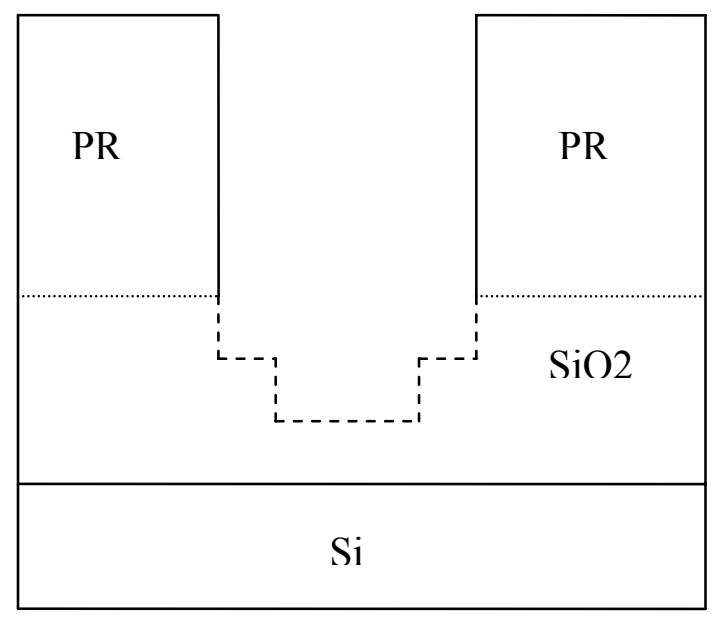

Figure 4.7: Structure upon etching for 'T' minutes

An example of the alpha step plot of the structure at this stage is given in figure 4.8. 


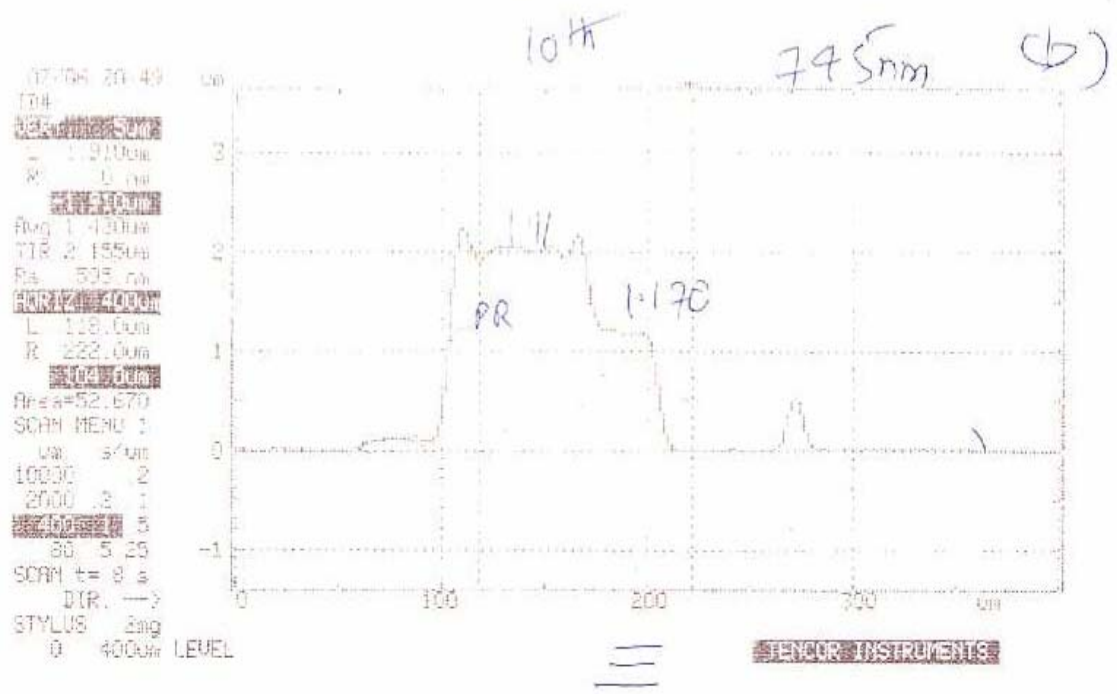

Figure 4.8: Alpha step plot of structure

As can be seen, the sample after having been etched for the complete duration of $\mathrm{T}$ minutes still has a layer of photoresist. This photoresist is removed by dipping it in an acetone bath for 10minutes. The sample is then removed, immersed in Methanol, dried and observed under the alpha step. The structure obtained and the alpha step plot of the same is given below.

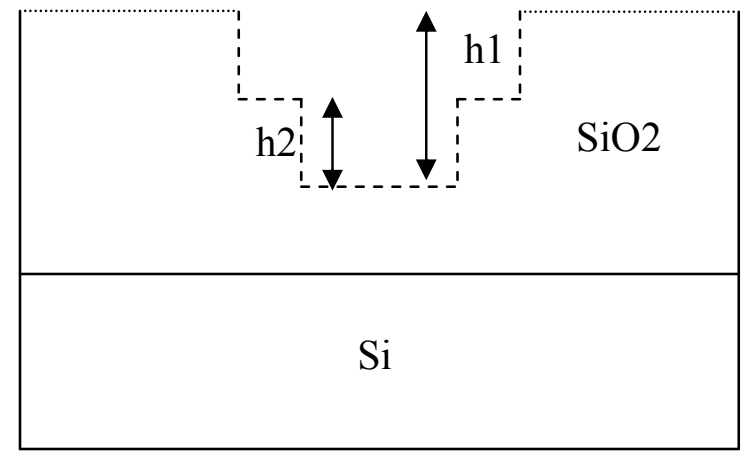

Figure 4.9: Structure after the acetone bath 


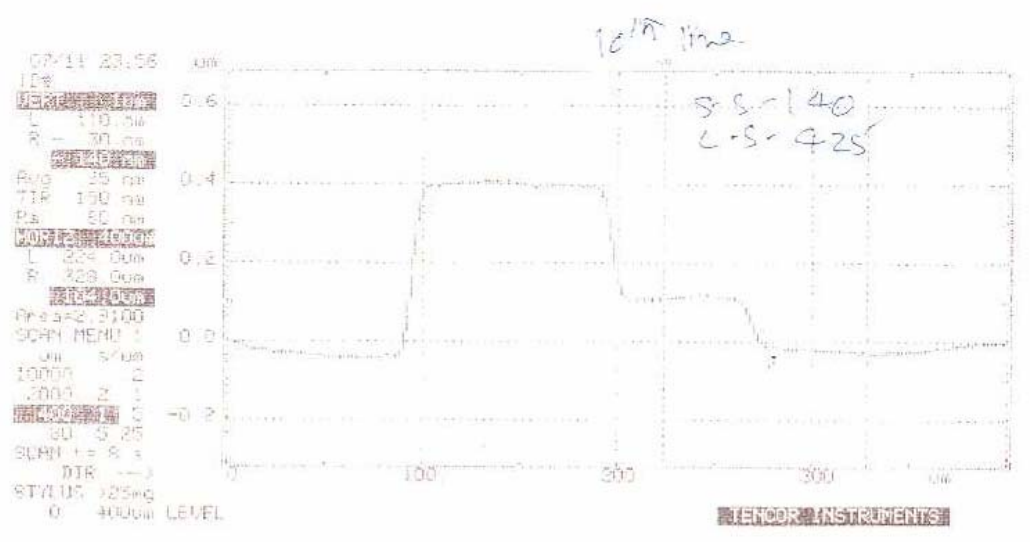

Figure 4.10: Alpha step of structure after the acetone bath

\subsubsection{Calculation of the Etch Rates of $\mathrm{SiO}_{2}$ and the PhotoResist}

Upon taking the above measurements the etch rates of the $\mathrm{SiO}_{2}$ and Photoresist are calculated as follows:

- The etch rate of the Silicon Dioxide can be calculated as $\mathrm{R}_{(\mathrm{SiO} 2)}=\mathrm{h}_{1} / \mathrm{T} \mathrm{nm} / \mathrm{min}$

-The etch rate for the Photo resist is calculated as follows:

-The time taken to etch the second step of photo resist is $=h_{2} / R_{(\mathrm{SiO} 2)}$

-We know the height of the second step of the photo resist $=h_{3}$

-Therefore the etch rate of the photo resist is $=\left(\mathrm{h}_{3} / \mathrm{h}_{2}\right)^{*} \mathrm{R}_{(\mathrm{SiO} 2)}$

-In this example the etch rate of $\mathrm{SiO}_{2}=0.4 \mu \mathrm{m} / 2.167 \mathrm{~min}=0.1845 \mu \mathrm{m} / \mathrm{min}$

- The time taken to etch the second step $=0.140 \mu \mathrm{m} / 0.1845(\mu \mathrm{m} / \mathrm{min})=0.758 \mathrm{~min}$

-Therefore the etch rate of the photo resist $=0.4 \mu \mathrm{m} / 0.758 \mathrm{~min}=0.527 \mu \mathrm{m} / \mathrm{min}$

It was observed however that there was a slight adhesion problem of the Photoresist on the Silicon Dioxide shown by a breaking of the lines and features patterned onto the wafer. A possible reason for this could be moisture absorbed on the surface of the Silicon Dioxide. Hard baking those wafers on which the Silicon Dioxide had been grown for over a period of 24 hours for half an hour seemed to help in improving the adhesion. 


\subsubsection{Determination of the etch rates of $\mathrm{SiO}_{2}$, Photoresist, and determining its variation with different parameters effecting the etch rates}

The next step was to develop a procedure to determine the etch rate of the $\mathrm{SiO}_{2}$ and Photoresist and understand their variation to different parameters effecting the etch rate for example the ICP power and the flow rate.

For the purpose of patterning the wafer, the same Soda Lime, Laser Mask was used to pattern this wafer. In order to avoid the edge effect of growing Silicon dioxide on separate small wafers, a large sample was cleaved from a 6 inch silicon wafer and cleaned with the same cleaning procedures as mentioned above. The sample was hard baked in the oven at 100 degrees centigrade for half and hour to remove moisture. The cleaned sample was then loaded onto the Oxford PlasmaLab 80 plus, Plasma Enhanced Chemical Vapor Deposition System. A 15-minute deposition was performed and the thickness of the grown oxide was measured with a prism coupler.

This sample was then cleaved into smaller pieces and was then patterned with the same procedure as mentioned above, with the only variation that a single exposure was performed for which the optimal time was found to be 60 seconds. The exposed sample was then developed for 90 seconds and dried in Nitrogen gas. The sample was then observed under the alpha step to look for any traces of remaining photoresist over the un exposed areas. The heights of the lines of the photoresist features were measured over a period of at least 10 lines in order to maintain a high degree of accuracy. This concluded the preparation of the wafers.

The next step comprised the actual etching of the wafer. The wafer was loaded onto the Oxford Plasmalab 80 plus Reactive Ion Etching system and was etched for an average of two minutes. Various parameters effect the etch rate of the sample in the RIE system and in this study the variation of the ICP power, Flow Rate and Chamber Pressure were considered.

Upon the completion etching, the samples were unloaded from the system and placed under the Alpha Step profilometer and the heights of the exactly same lines were 
measured again and noted down. Now, in order to achieve the exact depth to which the Silicon Dioxide has been etched, the sample was immersed in an acetone bath to remove the photoresist completely from the surface. The depth to which the $\mathrm{SiO}_{2}$ was etched was noted down and the etch rate calculated by dividing the etch rate by the time for etching. The same was done for the photoresist.

The same procedure was repeated for varying values of Flow rate, ICP power and Chamber pressure and certain trends were observed as mentioned in the following chapter.

\subsubsection{Determining the Etch Rate of Gallium Nitride}

The next step was to determine the etch rates of Gallium Nitride $(\mathrm{GaN})$. As mentioned previously, Gallium Nitride is a very stable material with a very low etch rate. In order to be able to etch the $\mathrm{GaN}$ for a longer period of time, just using the Photoresist as a mask will not be enough, especially since the etch rate of the photo resist is in the order of hundreds of nano meters per minute. Therefore, a mask of Silicon Dioxide is used along with that of the photoresist to increase the time available to etch the Gallium Nitride.Gallium Nitride samples grown previously in an AIXTRON Metal Organic Chemical Vapor Deposition System were used to determine the etch rates.

The Gallium Nitride samples were cleaned with the same procedure used to clean the silicon wafer. In other words the samples were put in an acetone and then methanol bath for both 5 minutes each and then after being dried in Nitrogen gas and were hard baked in an oven at 100 degrees centigrade for 30 minutes. The dried samples were placed in the PECVD system and a 15-minute deposition was performed. The thickness of this deposition was measured using a prism coupler.

This wafer was then cut into smaller pieces using a diamond scribe. Each smaller sample was mounted on a larger silicon wafer using a drop of the photoresist and soft baking it at 120 degrees for five minutes. These mounted samples were cooled for 10 
minutes. Upon attaining ambient temperature, photoresist was spun on them and they were again soft baked for 50 seconds this time taking into consideration the extra layer of silicon that the heat needs to propagate through.

The sample was then loaded onto the aligner and exposed to the UV light. This time the time required for exposure was increased to 270 seconds. The increase in the time of exposure is accounted for by the age factor of the photoresist. This sample was then developed for 90seconds and dried in Nitrogen gas. The sample was then hard baked in the oven at 100 degrees centigrade for half an hour.

The baked samples were taken and observed under the Alpha Step to determine the height of each feature. Heights were measured over 10 lines in order to maintain accuracy.

The next step was to etch the $\mathrm{SiO}_{2}$. A Buffered Oxide Etch (BOE) was performed on the wafer using a 1:10 solution of Transene's BOE solution. This was further diluted approximately by a factor of seven. The wafers were submerged in the solution for a period of up to four minutes to etch away the Silicon Dioxide. The sample was dipped in de-ionized water in order to remove any remaining solution from the surface and dried with Nitrogen gas. The samples were observed under the alpha step again to measure the total feature heights. This process was continued until the feature heights were a total of "photoresist height + Silicon dioxide height". The figure below shows the structures obtained before and after the BOE. 


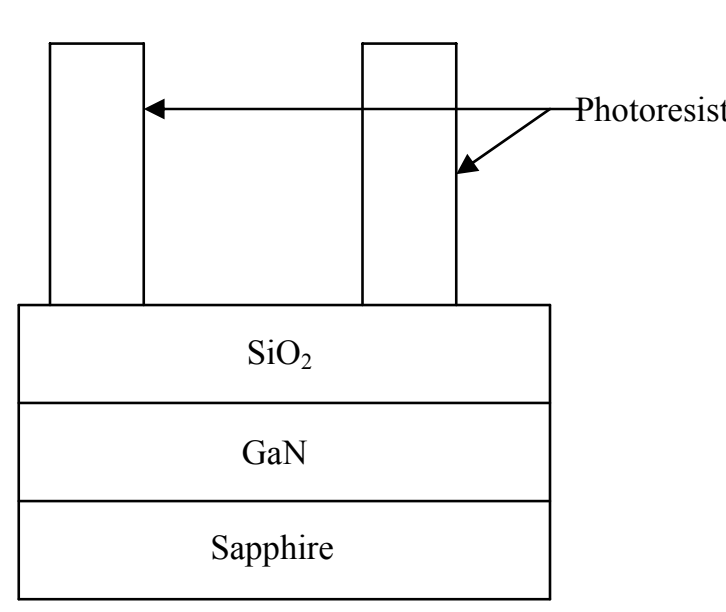

(a)

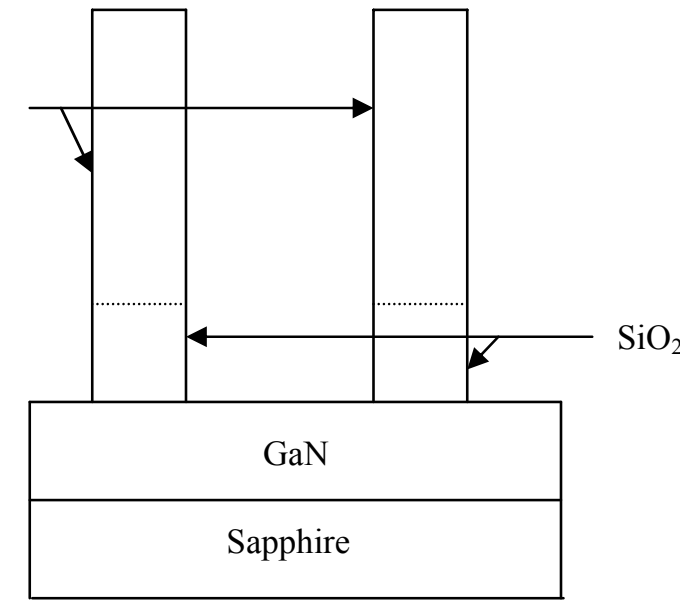

(b)

Figure 4.11: Structure of Gallium Nitride wafer processed (a) Before Buffered Oxide Etch and (b) after buffered oxide etch

At that point the samples were ready to be etched. The same three parameters, ICP power, Chamber Pressure and Flow Rate that were varied in order to determine the etch rates of Silicon Dioxide and photo resist were varied in the study of the etch of Gallium Nitride. The heights of the features are measured on the etched samples. Etching is done such that a buffer of at least $200 \mathrm{~nm}$ is left on the GaN surface to protect it and maintain the relative level. This also gives a measure of the etch rate of the Silicon Dioxide. The sample is then again submerged in the BOE in order to remove the remaining $\mathrm{SiO}_{2}$ completely. This gives one a measure of the deapth to which the Gallium Nitride has been etched. Then the etch rate is given as

Etch Rate of Gallium Nitride $=$ Depth of Etch/time taken to etch

The values of the etch rates calculated as shown above are then tabulated and analyzed. 


\subsection{Experimental Results}

As mentioned earlier, in order to determine the "ball park" figures of the Silicon Dioxide and Photoresist, the step like structure was patterned into the photoresist. The sample was etched at an ICP $=125 \mathrm{~W}, \mathrm{RF}=200 \mathrm{~W}$ and Flow Rate $=40 \mathrm{sccm}$.

Table 7: Etch Rates of Photoresist and $\mathrm{SiO}_{2}$ obtained at $\mathrm{ICP}=125 \mathrm{~W}, \mathrm{RF}=200 \mathrm{~W}$ and Flow Rate $=40 \mathrm{sccm}$

\begin{tabular}{|l|c|c|c|c|c|c|}
\hline $\begin{array}{l}\text { Sl } \\
\#\end{array}$ & $\begin{array}{c}\text { h1 } \\
\mathbf{( n m})\end{array}$ & $\begin{array}{c}\text { h2 } \\
\mathbf{( n m )}\end{array}$ & $\begin{array}{c}\text { Etch Rate } \\
\mathbf{\text { of SiO}} \\
\mathbf{( n m}\end{array}$ & $\begin{array}{c}\text { h3 } \\
\mathbf{( n m}\end{array}$ & $\begin{array}{c}\text { Time to } \\
\text { etch photo } \\
\text { resist(min) }\end{array}$ & $\begin{array}{c}\text { Etch rate of } \\
\text { photoresist } \\
\mathbf{( n m} / \mathbf{m i n})\end{array}$ \\
\hline 1 & 435 & 135 & 200.7383 & 370 & 0.681818 & 542.6667 \\
\hline 2 & 455 & 145 & 209.9677 & 335 & 0.732323 & 457.4483 \\
\hline 3 & 425 & 140 & 196.1237 & 385 & 0.707071 & 544.5 \\
\hline 4 & 430 & 135 & 198.431 & 430 & 0.681818 & 630.6667 \\
\hline 5 & 435 & 135 & 200.7383 & 405 & 0.681818 & 594 \\
\hline 6 & 425 & 140 & 196.1237 & 400 & 0.707071 & 565.7143 \\
\hline
\end{tabular}

Average Etch Rate of $\mathrm{SiO}_{2}=200.3538 \mathrm{~nm} / \mathrm{min}$ with an

Error margin $=5.142136 \mathrm{~nm} / \mathrm{min}$

Average Etch Rate of photoresist $=562.4403 \mathrm{~nm} / \mathrm{min}$

Error margin $=59.23786 \mathrm{~nm} / \mathrm{min}$

Upon going by the above results, a rough estimate could be made on the time required to etch the Silicon Dioxide and the Photo resist.

Implementing the procedure explained previously, the etch rates of Silicon Dioxide and photoresist were determined for various values of ICP power, Flow rate and chamber pressure. As an example, the height of the features and etch rates of silicon dioxide for a varying ICP power are given in the tables below. In the tables below $\mathrm{H}_{\mathrm{be}}$ 
is the height of photo resist before etching and $\mathrm{H}_{\mathrm{ae}}$ is the height of the photo resist after etching.

Table 8: Etch Rates of Photoresist and $\mathrm{SiO}_{2}$ obtained at $\mathrm{RF}=230 \mathrm{~W}$; ICP=230W; $\mathrm{t}=2 \mathrm{~min} ; \mathrm{p}=40 \mathrm{mT} ; \mathrm{FR}=40 \mathrm{sccm}$

\begin{tabular}{|c|c|c|c|c|}
\hline \multirow{4}{*}{$\mathbf{H}_{\mathrm{be}}$} & $\mathbf{H}_{\mathrm{ae}}$ & Diff & $\mathrm{SiO}_{\mathbf{2}} \mathbf{~ n m}$ \\
\hline 3.465 & 2.78 & 0.685 & 210 \\
\hline 3.595 & 2.945 & 0.65 & 270 \\
\hline 3.815 & 2.975 & 0.84 & 245 \\
\hline 3.615 & 2.33 & 1.285 & 255 \\
\hline 3.745 & 2.635 & 1.11 & 245 \\
\hline \multirow{5}{*}{ Average } & 3.44 & 2.53 & 0.91 & 235 \\
\cline { 2 - 5 } & 3.599285714 & 2.689285714 & 0.91 & 240 \\
\cline { 2 - 5 } & 3.52 & 2.63 & 0.89 & 242.8571 \\
\hline
\end{tabular}

Table 9: Etch Rates of Photoresist and $\mathrm{SiO}_{2}$ obtained $\mathrm{RF}=220 \mathrm{~W}$; ICP=250W; $\mathrm{t}=2 \mathrm{~min}$; $\mathrm{p}=40 \mathrm{mT} ; \mathrm{FR}=40 \mathrm{sccm}$

\begin{tabular}{|c|c|c|c|c|}
\hline Hbe & Hae & Diff & $\begin{array}{c}\text { SiO2 } \\
\mathbf{n m}\end{array}$ \\
\hline 2.955 & 1.875 & 1.08 & 330 \\
\hline 2.855 & 1.645 & 1.21 & 340 \\
\hline 2.855 & 1.74 & 1.115 & 275 \\
\hline 2.905 & 1.74 & 1.165 & 310 \\
\hline 2.93 & 1.87 & 1.06 & 295 \\
\hline \multirow{1}{*}{ Average } & 2.904166667 & 1.69 & 1.235 & 285 \\
\cline { 2 - 5 } & 2.925 & 1.76 & 1.144167 & 305.833 \\
\hline
\end{tabular}

Table 10: Etch Rates of Photoresist and $\mathrm{SiO}_{2}$ obtained $\mathrm{RF}=220 \mathrm{~W}$; ICP=220W; $\mathrm{t}=2 \mathrm{~min} ; \mathrm{p}=40 \mathrm{mT} ; \mathrm{FR}=40 \mathrm{sccm}$

\begin{tabular}{|c|c|c|c|}
\hline Hbe & Hae & Diff & SiO2 $\mathbf{~ m}$ \\
\hline 2.895 & 2.29 & 0.605 & 215 \\
\hline 2.87 & 2.27 & 0.6 & 220 \\
\hline 2.895 & 2.275 & 0.62 & 255 \\
\hline
\end{tabular}




\begin{tabular}{|c|c|c|c|c|}
\hline \multirow{4}{|c|}{2.895} & 2.275 & 0.62 & 245 \\
\hline 2.875 & 2.275 & 0.6 & 245 \\
\hline \multirow{4}{*}{ Average } & 2.87 & 2.275 & 0.595 & 255 \\
\cline { 2 - 5 } & 2.883333333 & 2.276666667 & 0.606667 & 239.1667 \\
\cline { 2 - 5 }
\end{tabular}

Table 11: Etch Rates of Photoresist and $\mathrm{SiO}_{2}$ obtained RF=220W; ICP=200W; $\mathrm{t}=2 \mathrm{~min} ; \mathrm{p}=40 \mathrm{mT} ; \mathrm{FR}=40 \mathrm{sccm}$

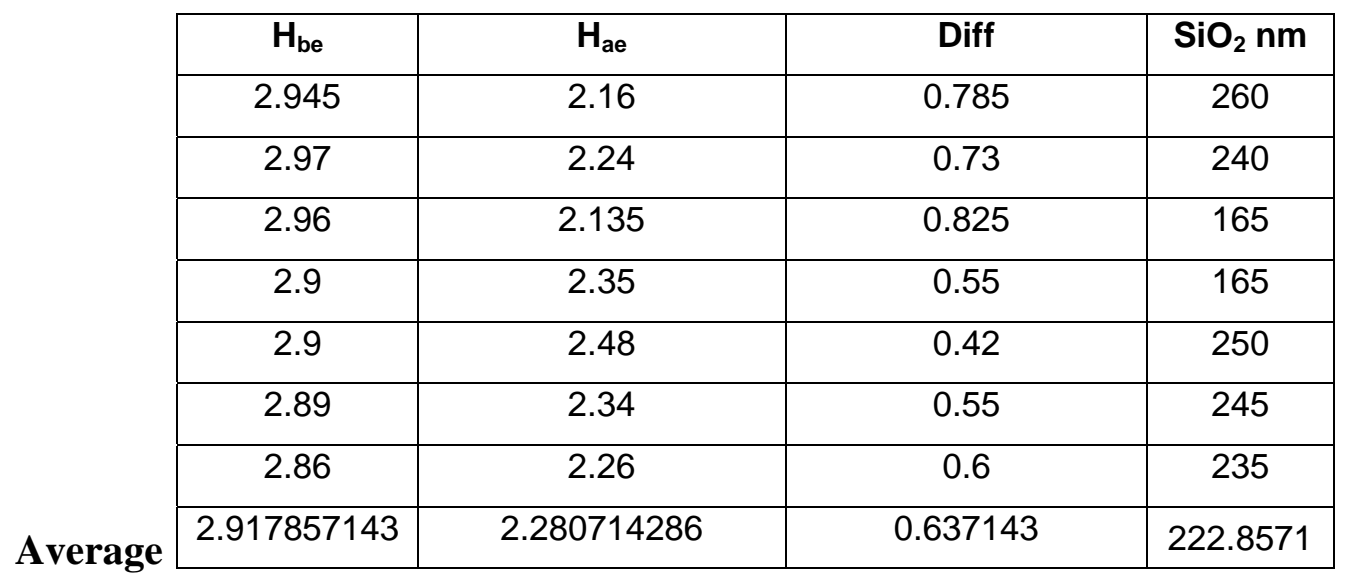

Table 12: Final etch rates of Silicon Dioxide and Photoresist

\begin{tabular}{|c|c|c|}
\hline ESiO2(nm/min) & EPR(nm/min) & ICP(Watts) \\
\hline 242.8571 & 572.083 & 230 \\
\hline 305.833 & 455 & 250 \\
\hline 239.1667 & 303.333 & 220 \\
\hline 222.8571 & 318.571 & 200 \\
\hline
\end{tabular}

Similarly, the etch rates under other conditions are determined. The tabulated results are listed in Appendix L.

Using the above procedure the Gallium Nitride etch rates were calculated and a plot showing the same is given in figure 4.17. 


\section{Etch Rate Vs Chamber Pressure(mT), Flow Rate(sccm) and ICP(Watt)}

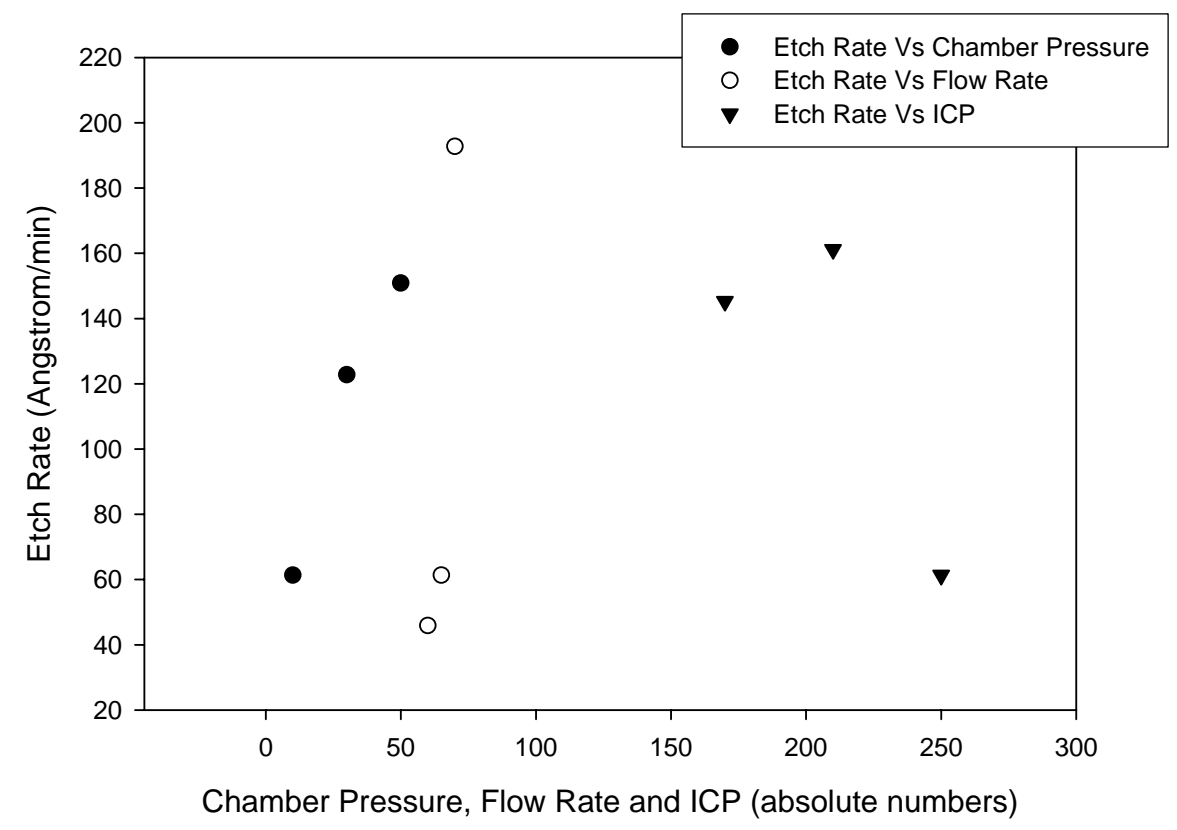

Figure 4.12: Plot showing the etch rates obtained for GaN at different values of chamber pressure, Flow Rate and ICP

An SEM image of a surface etched for one hour using Silicon Dioxide as a Hardmask Material is given below. It may be seen that the etch does not result in a clearly defined side wall and the side wall angle made is very small. This process must therefore be further optimized. One modification would be the use of another material for the Mask.

A preliminary test was done on a GaN sample using Chrome as a Masking material. An SEM image of the sample so etched is also given in the figure 4.19 below. 


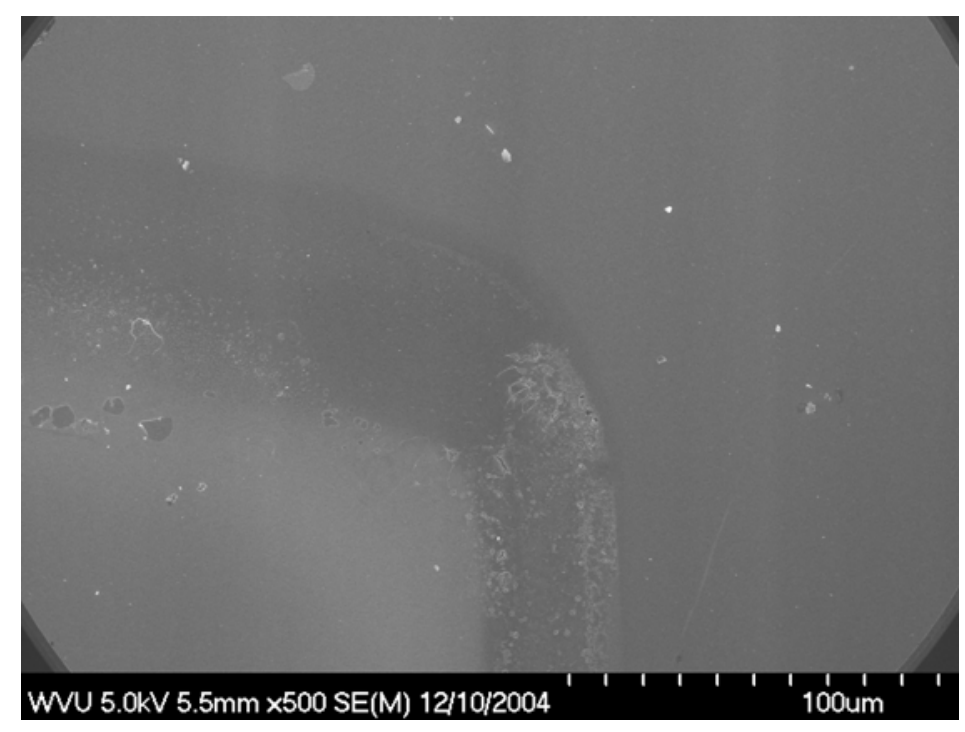

Figure 4.13: SEM image showing a GaN sample etched for a time period of 60 minutes at $I C P=250 \mathrm{~W}, P=10 \mathrm{mT}, R F=220 \mathrm{~W}$, Flow Rate $=65 \mathrm{sccm}$

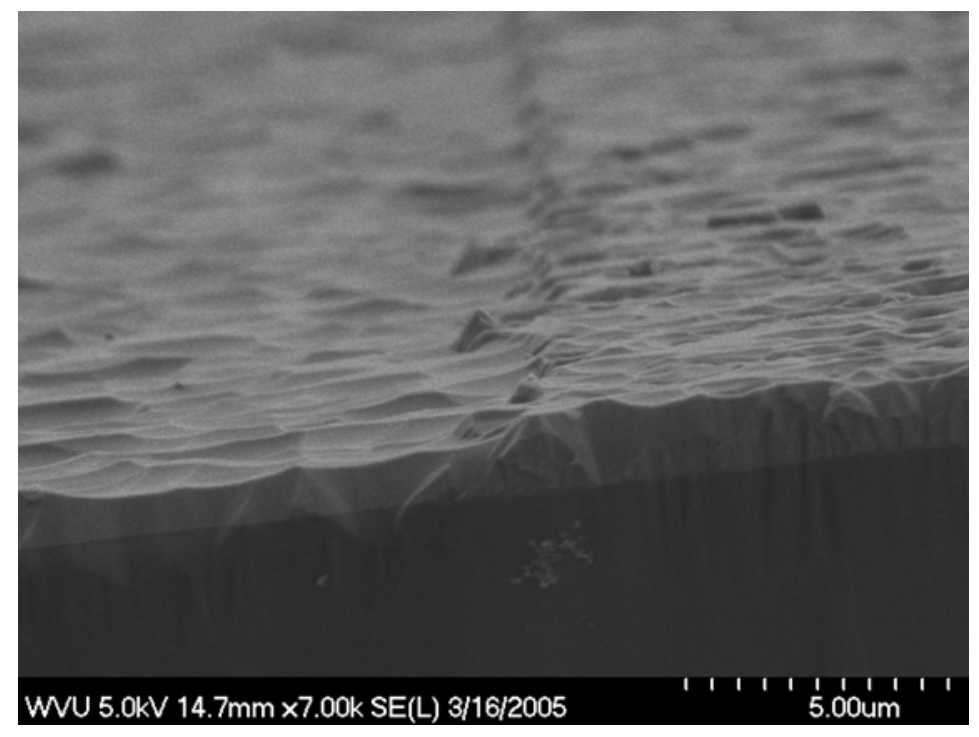

Figure 4.14: SEM image showing a GaN sample etched for a time period of 60 minutes at $I C P=170 \mathrm{~W}, P=17 \mathrm{mT}, R F=150 \mathrm{~W}$, Flow Rate $=30 \mathrm{sccm}$

From a comparison of the images 4.13 and 4.14, it may be seen that even though the side wall formed when etched with Chrome is not very well defined, it certainly has a 
better side wall angle than that of the sample etched with a $\mathrm{SiO}_{2}$ mask. Further work using this mask has been undertaken elsewhere [Kuchibhatla, 2005].

\subsection{Contacts on Etched Surfaces}

Upon etching the surface, n-type contacts were deposited on the etched surface. The procedure for depositing ohmic n-type contacts has been studied in detail elsewhere [Turlapati, 2004]. In this study the same procedure has been followed.

Three different samples of GaN were Reactive Ion Etched and contacts were deposited on the etched surface. Upon annealing, they exhibited ohmic characteristics. A plot of their specific contact resistivites Vs the Sheet resistance is given below.

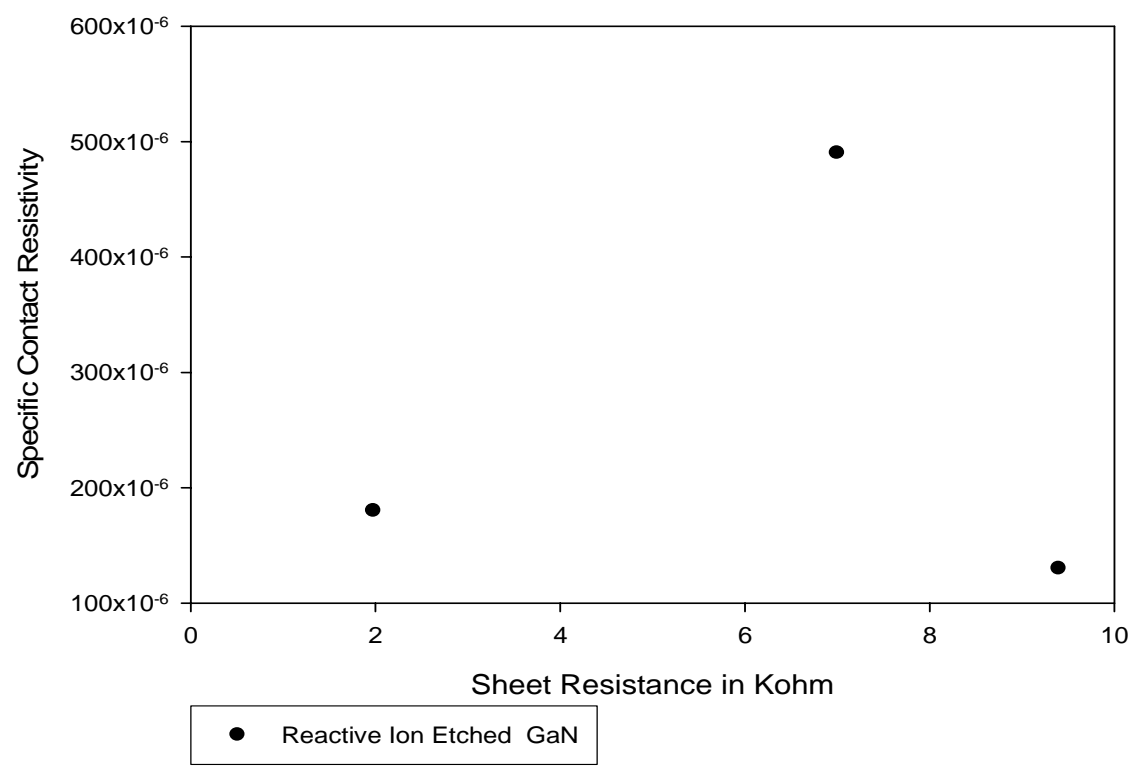

Figure 4.15: Plot of Specific Contact Resistivity Vs Sheet Resistance for contacts on Reactive Ion Etched surfaces

The values obtained were found to be suitable for the working of an LED. 


\section{LASER ABLATION OF GALLIUM NITRIDE AND EXPERIMENTAL RESULTS}

The Oxford Lasers Copper Vapor Laser lazes at a wavelength of $255 \mathrm{~nm}$ with a pulse repetition frequency of $60 \mathrm{KHz}$. The laser beam passes through 8 mirrors located at various stages of the system finally passing through a lens with a fixed focal length. The sample which is required to be ablated is mounted onto a glass slab which in turn is vacuum mounted onto a stage which may be programmed to move. The laser beam is therefore effectively stationary and the stage is the part that moves. A picture of the copper vapor laser is given below and the stage onto which the sample is mounted is given below.

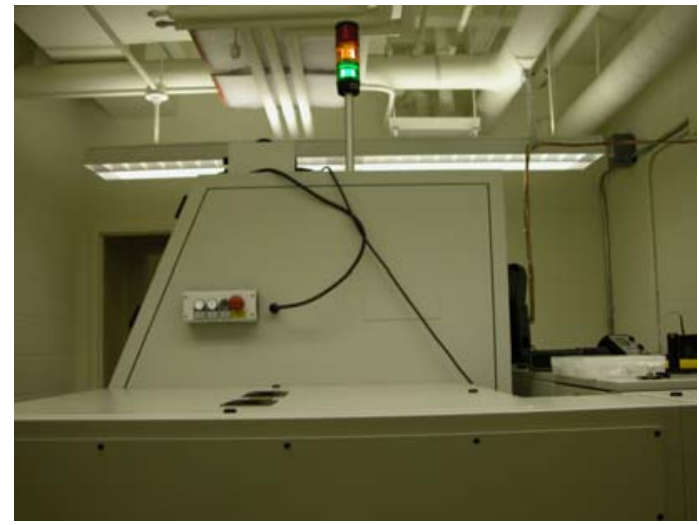

(a)

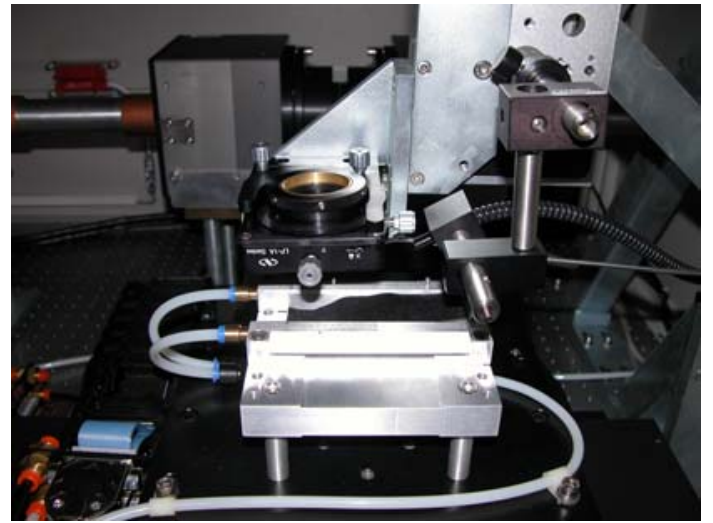

(b)

Figure 5.1: (a) Outer view of the Oxford Copper Vapor Laser System (b) Stage with the sample holder [3]

The movement of the stage may be followed by a closed circuit camera which is mounted near the lens, the image of the stage may be observed on the screen. A diagram of the optical path of the Laser is given below. 


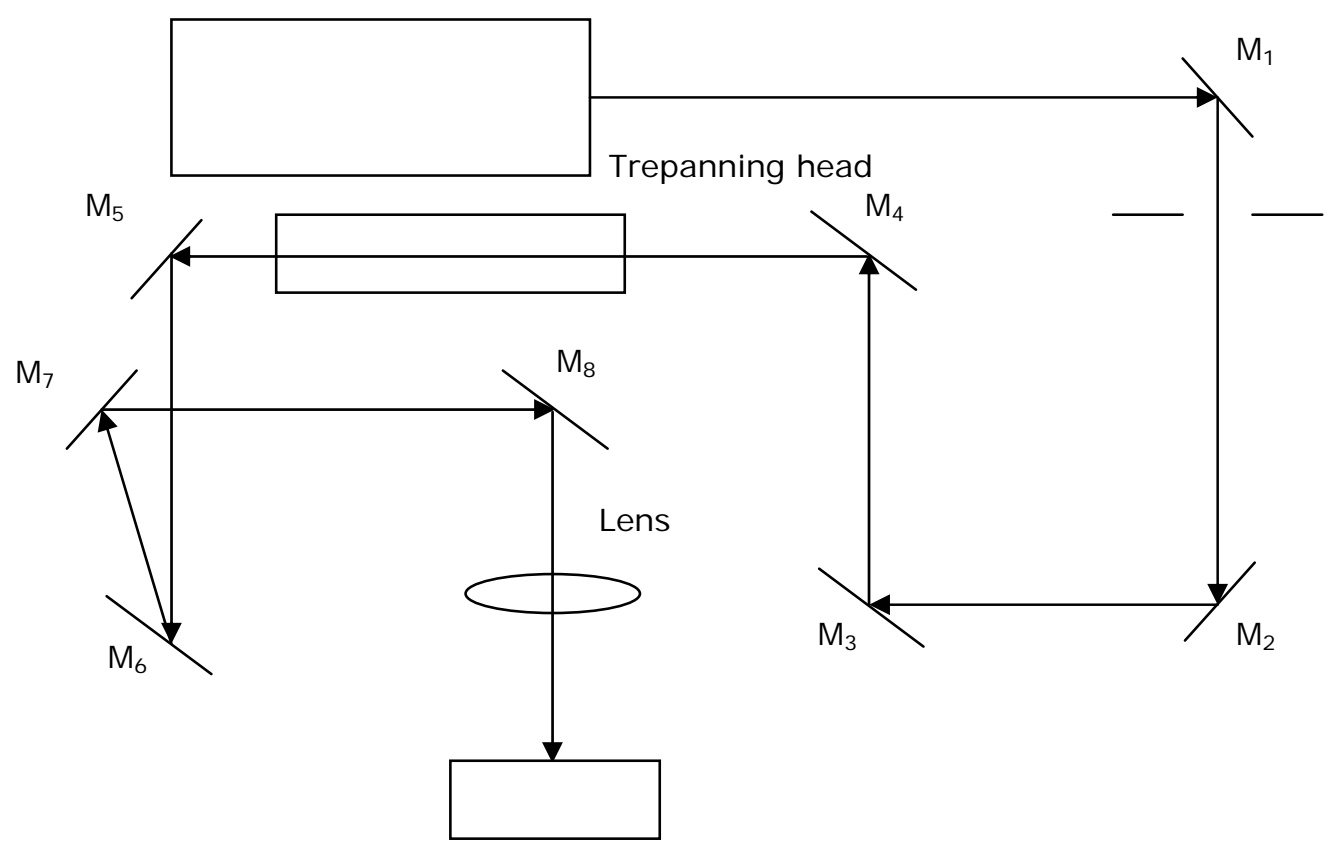

Figure 5.2: Optical path of the Oxford Copper Vapor Laser [3]

The Laser was found to exhibit a fluence of $36 \mathrm{~J} / \mathrm{cm}^{2}$ without any inhibiting aperture but with the lens in place and $4 \mathrm{~J} / \mathrm{cm}^{2}$ with a $0.75 \mathrm{~mm}$ aperture.

From the data and plots obtained from the laser ablation of Gallium Nitride on Sapphire, the following algorithm has been drawn up in order to systematically attain a desirable ablation procedure for the Gallium Nitride.

In view of being able to fabricate a Blue GaN LED, etch and deposit contacts in it the aim of the ablation was to be able to attain parameters which allowed one to etch into the 1.5 micro meter GaN layer. In order to reach the $\mathrm{n}-\mathrm{GaN}$ layer, and assuming the etch rates of $\mathrm{GaN}, \mathrm{InGaN}$ and $\mathrm{AlGaN}$ to be similar, around $570 \mathrm{~nm}$ to $600 \mathrm{~nm}$ of material has to be etched. The algorithm and the essential issues concerning the ablation will be detailed below. 


\subsection{Algorithm for performing Ablation on GaN using a Copper Vapor Laser}

1. Choose an appropriate Mask for the laser system.

2. Load the sample onto the table and perform the focus test to choose the focus

3. Write a program to perform the ablation in the desired fashion with the various variable parameters

4. Vary the parameters to attain the desired ablation. The parameters that may be varied include the following.
a. Speed
b. Number of passes

5. Treat the samples with $\mathrm{HCl}$ before observing under the SEM.

In the following section each point will be discussed in detail:

\subsubsection{Choosing an appropriate Mask for the System}

In the basic Oxford Copper Vapor Laser setup, the laser beam is allowed to pass through 8 strategically placed mirrors which cause approximately $5 \mathrm{~mW}$ attenuation at each reflection. The beam has to pass through a final lens before hitting the target on which the ablation is desired as shown in the figure 5.2 above. The final power that the laser may give may be measured at the table upon which the substrate is mounted and upon which the beam finally focuses using a power meter. The final power of the laser is a constant.

Since different materials possess various material properties, the power of the laser must be adjusted in order to obtain optimal etching conditions. The only way of varying the power is to insert a Mask or Aperture of a certain width. The setup used has a selection of Square and Circular apertures with diameter. The diameters available are $0.5 \mathrm{~mm}, 0.75 \mathrm{~mm}, 1 \mathrm{~mm}, 2 \mathrm{~mm}, 2.5 \mathrm{~mm}$ and so on.

In order to find the optimal mask required for the GaN ablation. First a low square aperture of $0.75 \mathrm{~mm}$ is used to ablate the surface. It was found that the power through 
this aperture was insufficient to ablate through the GaN. Therefore a mask of a higher aperture was considered. A $2 \mathrm{~mm}$ mask was then taken. The power of the laser beam through this mask was found to be $0.176 \mathrm{~W}$.

Upon performing the percussion test as explained below on this sample and ablating lines with varying speed and number of passes, it was found that this power was too high for the sample and was ablating the GaN into the Sapphire to the extent that it was melting the sapphire. Therefore this mask was also considered inappropriate to work on the ablation of the GaN. However this could be of use in the area of machining of Sapphire. Hence a mask with a smaller aperture needed to be considered. The $2 \mathrm{~mm}$ mask was then replaced by the $1 \mathrm{~mm}$ square aperture mask.

The power through the $1 \mathrm{~mm}$ mask was found to be $0.058 \mathrm{~W}$. Upon performing the focus test and ablating lines with varying speeds and number of passes, it was seen that this power was sufficient to control the etch rates of the GaN and Sapphire. Therefore for the further experiments on the etching properties of the Copper Vapor Laser the $1 \mathrm{~mm}$ mask was used.

\subsubsection{Load the sample onto the table and perform the focus test to choose the focus}

In order for the laser beam to be in its best possible shape and power value, the lens needs to be adjusted so that it puts the beam in focus. The test to be performed is called the "Percussion Test". In this test holes are drilled into the GaN and then observed under a microscope with 10X, 20X and 50X magnification for the hole smallest in diameter and most circular in shape. The program for this test is given in the appendix $\mathrm{D}$. The various parameters that may be varied include:

1. Drill time

2. Spacing between holes

3. $\mathrm{Z}$ value 
The initial $\mathrm{Z}$ value may be estimated roughly from the image of the substrate seen from the camera. This was estimated to be around 78 or $79 \mathrm{~mm}$. The program was then written to increment this value in steps of for example 0.25 or 0.10 .

The program is then run and is written so as to automatically increment the focus and drill holes. As mentioned above the holes are observed under an optical microscope. Images of the holes taken from the optical microscope are shown below.

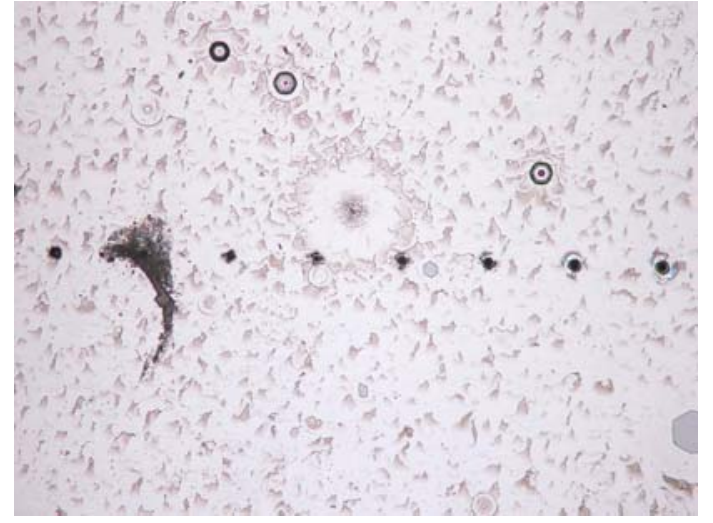

(a)

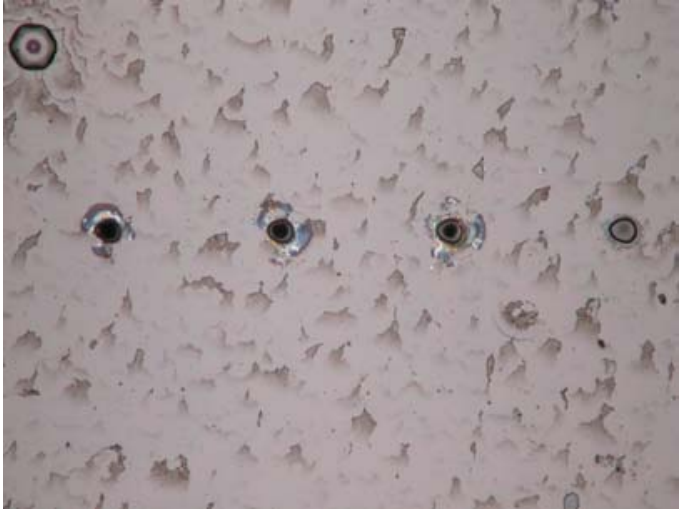

(b)

Figure 5.3: (a) picture showing eight percussion holes ablated into the GaN substrate seen with a 10x magnification (b) zoomed in image of the holes clearly showing a shift in focus from out of focus to in from right to left respectively seen with a $20 x$ magnification 


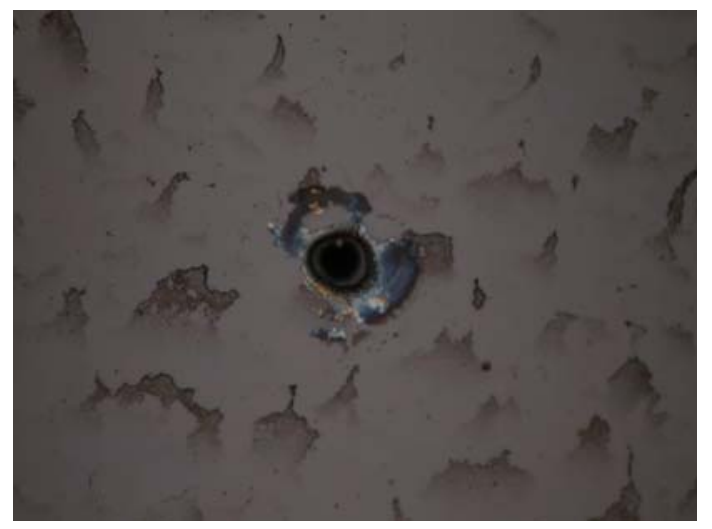

Figure 5.4: picture zoomed into the hole with the smallest diameter and best shape

The debris field can be clearly seen around the holes drilled into the material. This debris is thought to be Gallium formed as a reaction to the ablation. This is confirmed as it is removed upon treating the sample with a solution of HCL [Kim, 2001]. When observed under the SEM, the transition from out of focus to in focus is seen clearly as seen in the SEM images below.

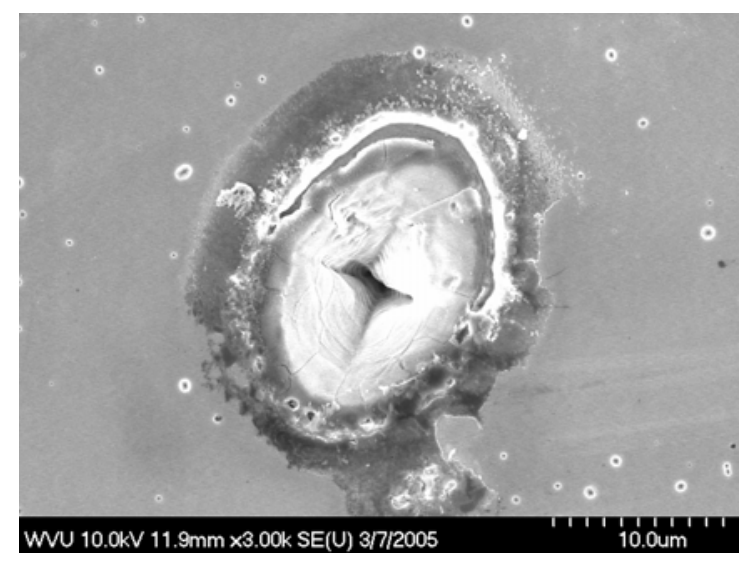

(a)

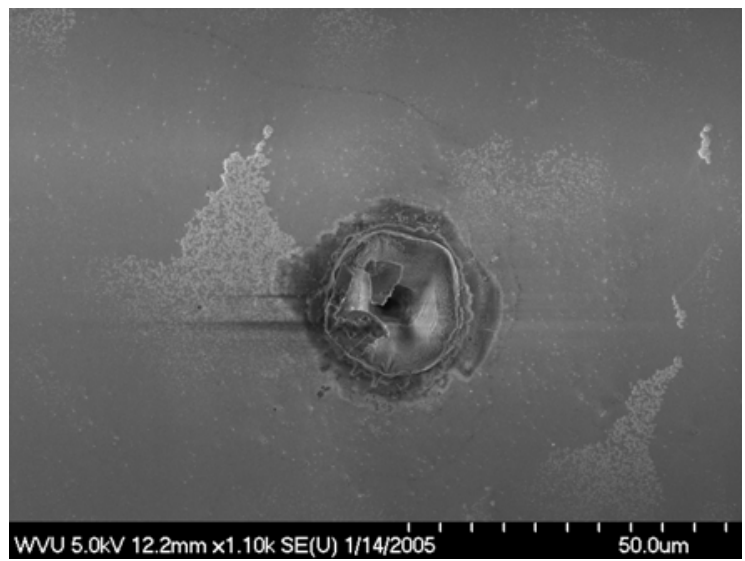

(b)

Figure 5.5: SEM image of percussion hole (a) out of focus and (b) in focus

From the above images it may be observed that the hole created by the laser is not perfectly shaped, and there is also a debris field around the hole. The shape of the hole is attributed to two reasons, the first being that the mask chosen was a square mask and the second being that the beam is not a perfectly shaped, there being 
distortions in the shape of the beam. The best shaped hole is chosen and the corresponding objective distance is considered to be in focus.

\subsubsection{Write a program to perform the ablation in the desired fashion with the various variable parameters.}

In the setup of the system, the location of the laser beam is fixed. The sample to be ablated is set on a table which is the part of the equipment which moves ablating whatever pattern in required. In order to control the movement of this mount, programs are written which not only control the stage movement, but also controls the values of the number of passes, objective distance and the stage speed, three very important parameters of control for the ablation of the materials. The programs used for the experiments performed are given in the appendix E, F and G.

\subsubsection{Vary the parameters to attain the desired ablation}

The parameters which influence the ablation depth are

- Objective distance

- Number of passes and Stage Speed

Objective Distance: In order to study the effect of the objective on the etch depth; lines were ablated into the $\mathrm{GaN}$ for a constant speed and a single pass varying the lens from in to out of focus. From the plot obtained it can be seen that the depth of ablation decreases as the lens goes from in to out of focus 


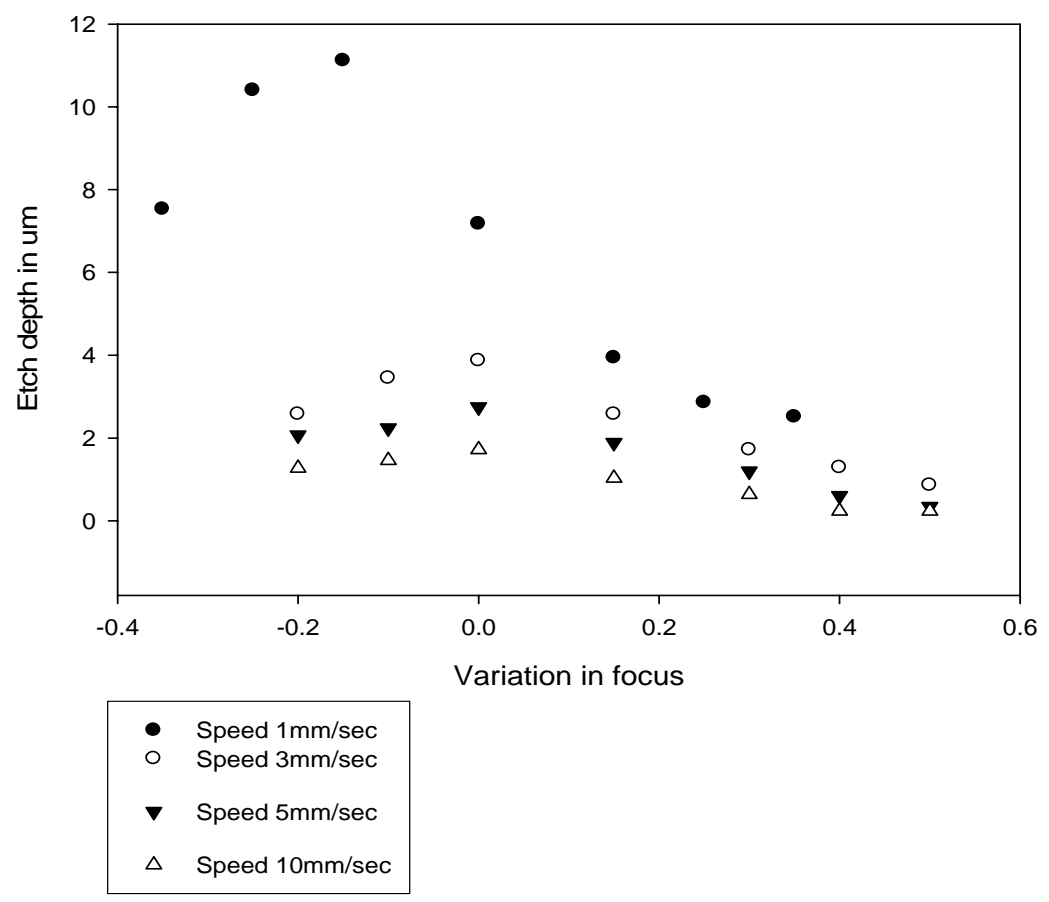

Figure 5.6: Plot showing the variation of etch depth with a variation from in to out of focus

From the above plot it may be seen that etch depths in the range of around $500 \mathrm{~nm}$ are obtained in the region below the dotted line. Therefore in order to ablate the future LED, one would need to work in the bottom right region of the plot, in other words in areas out of focus and at high speeds. The SEM image of a sample ablated with varying focus but for one pass and at one particular speed is given below.

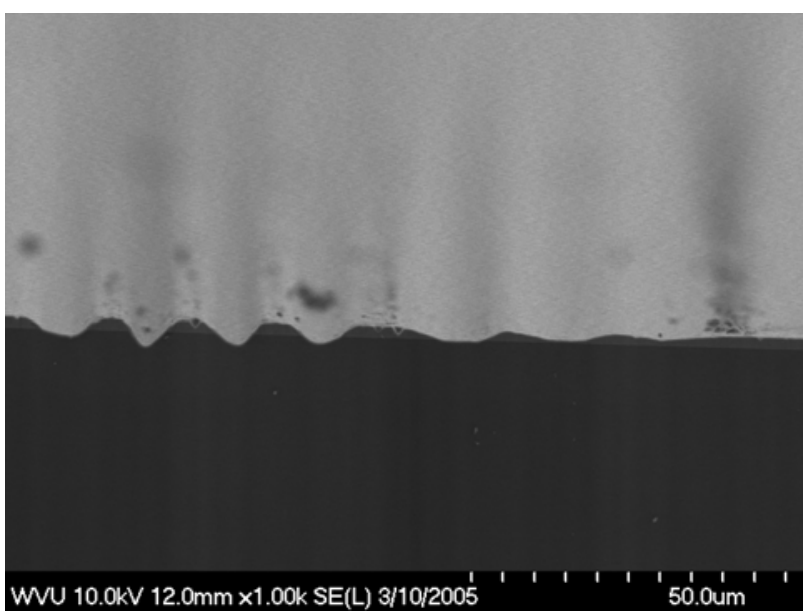

Figure 5.7: SEM image showing a variation in etch depth for a single mask at a single speed but at different focus 
Number of Passes and Stage Speed: In order to study the effect of the speed and the number of passes on the ablation, a program is written which takes as an input the speed and the number of runs or passes that the stage makes from a particular coordinate. For a constant speed, at a constant objective distance, several lines are drawn, the number of passes varying as 1, 3, 5 and 7. The same is continued for different speeds like 5, 10, 15 and $20 \mathrm{~mm} / \mathrm{s}$. From the data obtained a plot may be made of ablation depth Vs the Speed for a constant number of passes and ablation depth Vs the speed for a constant number of passes. The plots obtained from this data are given below.

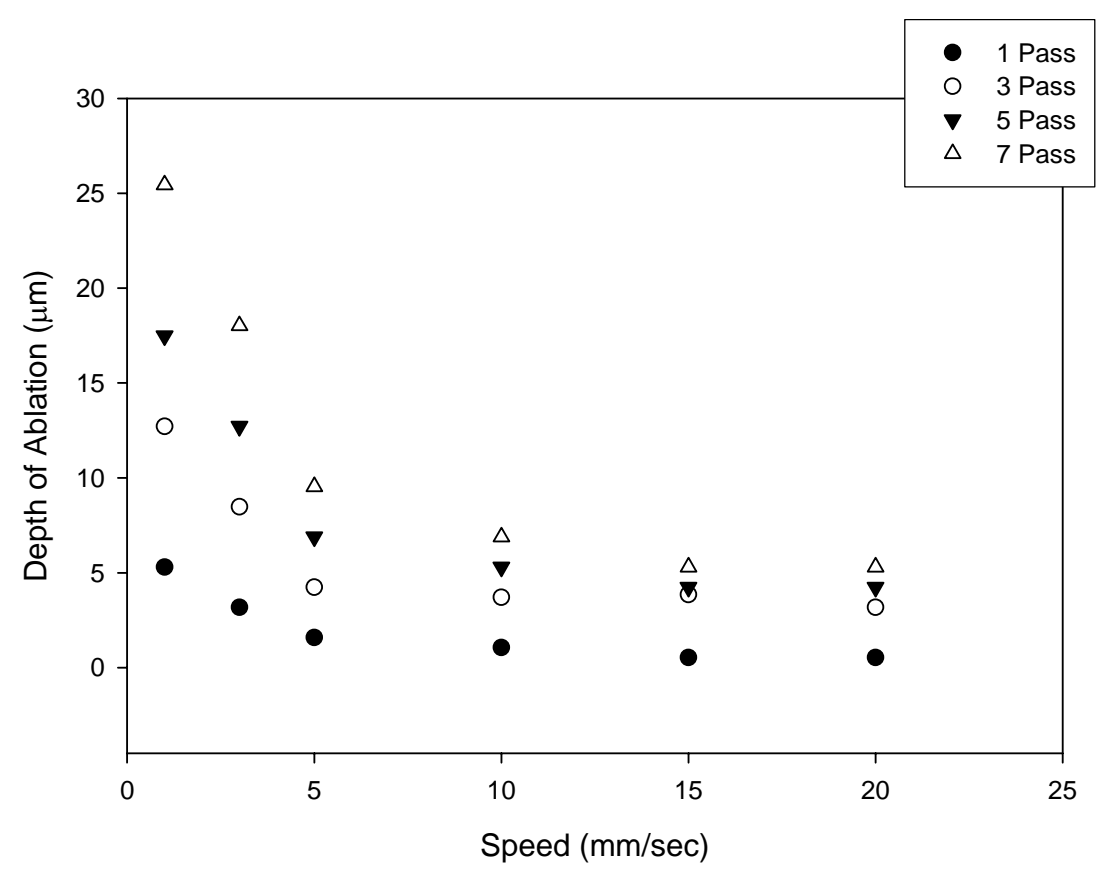

Figure 5.8: Plot showing depth of ablation Vs Speed for a constant number of passes 


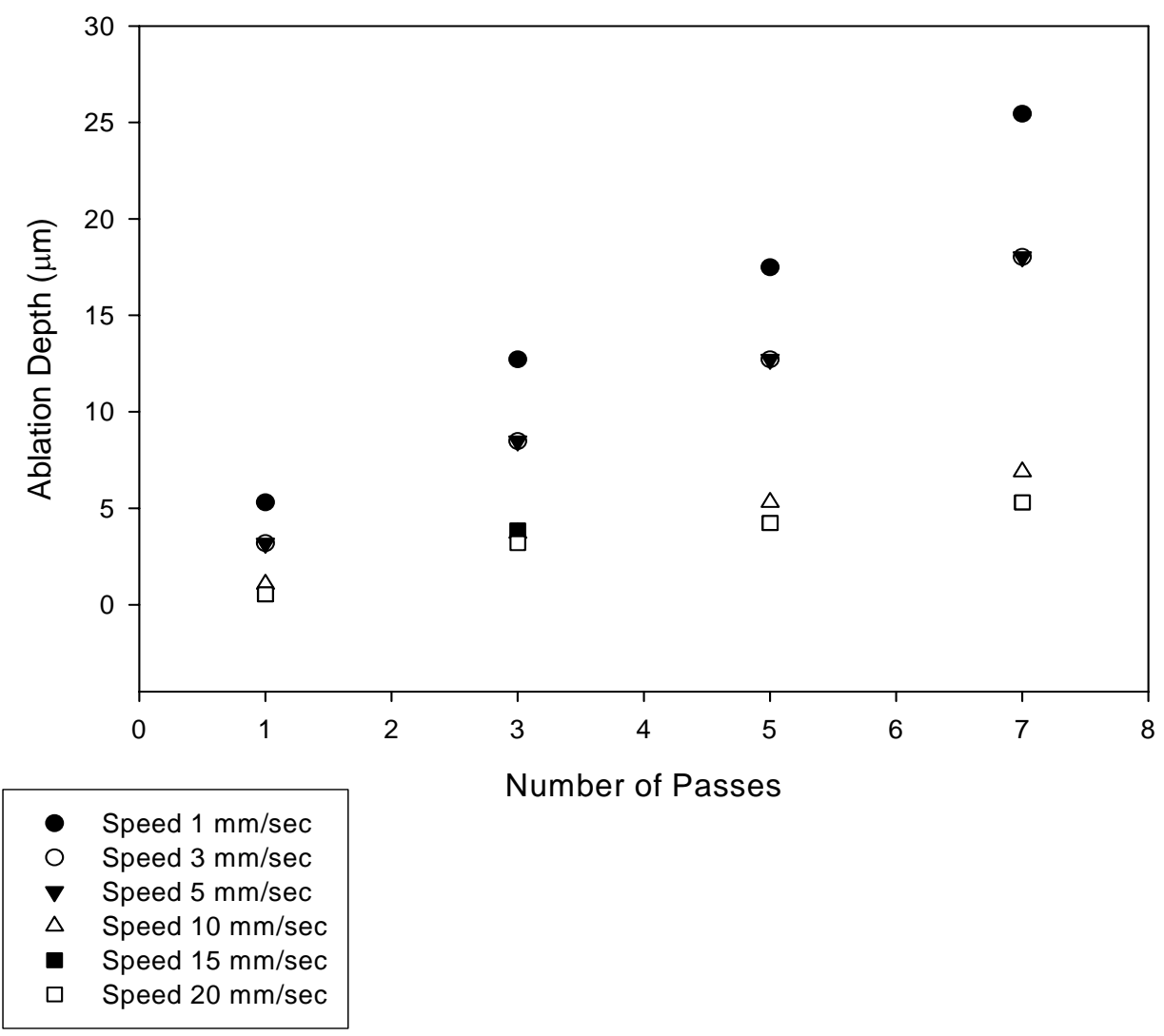

Figure 5.9: Plot showing the progression in the etch depth with a varying number of passes

From figure 5.8 shown above, it may be observed that as the speed of the stage increases the depth of the ablation decreases for a constant number of passes. Also from figure 5.9 as the number of passes decreases, the etch depth decreases for a constant speed. This data indicates that in order to obtain lower etch depths, one must work at high speeds and go for preferably a lower number of passes. The SEM images below give a visual indication of how the etch depth can be controlled by controlling the number of passes and stage speed. 


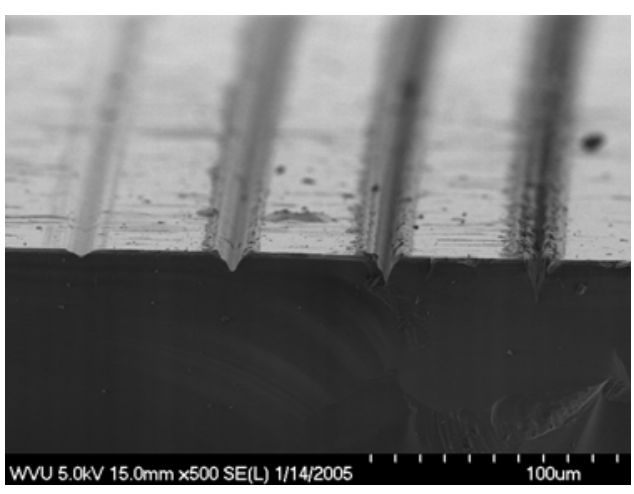

(a)

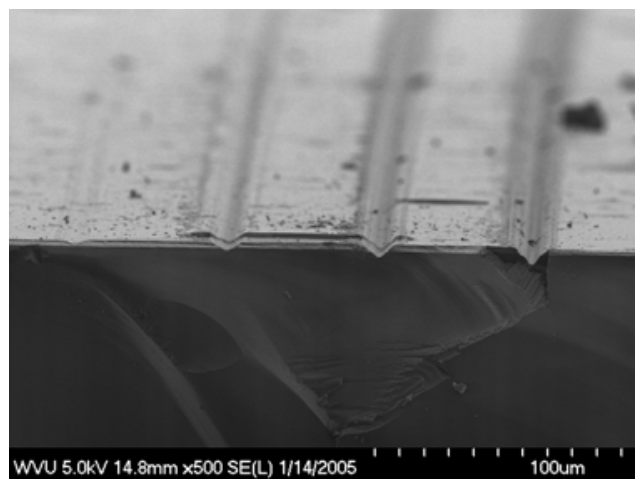

(c)

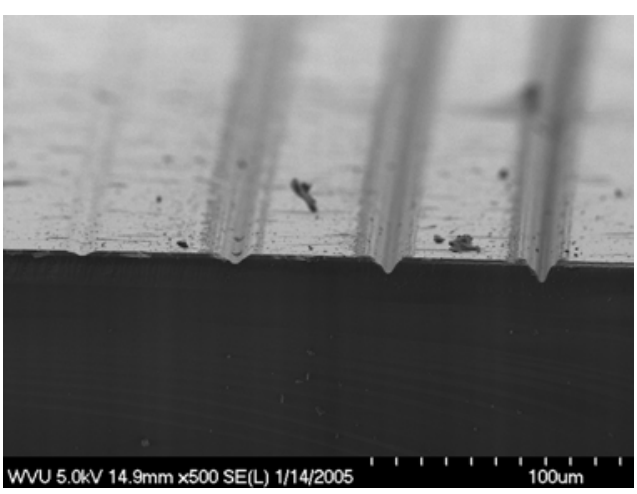

(b)

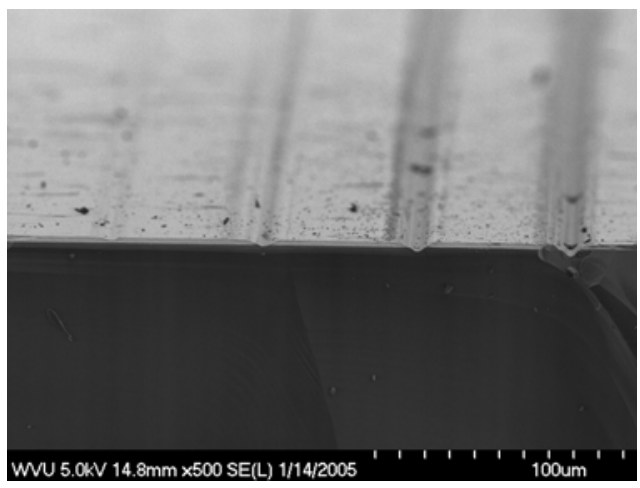

(d)

Figure 5.10: SEM images showing the impact of speed and number of passes on the etch depth

(a) Speed: 5mm/sec; \# of passes 1,3,5,7 (b) Speed: 10mm/sec; \# of passes 1,3,5,7

(c) Speed: 15mm/sec; \# of passes 1,3,5,7 (d) Speed: 20mm/sec; \# of passes 1,3,5,7

Figure 5.11 shown below shows how fine variation in the width and depth may be attained for different speeds for one pass in focus. 


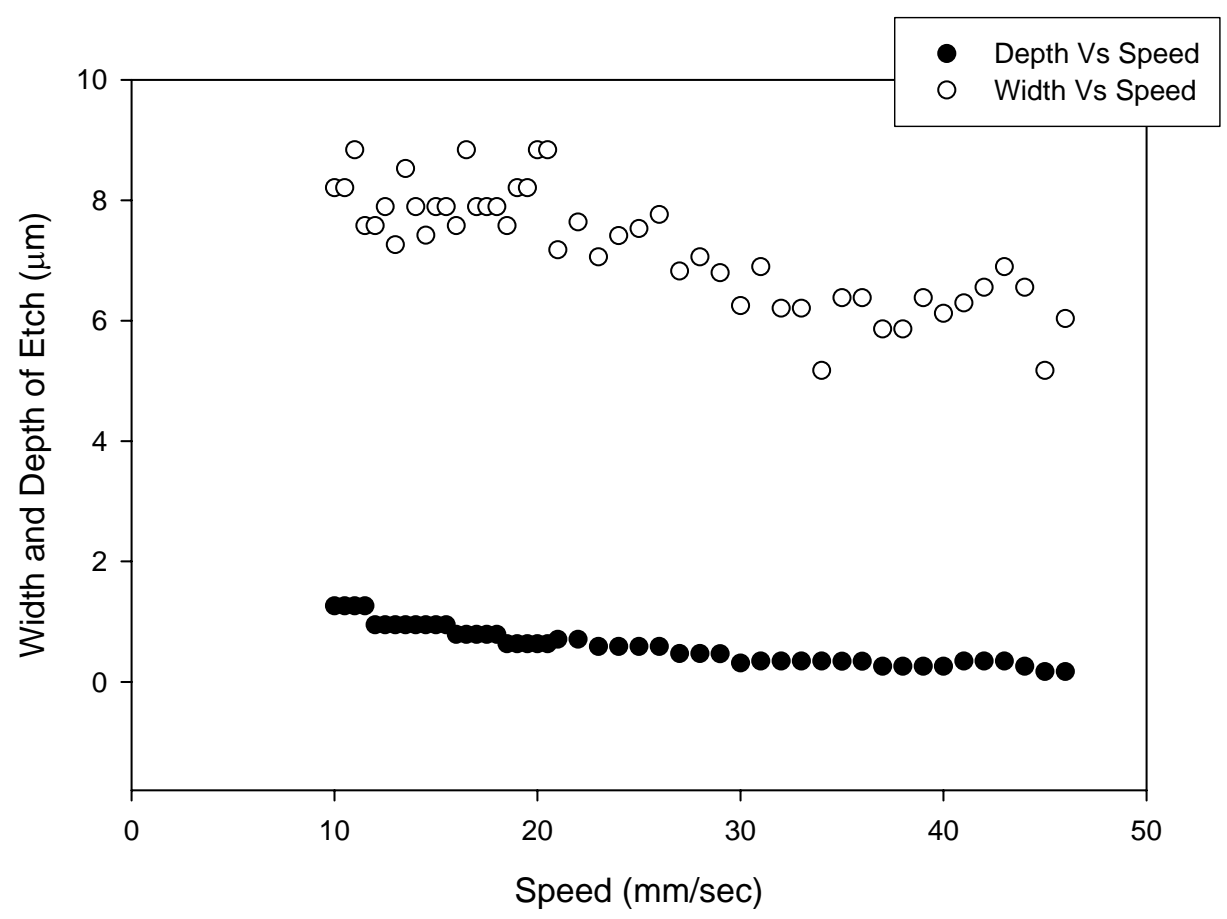

Figure 5.11: Plot showing the variation in the etch depth and width for varying speed and a single pass

\subsubsection{Treat the sample with $\mathrm{HCl}$ before observing under the SEM}

Upon ablating the sample, fuzzy white debris was found to surround the ablated area. This debris poses to be a problem when it comes to observe the sample under the Scanning Electron Microscope or the Alpha Step Surface Profiler and therefore the sample must be treated. An SEM showing the nature of the debris before having been removed is shown below. 


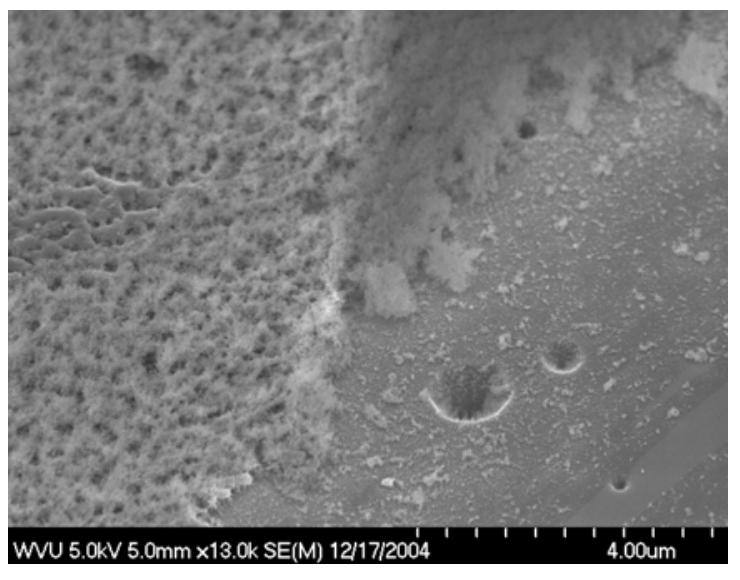

(a)

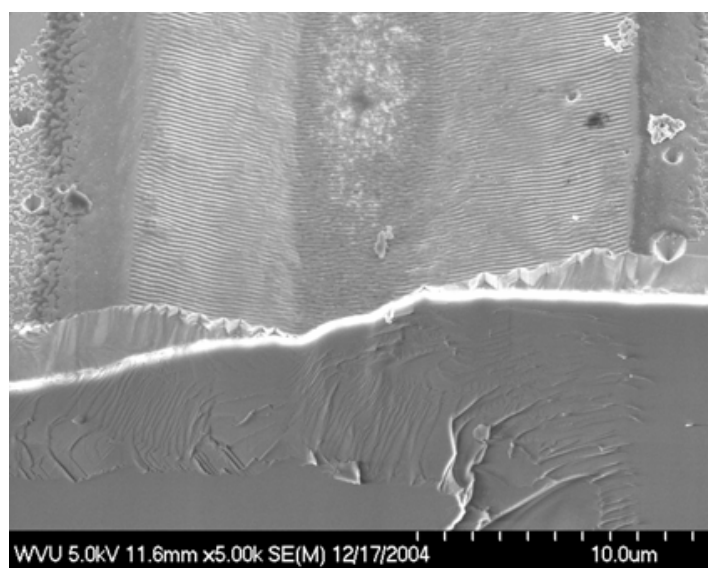

(b)

Figure 5.12: SEM image of ablated GaN (a) Before cleaning with $\mathrm{HCl}$ and (b) after cleaning with $\mathrm{HCl}$

It was seen that the debris was removed upon immersing the sample in a $50 \%$ dilute solution of $\mathrm{HCl}$ for 10 minutes. After cleaning the sample in $\mathrm{HCl}$, it was rinsed in deionized water and blow dried in Nitrogen gas.

\subsection{Trepanning}

Trepanning is a technique wherein the laser beam passes through two rotating mirrors. Two parameters may be varied while trepanning, one being the angle between the mirrors, the second the frequency of rotation of the mirrors. In order to observe the pattern ablated while using the Trepanning technique, lines were ablated into the Gallium Nitride at a constant frequency of $40 \mathrm{~Hz}$ varying the speed and angle between the mirrors to observe the effect of the angle on the nature of the ablation.

Eight sets of lines were drawn. Each set of lines comprised of three lines of 1, 3 and 5 passes. The speeds were kept at $0.25,0.5,1$ and $5 \mathrm{~mm} / \mathrm{sec}$. The first four sets of lines were drawn at an angle of 180 degrees and the second set of four lines was drawn at an angle of 60 degrees. Each of these lines was observed under the Scanning Electron Microscope in order to observe the nature of the surface, to check for surface smoothness. 
From the SEM images, it could be seen that the ablated surface was extremely uneven. This is thought to be unsuitable for the ablation not only because of the surface roughness, but also because islands of material are left behind, not removing the complete material.

The SEM images showed that with a high angle of 180degrees and high speed of $5 \mathrm{~mm} / \mathrm{sec}$ a spring like pattern was formed as shown below. This did not improve even with increasing the number of passes for the same speed, and a lot of material was left un ablated in between the spring. With a decrease in speed, there was an improvement in the spring like pattern, however the surface roughness was very high and islands of material were still left behind in between the ablated material.

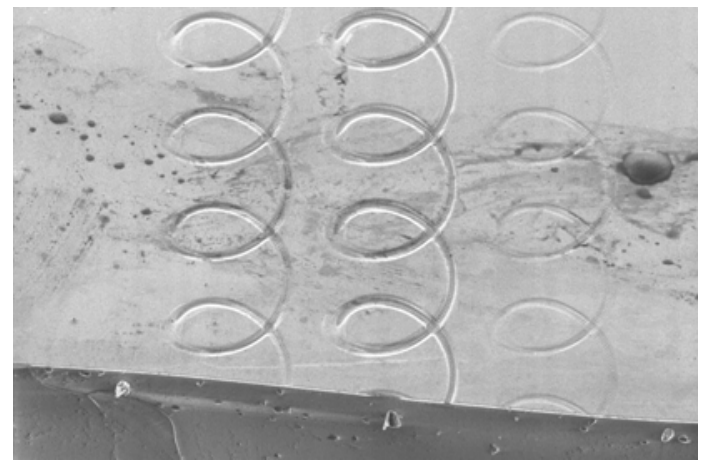

(a)

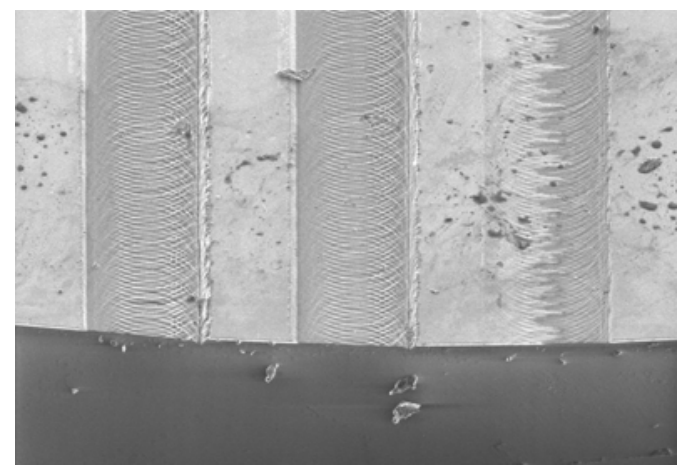

(b)

Figure 5.13: SEM images of trepanned lines with (a) an angle of 180 degrees frequency of $40 \mathrm{~Hz}$ and speed of $5 \mathrm{~mm} / \mathrm{s}$ showing spiral structure and (b) an angle of 180 degrees and frequency of $40 \mathrm{~Hz}$ but with a much lower speed of $0.125 \mathrm{~mm} / \mathrm{sec}$

A second set of lines were ablated with a decreased angle of 60 degrees with the same frequency of $40 \mathrm{~Hz}$. In this case too a similar pattern was observed. For a high speed of $5 \mathrm{~mm} / \mathrm{sec}$, a spring like pattern was seen to be formed where the loop like structures were brought considerably closer together when the speed of ablation was decreased considerably. The surface roughness, however for the same speed in comparison with the ablation at 180 degrees was much greater. SEM images of the ablated lines are shown below. 


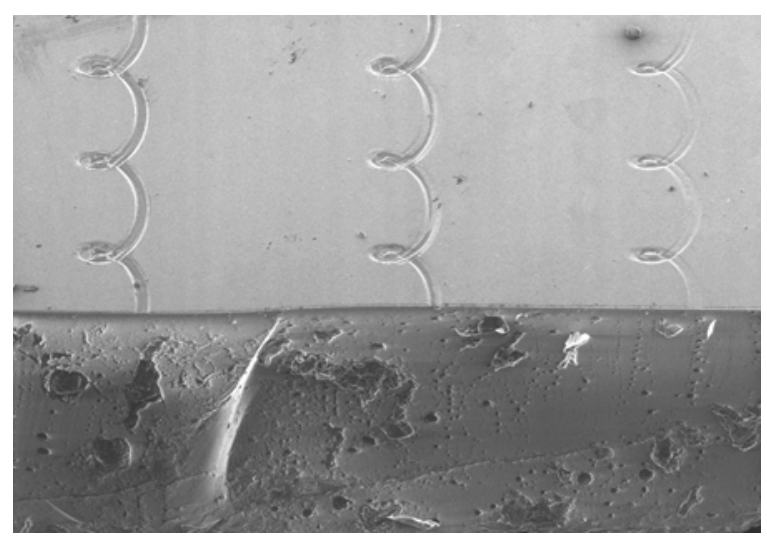

(a)

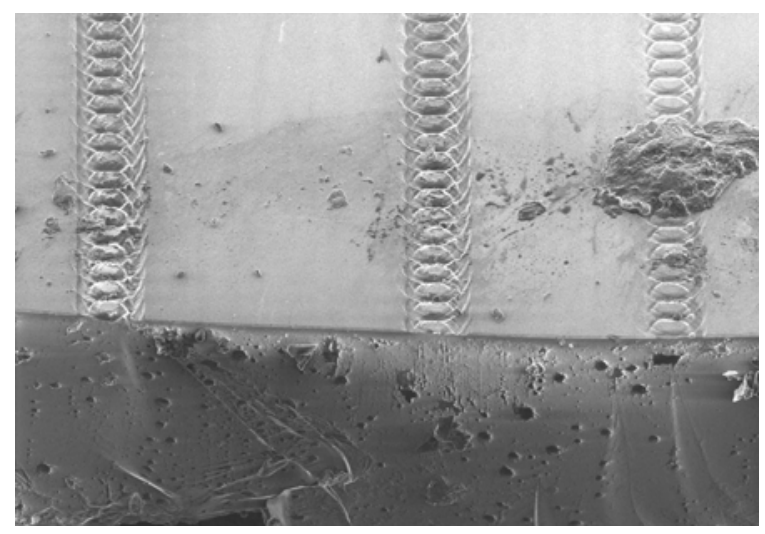

(b)

Figure 5.14: SEM images of Trepanned lines showing (a) a spring line ablation with an angle of 60 degrees, frequency of $40 \mathrm{~Hz}$ and speed $5 \mathrm{~mm} / \mathrm{sec}$ (b) a rough ablation texture with an angle of 60 degrees, frequency of $40 \mathrm{~Hz}$ and speed $0.125 \mathrm{~mm} / \mathrm{sec}$

The plot shown in figure 5.15 below shows the variation in the width of the trepanned lines. When compared to the width obtained by a single line ablation as shown in figure 5.11 we can see that the ablation width is around $110 \mu \mathrm{m}$ as compared with the $10 \mu \mathrm{m}$ obtained for single line ablation without Trepanning. 


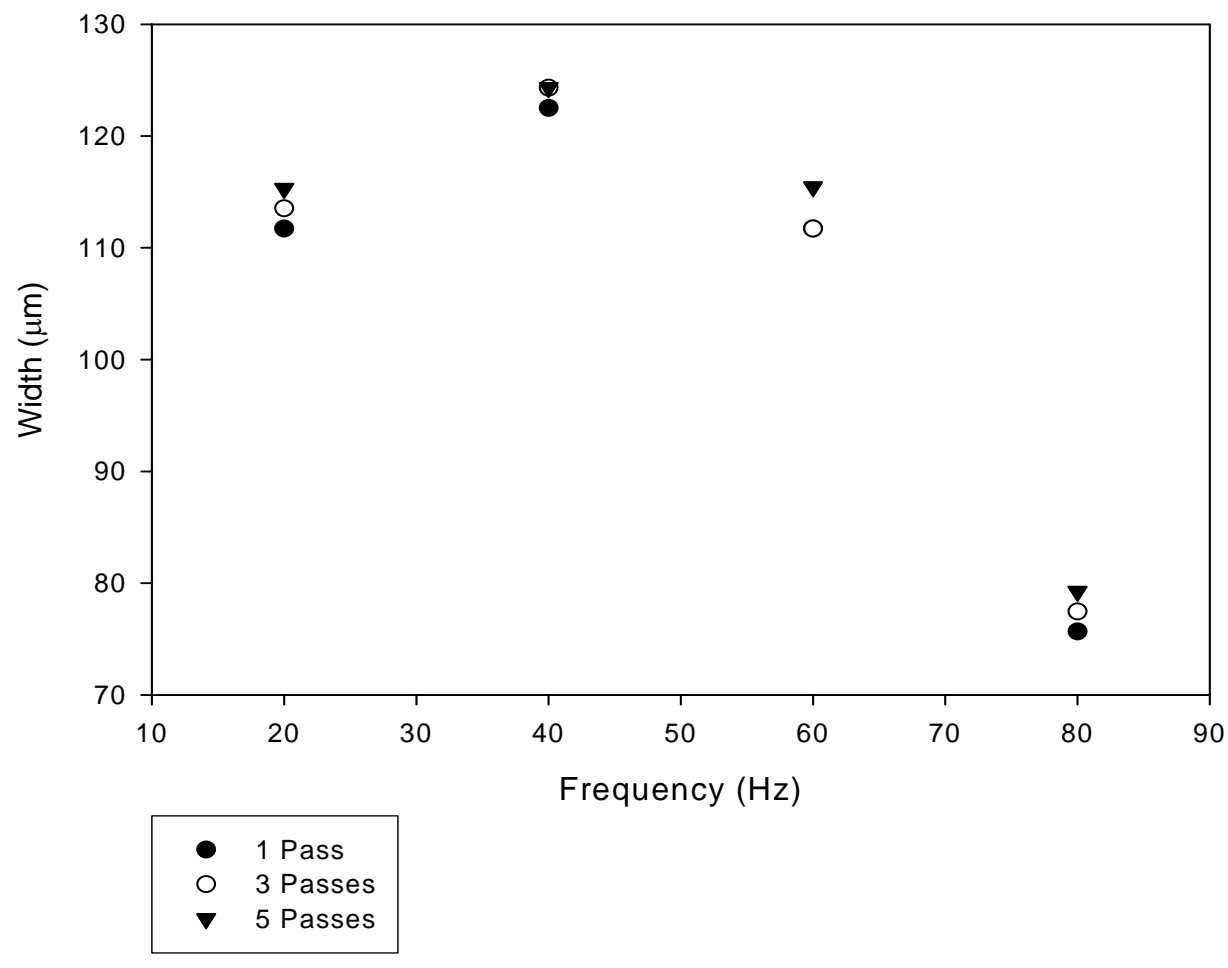

Figure 5.15: Plot showing the variation in the width of ablation with frequency for a constant number of passes

\subsection{Deposition of Contacts on the Ablated Gallium Nitride}

In order to study the effect of the ablation on the Gallium Nitride and its effects on the deposition of n-type contacts on the material, n-contacts are grown on different GaN samples and the specific contact resistivities and Sheet Resistances are studied. The procedure followed was developed elsewhere [Turlapati, 2004].

The laser ablation of the Gallium Nitride gives a surface roughness as shown in the Figure 5.16 below. 


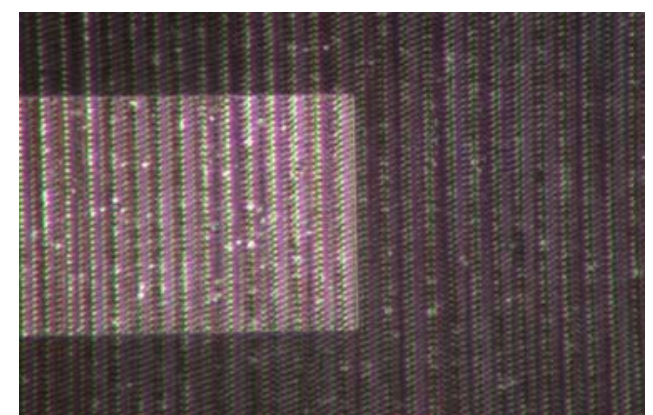

(a)

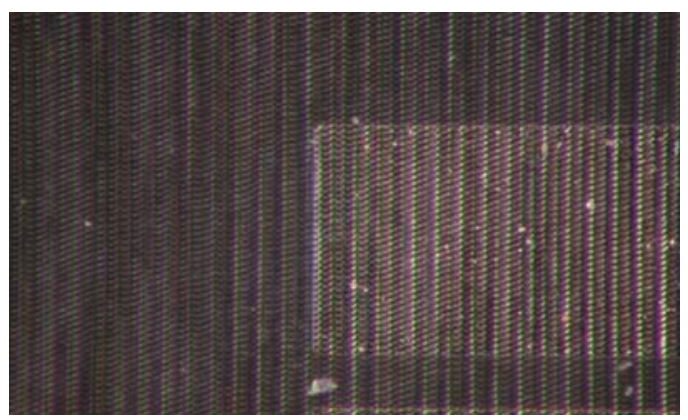

(b)

Figure 5.16: Pictures of GaN 34 (a) before and (b) after annealing

The surface of the Ablated Gallium Nitride was treated in several ways in an attempt to study any possible improvements in the specific contact resistivity by reducing the surface roughness. The Sheet Resistance and Specific Contact Resistivities were thus measured under various sets of conditions for different samples.

1. The first set of contacts were deposited on unablated Gallium Nitride cleaned through standard cleaning procedures, involving a 5 minute Acetone bath followed by a 5 minute Methanol bath and a half hour dehydration bake.

2. The second set of contacts was deposited on ablated and cleaned Gallium Nitride.

3. The third set of contacts were deposited on Gallium Nitride which went through a pre anneal. The Ablated Gallium Nitride was annealed at 600 degrees centigrade in a Nitrogen Ambient for a period of two minutes before depositing contacts.

4. The fourth set of contacts was deposited on ablated Gallium Nitride treated with Transetch-n.

The Specific Contact Resistivites and Sheet Resistance Values obtained from the plots are presented in Figure 5.17 below. 


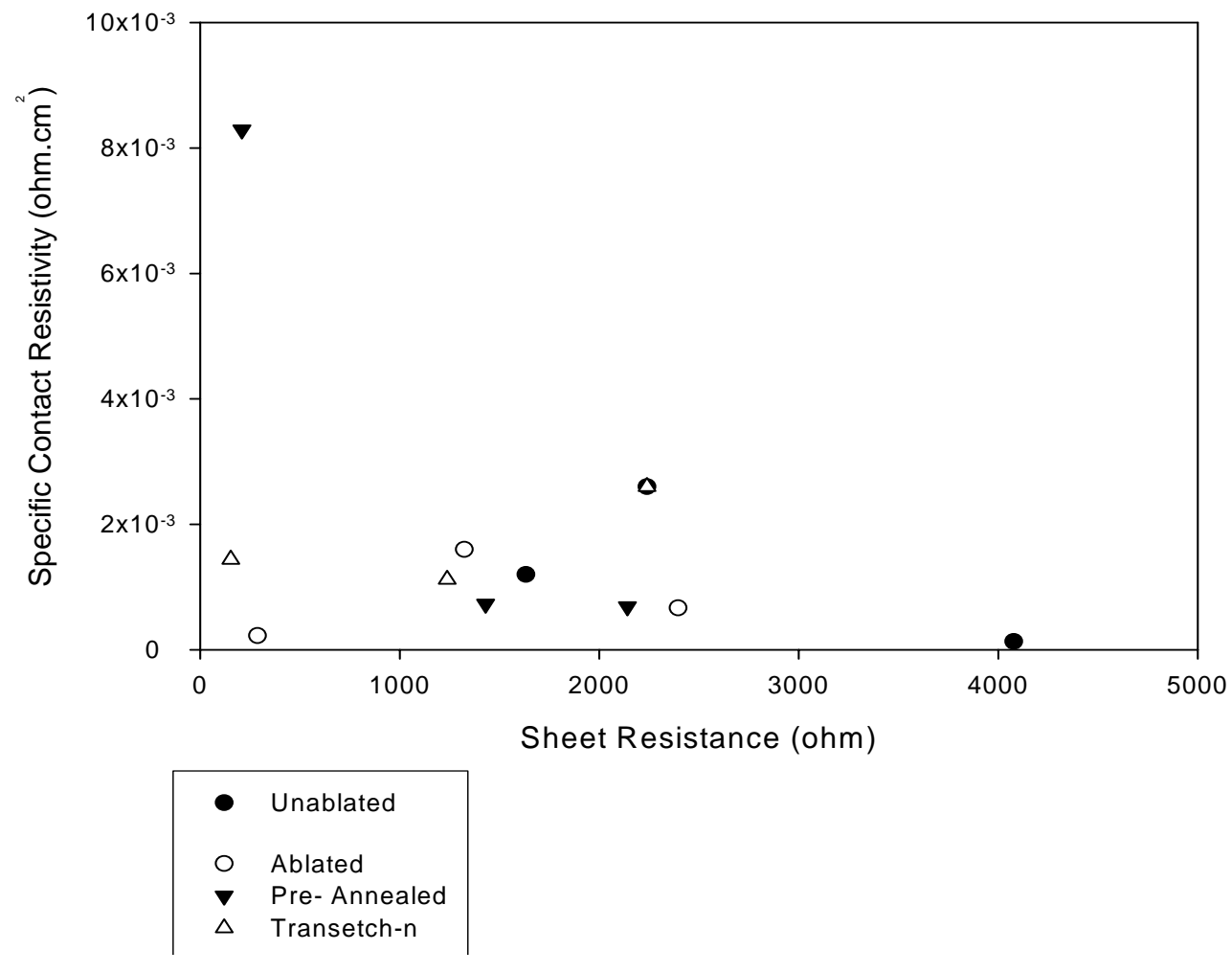

Figure 5.17: Specific Contact Resistivity Vs Sheet Resistance for samples processed under different conditions

The above results indicate that the resistivity values are slightly degraded upon ablation. This might be due to the surface conditions produced by the ablation as can be seen in Figure 5.16. The pictures show an irregularity in the surface texture due to the overlap caused by the laser beam. This might be one reason contributing to the reduction in the resistivity values. Treating the samples was found not to affect the resistivity values to a great extent. The tabulated data of the obtained Specific Contact Resistivities are given in Appendix L. 
As seen from Figure 3.22, in order to reach to the $n-G a N$ layer atleast $600 \mathrm{~nm}$ of material needs to be etched into. A setup for the ablation process to deposit the contacts on a wafer using a particular mask is discussed below.

\subsection{Proposed Laser Ablation for deposition of Metal Contacts}

We consider an area of Sapphire on which the different layers of material are going to be deposited in order to form the basic body of the Light Emitting diode. A side profile of such a structure is given below.

\begin{tabular}{|c|}
\hline $\mathrm{p}-\mathrm{GaN} 0.5 \mu \mathrm{m}$ \\
\hline $\mathrm{Al}_{0.1} \mathrm{Ga}_{0.9} \mathrm{~N}: \mathrm{Mg} 25 \mathrm{~nm}$ \\
\hline $5 \mathrm{MQW}$ \\
$\mathrm{In}_{0.15} \mathrm{Ga}_{0.85} \mathrm{~N}(4 \mathrm{~nm}) / \mathrm{GaN}(7 \mathrm{~nm})$ \\
\hline $\mathrm{GaN}: \mathrm{Si} 3 \mu \mathrm{m}$ \\
\hline GaN Nucleation Layer $25 \mathrm{~nm}$ \\
\hline Sapphire Substrate \\
\hline
\end{tabular}

Figure 5.18: Side profile of a basic Light Emitting Diode wafer

From the literature [Mukai, 1998] it is seen that the dimensions of the LED's are 350 x $350 \mu \mathrm{m}$. In order to reach into the $\mathrm{n}-\mathrm{GaN}$ layer, the material needs to be ablated to at least a depth ranging between $580 \mathrm{~nm}$ to $600 \mathrm{~nm}$. This may be done using the conditions obtained from the ablation conditions given above.

The mask to be used comprises of lines of varying thicknesses. The set of lines chosen to pattern the resist consist of pairs of lines $50 \mu \mathrm{m}$ and $70 \mu \mathrm{m}$ in width separated by a $480 \mu \mathrm{m}$ gap as shown in the figure 5.19. 


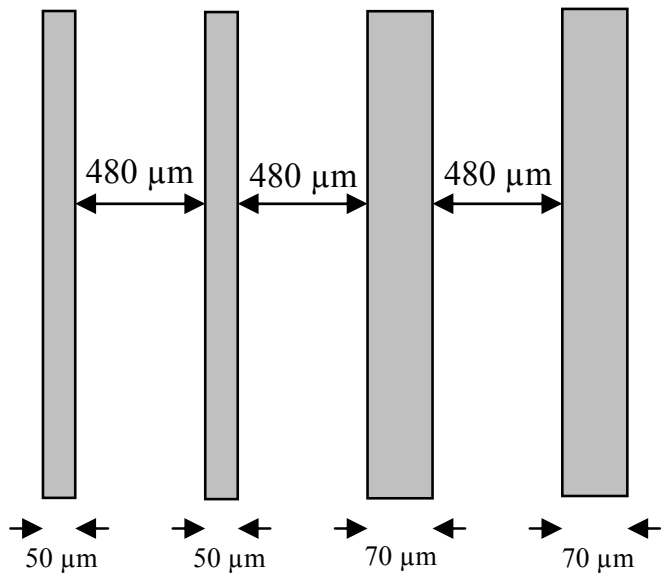

Figure 5.19: Pattern used to ablate GaN surface for future deposition of contacts

In order to deposit the contacts, the following procedure is adopted:

1. The wafer upon which the contacts are required to be deposited is taken and a discerning ablation line is made on the sample to serve as a reference point.

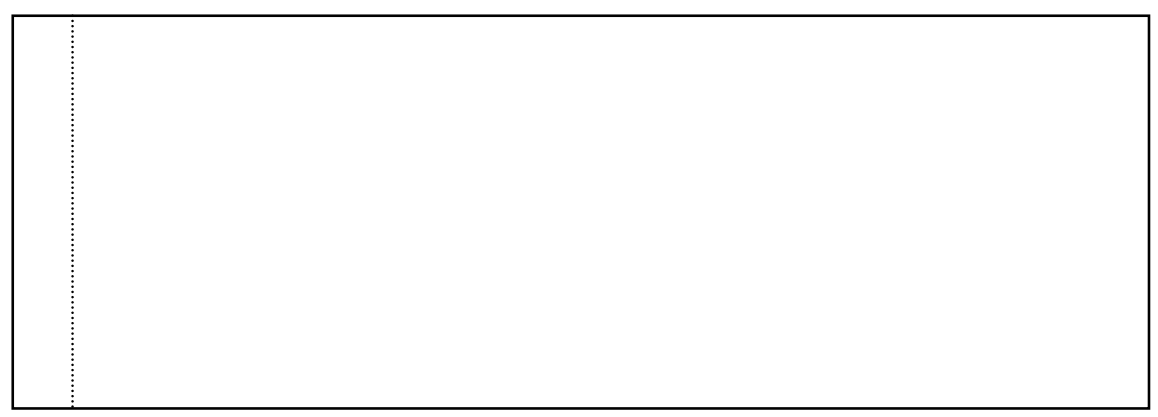

Figure 5.20: Wafer with a discerning line ablated onto it

2. Lines of appropriate thickness are ablated into the GaN as shown in the Figure 5.21 below. 


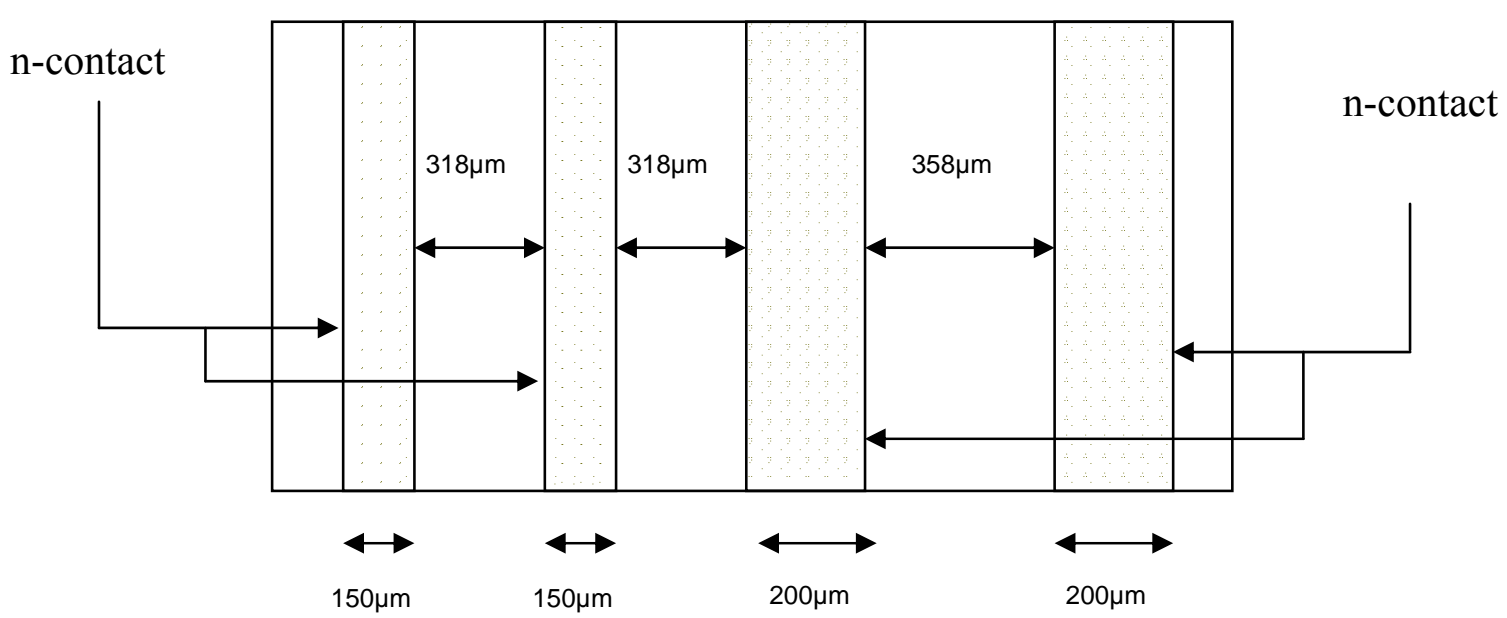

Figure 5.21: Top view of wafer structure with the darkened areas indicating the ablated regions

From figure 5.19 it can be seen that the mask line widths are $50 \mu \mathrm{m}$ and $70 \mu \mathrm{m}$, those of the ablated areas are more than double in width. This provides room for error while aligning the mask with the substrate in order to perform the exposure while actually depositing the metal contacts. SEM images of the ablated $\mathrm{GaN}$ are shown in figures 5.22, 5.23(a) and 5.23(b) below.

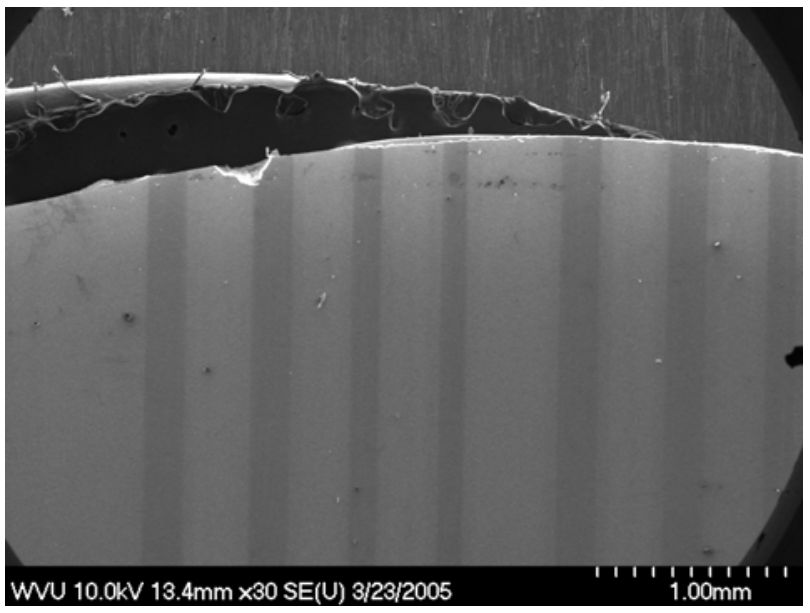

Figure 5.22: SEM image of laser ablated GaN sample showing dark ablated areas where contacts are to be deposited 


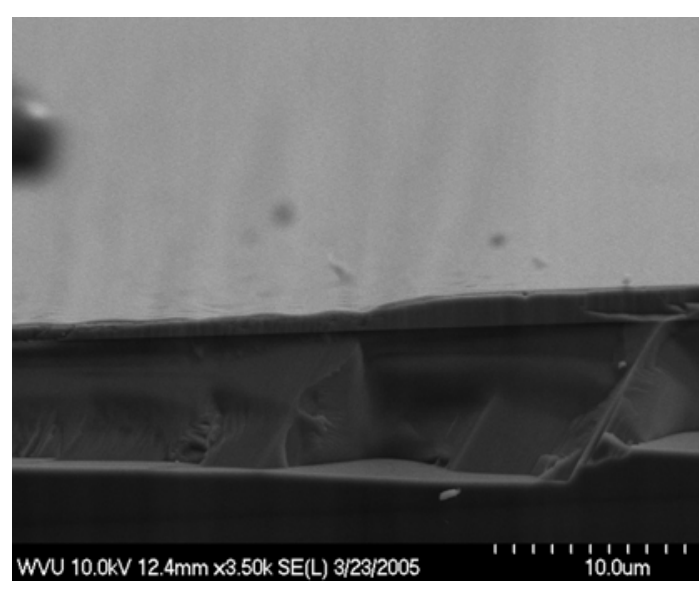

(a)

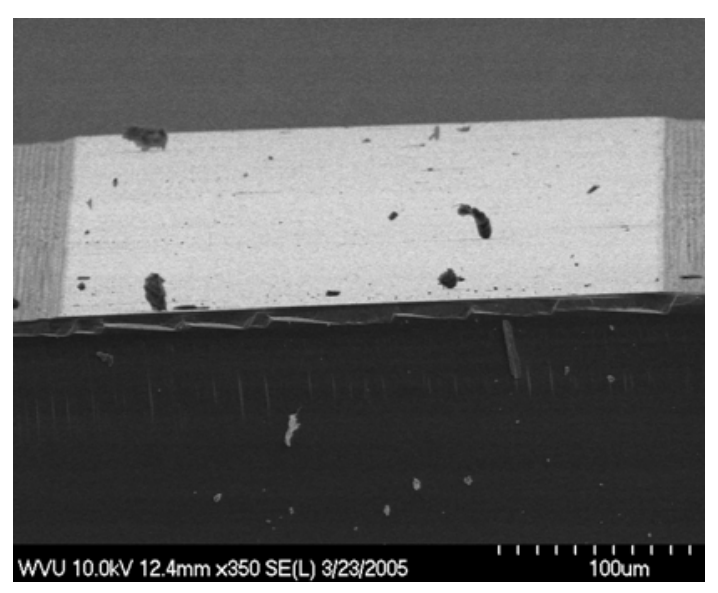

(b)

Figure 5.23: Close up SEM images of structure shown in Figure 5.25 showing (a) an ablated edge and (b) the central un-ablated strip (p-contact area) 


\section{CONCLUSIONS AND FUTURE WORK}

A new structure for a Gallium Nitride Light Emitting Diode whose emission wavelength is predicted to be in the $460 \mathrm{~nm}$ range has been designed. The parabolic gradient in the $\mathrm{Al}$ mole fraction in the $\mathrm{Al}_{\mathrm{x}} \mathrm{Ga}_{(1-\mathrm{x})} \mathrm{N}$ layer has been calculated. This is predicted to assist in the blocking of electrons from overflowing into the p-GaN region and assist the flow of holes to the Quantum Well region thereby increasing the over all internal efficiency.

Reactive Ion Etching has been performed on GaN grown in the MOCVD system using Silicon Dioxide as a hard mask material using $\mathrm{SF}_{6}$ gas. The etch rates were determined to be in the Angstrom range, not exceeding 200 Angstroms. A test etch was also performed using Chrome as a mask and this was found to be more suitable for etching GaN.

The Laser Ablation of $\mathrm{GaN}$ was studied in detail. It was seen that the etch rate of $\mathrm{GaN}$ could be controlled by controlling the fluence of the laser which in turn could be controlled by using a mask or by defocusing the lens. It was also shown that increasing the stage speed and decreasing the number of passes decreased the etch depth.

$\mathrm{N}$ type contacts were deposited on both the Reactive Ion Etched and the Laser ablated Gallium Nitride surfaces. Although there was an increase in the Specific Contact Resistivity of the etched and ablated as compared with that of the un etched and un ablated surface, the values were considered adequate for the operation of a Light Emitting Diode.

The proposed structure can be grown and tested for various factors. In addition, the Reactive Ion Etching has yet to be optimized to obtain smoother and better defined side walls. The process of Laser Ablation too needs to be more optimized to take advantage of features that it provides such as the fact that one is not limited by the use 
of a mask to etch into the material. The contact properties need to be optimized to improve the specific contact resistivities, this may be done further by reducing the roughness of the etched and ablated surfaces. 


\section{REFERENCES}

[Akane, 2002] T. Akane, K. Sugioka, K. Obata, N. Aoki, K. Toyoda, K. Midorikawa, Proceedings of SPIE Vol. 4426 (2002).

[Basak, 1997] D. Basak, M. Verdu, M. T. Montojo, M. A. Sanchez-Garcia, F. J. Sanchez, E. Munoz, E. Calleja, Semicond. Sci. Technol. 12(1997).

[Cao, 2003] X.A. Cao, S. F. LeBoeuf, J. L. Garrett, A. Ebong, L.B. Rowland, S.D. Arthur, Materials Research Society.

[Chang, 2002] S.J. Chang, W.C. Lai, Y.K. Su, J.F. Chen, C.H.Liu, U.H. Liaw, IEE Journal on Selected Topics in Quantum Electronics, Vol 8, No. 2.

[Chang, 2003] S. J. Chang, C. H. Kuo, Y. K. Su, L. W. Wu, J. K. Sheu, T. C. Wen, W. C. Lai, J. F. Chen, J. M. Tsai, IEEE.

[Cheong, 2001] M.G. Cheong, E. Suh, H. J. Lee, M. Dawson, IOP Electronic Journals.

[Cheong, 2001] M.G. Cheong, E. Suh, H. J. Lee, Journal of Luminescence, 99.

[Choi, 2003] R. Choi, H. J. Park, H.J. Lee, Y. Hahn, Metallurgical and Materials

Processiong: Principals and Technologies. Vol 1: Materials Processing Fundamentals and New Technologies.

[Chu, 2001] C. Chu, C.K. Lee, C.C. Yu, Y.K. Wang, J.Y. Tasi, C.R. Yang, S.C.

Wang, Materials Science and Engineering B82 (2001) 42-44.

[Dadgar, 2001] A. Dadgar, J. Christen, T. Riemann, S. Richter, J. Blasing, A. Diez, A. Krost, Appl. Phys. Lett, Vol 78, No 15.

[Dang, 1999] X. Z. Dang, P. M. Asbeck, E. T. Yu, G. J. Sullivan, M. Y. Chen, B. T. McDermott, K. S. Butros, J. M. Redwing, Appl. Phys. Lett, Vol 74, No. 25.

[Dumitrescu, 2002] M.M. Dumitrescu, M.J. Saarinen, M.D. Guina, M.V. Pessa, IEEE Journal on selected topics in Quantum Electronics, Vol 8, No.2.

[Egawa, 2002] T. Egawa, H. Ohmura, H. Ishikawa, T. Jimbo, Appl. Phys. Lett, Vol 81, No. 2 .

[Eliseev, 2000] P.G. Eliseev, S. Juodkazis, T. Sugahara, H. Sun, S. Matsuo, S. Saki, H. Misawa, Proceedings of SPIE Vol. 4065(2000). 
[Eliseev, 2002] P.G. Eliseev, A.A. Ionin, Y.M. Klimachev, D.V. Sinitsyn, J. Lee, M. Osinski, Proceedings of SPIE Vol. 4760(2002).

[Fischer, 2000] P. Fischer, J. Christen, S. Nakamura, Jpn. J. Appl Phys, Vol. 39.

[Gu, 2004] E. Gu, C.W. Jeon, I.I. W. Choi, G. Rice, M.D. Dawson, E.K. Illy, M.R.H. Knowles, Thin Solid Films 453-454(2004) 462-466.

[Harberer, 2000] E.D. Harberer, C. Chen, A. Abare, Appl. Phys. Lett, Vol 76, No. 26, 2000.

[Hori, 2001] A. Hori, D. Yasunaga, A. Satake, K. Fujiwara, Appl. Phys. Lett, Vol 79, No 22.

[Huh, 2000] C. Huh, H. Kim, S. Kim, J. Lee, D. Kim, I. Lee, S. Park, Journal of Appl. Phys, Vol 87, No 9.

[Huh, 2001] C. Huh, S. Kim, H. Kim, H. Kim, H. Hwang, S. Park, Appl . Phys. Lett, Vol 78, No 12.

[Im, 2000] Y.H. Im, J.S. Park, Y. B. Hahn, K. S. Nahm, Y. S. Lee, B. C. Cho, K. Y. Lim, H. J. Lee, S. J. Pearton, J. Vac. Sci. Technol, A 18(5).

[Jeon, 2001] S. Jeon, Y. Song, H. Jang, G. M. Yang, S.W. Hwang, S.J. Son, Appl. Phys. Lett, Vol 78, No 21.

[Jeon, 2002] S. Jeon, C. S. Oh, J. Yang, G. M. Yang, B. Yoo, Appl. Phys. Lett, Vol 80, No. 11.

[Kim, 1999] K.S. Kim, C.S. Oh, K.J. Lee, J.H. Kim, Y.S. Kim, G.M. Yang, C. H.

Hong, K. Y. Lim, H. J. Lee, IEEE, Pacific Rim 1999.

[Kim, 2001] T. Kim, H.S. Kim, M. Hetterich, D. Jones, J.M. Girkin, E. Bente, M.D.

Dawson, Materials Science and Engineering B82 (2001) 262-264.

[Koike, 2002] M.Koike, N. Shibata, H. Kato, Y. Takahashi, IEEE Journal on Selected Topics in Quantum Electronics, Vol 8, No. 2.

[Kuchibhatla, 2005] Sridhar Kuchibhatla, Gallium Nitride based Blue Laser Diodes, Masters Thesis, West Virginia University, 2005.

[Lee, 2001] C. Lee, K. Seol, J. Yeon, D. Choi, H. Ahn, Journal of Crystal Growth, 222.

[Lee, 2002] D.S. Lee, A. J. Steckl, Appl. Phys. Lett. Vol 81, No 13. 
[Mohs, 1995] G. Mohs, B. Fluegel, H. Giessen, H. Tajalli, N. Peyghambarian, P.

Chiu, B.Scott Phillips, M. Osinski, Appl. Phys. Lett, 67(11).

[Mukai, 1998] T. Mukai, K. Takekawa, S. Nakamura, Jpn. J. Appl. Phys. Vol. 37 (1998) pp. L839-L841.

[Mukai, 2002] T. Mukai, IEEE Journal on Selected topics in Quantum Electronics, Vol 8, No.2.

[Mukai, 2003] T. Mukai, M. Yamada, T. Mitani, Y. Narukawa, S. Shioji, I. Niki, S.

Sonobe, K. Izuno, R. Suenaga, Proceedings of SPIE Vol. 4996 (2003).

[Muthu, 2002] S.Muthu, F.J.P. Schuurmans, M.D. Pashley, IEEE Journal on Selected Topics in Quantum Electronics, Vol. 8, No. 2.

[Nagahama, 2001] S. Nagahama, N. Iwasa, M. Senoh, T. Matsushita, Y. Sugimoto, H. Kiyoku, T. Kozaki, M. Sano, H. Matsumura, H. Umemoto, k. Chocho, T.

Yanamoto, T. Mukai, Phys. Stat. Sol (a) 188, No. 1, 1-7 (2001).

[Nakamura, 1995] S. Nakamura, M. Senoh, N. Iwasa, S. Nagahama, T. Yamada, T. Mukai, Jpn. J. Appl. Phys, Vol 34.

[Nakamura, 1995] S. Nakamura, M. Senoh, N. Iwasa, S. Nagahama, Appl. Phys. Lett, 67.

[Nakamura, 1991] S. Nakamura, T. Mukai, M. Senoh, Jpn. Jnl of Applied Phys, Vol 30, No. 12A, pp. L 1998-L2001.

[Nakamura, 1999] S. Nakamura, Journal of Crystal Growth 201/202.

[Nakamura, 2000] S. Nakamura, IEICE Trans. Electron, Vol. E83-C, No.4.

[Ozono, 2001] K. Ozono, M. Obara, A. Usui, H. Sunakawa, Optics Communications 189 (2001) 103-106.

[Ozono, 2002] K. Ozono, T. Imahoko, M. Obara, Proceedings of SPIE Vol.4760 (2002).

[Pelzmann, 1998] A. Pelzmann, C. Kirchner, M. Mayer, V. Schwegler, M. Schauler, M. Kamp, K. J. Ebeling, I. Grzegor, M. Leszczynski, G.Nowak, S. Porowski, Journal of Crystal Growth.

[Polyakov, 2001] A. Y. Polyakov, N. B. Smirnov, A. V. Govorkov, A. V. Osinsky, P. E. Norris, S. J. Pearton, J. Van Hove, A. M. Wowchack, P. P. Chow, Jrnl of Appl Phys, Vol. 90, No. 8. 
[Rice, 2003] G. Rice, D. Jones, K.S. Kim, J.M. Girkin, D. Jarozynski, M.D. Dawson, Proceedings of SPIE Vol. 5147.

[Rong, 2000] B.Rong, R. Cheung, W.Gao, M.M. Alkaisi, R.J.Reeves, J. Vac. Sci.

Technol. B 18(6), 2000.

[Rong, 2001] B. Rong, E. van der Drift, R.J. Reeves, W.G. Sloof, R. Cheung, J. Vac. Sci. Technol. B 19(6).

[Roycroft, 2002] B. Roycroft, M. Akhter, P. Maaskant, P. De Mierry, S. Fernandez, F. B. Naranjo, E. Calleja, T. McCormack, B. Corbett, Phys. Stat. Sol. (a) 192, No. 1, 97-102.

[Schauler, 1997] M. Schauler, C. Kirchner, M. Mayer, A. Pelzmann, F. Eberhard, M. Kamp, P. Unger, K. J. Ebeling, MRS Internet Journal of Nitride Semiconductor Research.

[Sheu, 2000] J.K. Sheu, G.C. Chi, Y.K. Su, C.C. Liu, C. M. Chang, W.C. Hung, M.J. Jou, Solid State Electronics, 44.

[Schubert, 2003] Fred. E.Schubert, Light-emitting diodes,2003.

[Singh,1993] Jasprit Singh, Physics of Semiconductors and their Heterostructures.

[Song, 1999] Y.K. Song, M. Diagne, H. Zhou, A.V. Nurmikko, C.Carter-Connan, R.S. Kern, F. A. Kish, M.R. Krames, Appl. Phys. Lett, , Vol 74, No. 24.

[Su, 2003] Y.K. Su, S. J. Chang, L.W. Ji, C. S. Chang, L.W. Wu, W.C. Lai, T. H. Fang, K. T. Lam, Iop Electronic Journals.

[Sugioka, 2001] Koji Sugioka, Proceedings of SPIE Vol. 4157 (2001).

[Sun, 2000] H. Sun, S. Juodkazis, P.G. Eliseev, T. Sugahara, T. Wang, S. Matsuo, S. Sakai, H. Misawa, Proceedings of SPIE Vol. 3885 (2000).

[Tran, 1999] C. A. Tran, A. Osinski, R.F.Karlicek. Jr, I. Berishev, Appl. Phys. Lett, Vol 75, No. 11.

[Tripathi, 2001] S. Tripathi, A. Ramam, S.J.Chua, J.S.Pan, Alfred Hunan, J. Vac.Sci. Technol. A 19(5), 2001.

[Turlapati, 2004] Lavanya Turlapati, Developing UV Photodetector and Ohmic Contact techniques on Gallium Nitride, Masters Thesis, West Virginia University, 2004. 
[Yang, 2002] F. Yang, C. Hsiao, Y. Yang, J. Lin, L. Wang, Jpn. J. Appl. Phys. Vol

41, pp L468-470 (2002).

[Youn, 2002] C.J. Youn, T.S. Jeong, M.S.Han, J.W.Yang, K.Y. Lim. H.W. Yu, Journal of the Korean Physical Society, Vol 41, No. 5.

[Zhang, 2003] B. Zhang, T. Egawa, H. Ishikawa, Y. Liu, T. Jimbo, Jpn. J. Appl. Phys, Vol 42(2003) pp L 226-L228.

[Zorpette, 2002] Glenn Zorpette, IEEE Spectrum 2002.

[1] http://www.darpa.mil/mto/suvos/presentations/Bedair.pdf

[2] http://srs.dl.ac.uk/Annual_Reports/AnRep01_02/confocal.htm

[3] Department of Chemistry, West Virginia University 


\section{APPENDIX A: SOLUTION TO THE 1- DIMENSION TIME INDEPENDENT SCHRODINGER WAVE EQUATION USING MATLAB}

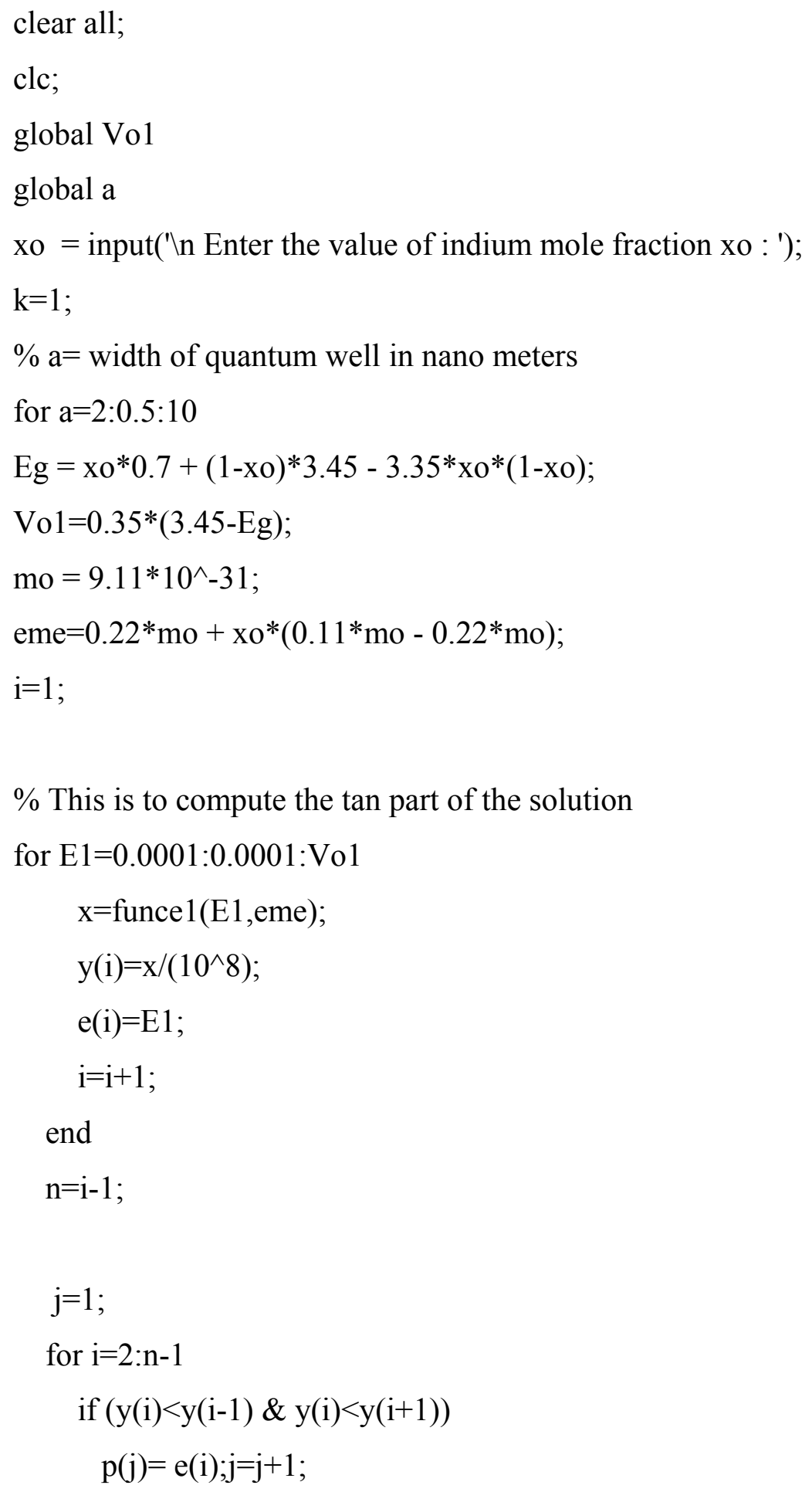




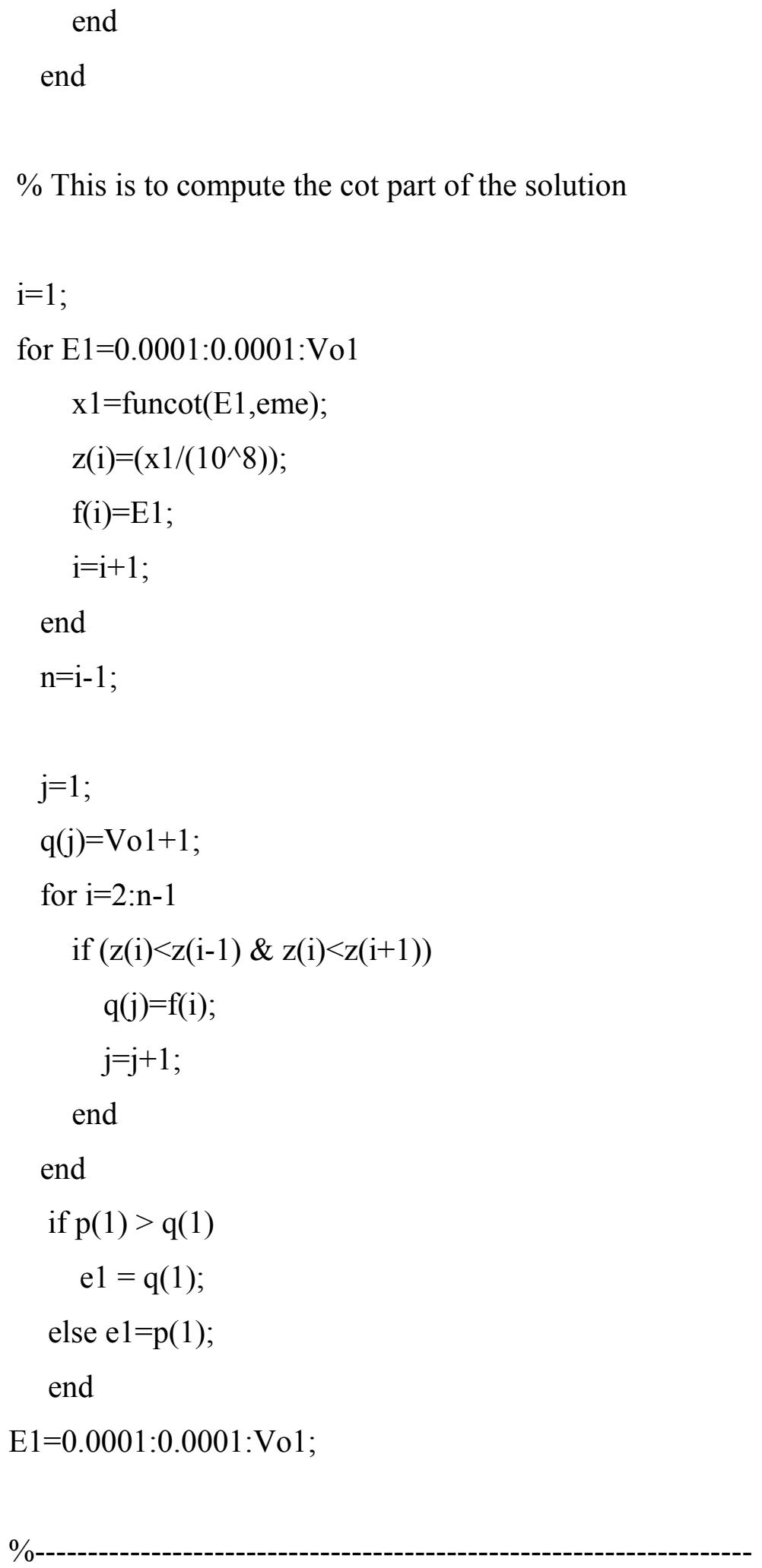

$\%$ This is the calculation for the light hole 


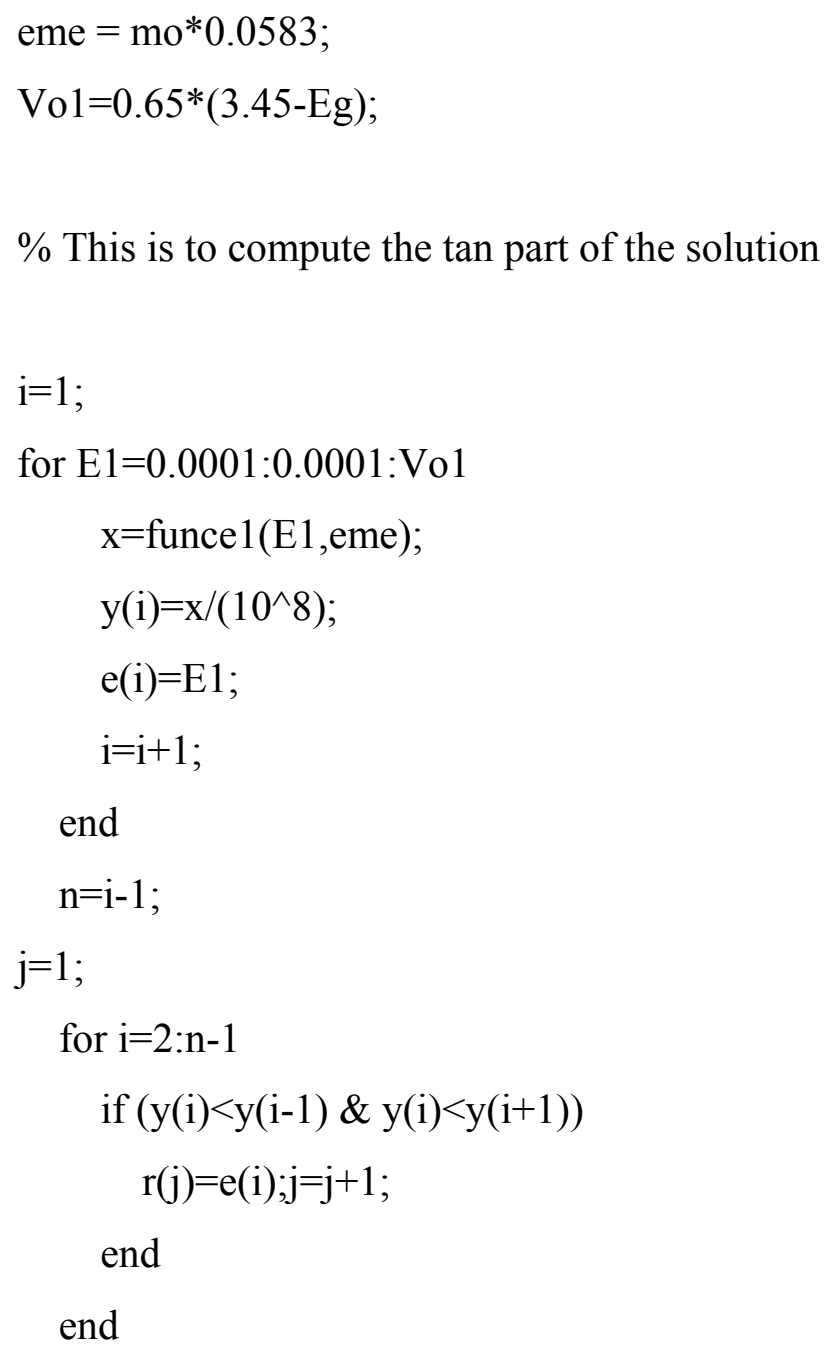




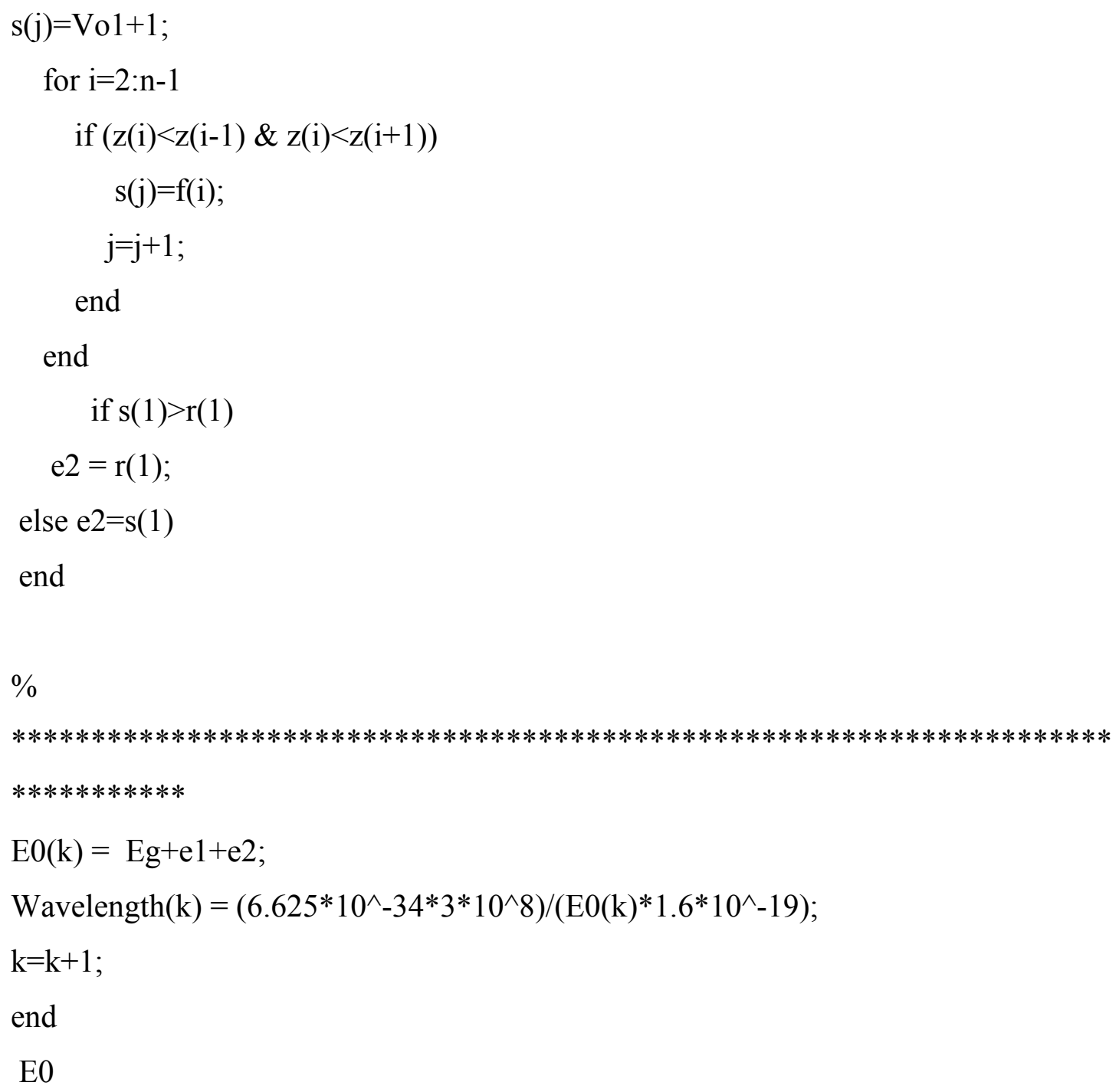




\section{FUNCTIONS USED IN THIS PROGRAM:}

The function funcval calculates the Tangent solution to the Schrödinger's equation.

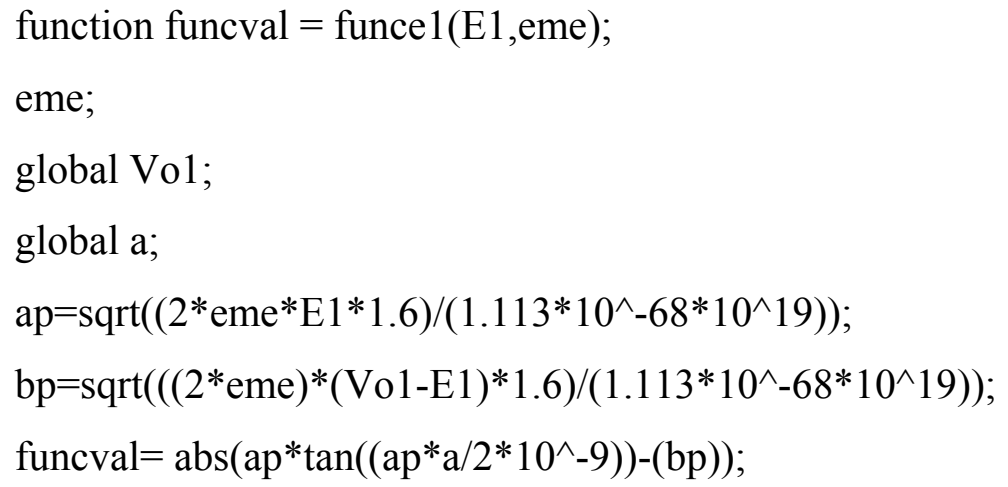

The function funcot calculates the Cotangent solution to the Schrödinger's equation.

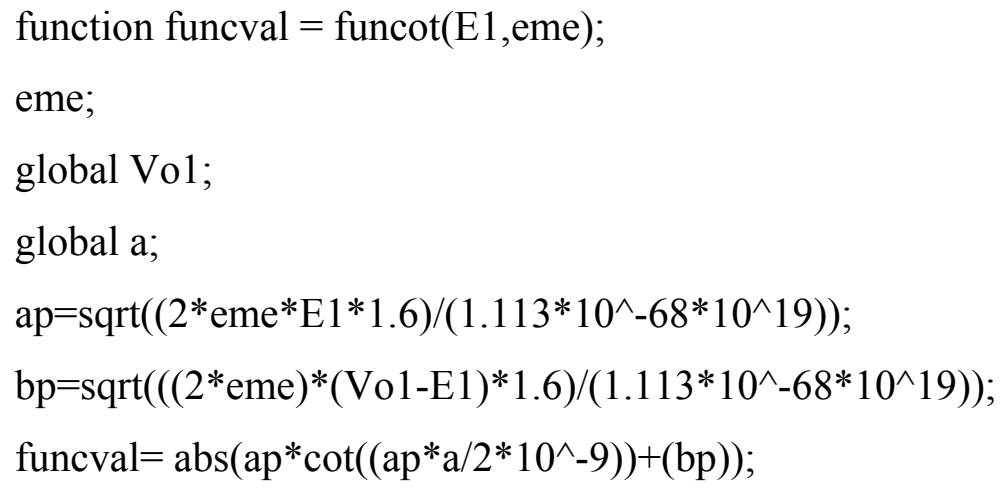




\title{
APPENDIX B: MATLAB PROGRAM TO CALCULATE THE WIDTH OF THE AIGaN BARRIER
}

\author{
$\%$ Program to calculate the graded region of the AlGaN barrier \\ xo = input ('In Enter the mole fraction of $\mathrm{Al}$ in the AlGaN : '); \\ nd = input ('\n Enter the AlGaN doping concentration : '); \\ diconst $=(10.89-(2.73 * \mathrm{xo}))$; \\ Egalgan $=\left(\left(\mathrm{xo}^{*} 6.28\right)+((1-\mathrm{xo}) * 3.42)-(\mathrm{xo} *(1-\mathrm{xo}) * 1.0)\right)$ \\ delEg $=$ Egalgan-3.42 \\ $\operatorname{delEc}=0.7 * \operatorname{delEg}$ \\ $\mathrm{Wd} 1=\operatorname{sqrt}\left(\left(2 * \operatorname{diconst} * 8.85^{*}\left(10^{\wedge}-14\right) * \operatorname{delEc}\right) /\left(\left(1.6^{*} 10^{\wedge}-19\right) * \mathrm{nd}\right)\right)$; \\ $\mathrm{Wd}=\mathrm{Wd} 1 * 10^{\wedge}(-2) * 2 * 10^{\wedge} 9$ \\ fprintf(' $\backslash n$ The values of the grading width is in $\mathrm{m:} \% \mathrm{~d} \backslash \mathrm{n} \mathrm{nm}$ ', Wd);
}




\section{APPENDIX C: MATLAB PROGRAM TO CALCULATE THE OVERFLOW CURRENT OF A LIGHT EMITTING DIODE}

This is a program to calculate the current overflow

$\%$ in a quantum well varying the well thickness

$\%$ me=effective mass of electron in $\mathrm{InGaN}$

clc;

xo = input ('InPlease input the mole fraction of In: ');

Eo1 = input ('InPlease input the value of Eo from the previous program: ');

$\mathrm{Eo}=\mathrm{Eo} 1 * 10^{\wedge}-3$

Wqw = input ('InPlease input the value of the width of the quantum well in nm: ');

Egingan $=\mathrm{xo}^{*} 1.97+(1-\mathrm{xo}) * 3.42-\mathrm{xo} *(1-\mathrm{xo})$;

$\% \mathrm{~B}=$ Bimolecular Recombination Coefficient

$\% \mathrm{~B}=\left(3.0^{*} 10^{\wedge}-10\right)^{*}\left((\text { Egingan } / 1.5)^{\wedge} 2\right)^{*} 10^{\wedge} 21$ Use this to convert to $\mathrm{nm}$;

$\mathrm{B} 1=\left(3.0^{*} 10^{\wedge}-10\right)^{*}\left((\text { Egingan } / 1.5)^{\wedge} 2\right)$;

$\mathrm{B}=\mathrm{B} 1 *\left(10^{\wedge}-6\right)$

$\mathrm{me}=\left(0.22 * 9.10938188 * 10^{\wedge}-31\right)+\mathrm{xo} *\left(\left(0.11 * 9.10938188^{*} 10^{\wedge}-31\right)-\right.$

$\left.\left(0.22 * 9.10938188 * 10^{\wedge}-31\right)\right)$;

delEc $=3.42$-Egingan;

$\mathrm{a}=\left(\left(\mathrm{me}^{*}(\text { delEc-Eo })\right) /\left(\mathrm{pi}^{*}\left(\left(6.5821^{*} 10^{\wedge}-16\right)^{\wedge} 2\right)\right)\right)^{\wedge} 2$;

$\mathrm{b}=\left(\left(1.6^{*} 10^{\wedge}-19\right) * \mathrm{~B}\right) /\left(\mathrm{Wqw}^{*} 10^{\wedge}-9\right)$;

$\mathrm{J}=\mathrm{a}^{*} \mathrm{~b}^{*}\left(\left(0.3906^{*} 10^{\wedge} 38\right)\right) *\left(10^{\wedge}-4\right)$;

fprintf('ไnThe overflow current for this quantum well is: \%d $\mathrm{dn} \mathrm{A} / \mathrm{cm} 2 ', \mathrm{~J})$; 


\section{APPENDIX D: PROGRAM TO DETERMINE THE FOCUS OF THE LASER}

DVAR \$TIME

DVAR \$ZSTART

DVAR \$DISTX

DVAR \$DISTY

DVAR \$DISTZ

DVAR \$NUMBER

$\$$ TIME $=0.1$

\$ZSTART $=79$

$\$ \mathrm{DISTX}=0.2$

\$DISTY $=0$

\$DISTZ $=0.05$

$\$ N U M B E R=42$

ENABLE X Y Z

G90

G71

\$TIME=MSGINPUT DF_MSGBOX_OKONLY "Drill time;Enter drill time/s.;"\$TIME

\$ZSTART=MSGINPUT DF_MSGBOX_OKONLY "Z-START POSITION;Enter ZStart Position/s.;"\$ZSTART

\$DISTX=MSGINPUT DF_MSGBOX_OKONLY "X movement;Enter X-axis step in mm.;"\$DISTX

\$DISTY=MSGINPUT DF_MSGBOX_OKONLY "Y movement;Enter Y-axis step in mm.;"\$DISTY

\$DISTZ=MSGINPUT DF_MSGBOX_OKONLY "Z movement;Enter Z-axis step in mm.;"\$DISTZ

\$NUMBER=MSGINPUT DF_MSGBOX_OKONLY "Number of holes; Enter No. of holes to be drilled.;"\$NUMBER 
G90 G1 Z\$ZSTART F 20

G91

REPEAT \$NUMBER

CLOSESHUTTER

;M0

; cycle to continue

G4 F.5

; wait for $0.5 \mathrm{sec}$ before next

command

OPENSHUTTER

G4 F\$TIME

; open shutter for time

value

CLOSESHUTTER

G1 X\$DISTX Y\$DISTY Z\$DISTZ F10

ENDREPEAT

CLOSESHUTTER

G1 X-(\$DISTX*\$NUMBER) Y-(\$DISTY*\$NUMBER) Z-(\$DISTZ*\$NUMBER)

F20

M2

; end of program 


\section{APPENDIX E: PROGRAM TO ABLATE A SAMPLE OF GALLIUM NITRIDE TO DEPOSIT CONTACTS}

DVAR \$SPEED

DVAR \$ZSTART

;starting Z

DVAR \$DISTX

;length of line in

$\mathrm{X}$

DVAR \$DISTY

;step distance between lines

;DVAR \$DISTZ

DVAR \$NUMBER

;number of lines to do

DVAR \$INCREMENTNUMBER

;amount to increment stage speed by

$\$ S P E E D=35$

\$ZSTART $=80.30$

\$DISTX $=25$

\$DISTY $=0.004$

;\$DISTZ $=0.1$

$\$ N U M B E R=3500$

\$INCREMENTNUMBER $=0.5$

ENABLE X Y Z

;HOME A B

DISABLE A B

G71

;\$DISTX=MSGINPUT DF_MSGBOX_OKONLY "X movement;Enter line length (X-axis) in mm.;"\$DISTX

;\$DISTY=MSGINPUT DF_MSGBOX_OKONLY "Y movement;Enter Y-axis step between lines in mm.;"\$DISTY

;\$DISTZ=MSGINPUT DF_MSGBOX_OKONLY "Z movement;Enter Z-axis step in mm.;"\$DISTZ 
;\$NUMBER=MSGINPUT DF_MSGBOX_OKONLY "Number of holes;Enter No. of lines to be drilled.;"\$NUMBER

;\$INCREMENTNUMBER=MSGINPUT DF_MSGBOX_OKONLY "stage speed increment; Enter stage speed increment mm/sec;"\$INCREMENTNUMBER

;M0

; cycle to continue

G92 X0 Y0 


\section{APPENDIX F: PROGRAM TO ABLATE LINES IN GaN VARYING THE SPEED OF ABLATION}

DVAR \$SPEED

DVAR \$ZSTART

starting Z

DVAR \$DISTX

;length of line in $\mathrm{X}$

DVAR \$DISTY

;step distance between lines

;DVAR \$DISTZ

DVAR \$NUMBER

;number of lines to do

DVAR \$INCREMENTNUMBER

;amount to increment stage speed by

\$SPEED=31

\$ZSTART $=80.45$

$\$$ DISTX $=10$

SDISTY $=0.010$

;\$DISTZ $=0.1$

$\$ N U M B E R=11$

$\$$ INCREMENTNUMBER $=0.5$

ENABLE X Y Z

;HOME A B

DISABLE A B

G71

;\$DISTX=MSGINPUT DF_MSGBOX_OKONLY "X movement;Enter line length (X-axis) in mm.;"\$DISTX

;\$DISTY=MSGINPUT DF_MSGBOX_OKONLY "Y movement;Enter Y-axis step between lines in mm.;"\$DISTY

;\$DISTZ=MSGINPUT DF_MSGBOX_OKONLY "Z movement;Enter Z-axis step in mm.;"\$DISTZ 
;\$NUMBER=MSGINPUT DF_MSGBOX_OKONLY "Number of holes;Enter No. of lines to be drilled.;"\$NUMBER

;\$INCREMENTNUMBER=MSGINPUT DF_MSGBOX_OKONLY "stage speed increment; Enter stage speed increment mm/sec;"\$INCREMENTNUMBER

;M0 ; cycle to continue

G92 X0 Y0

G91

REPEAT \$NUMBER

CLOSESHUTTER

M0 ; cycle to continue

G4 F.5 ; wait for $0.5 \mathrm{sec}$ before next command \$SPEED=MSGINPUT DF_MSGBOX_OKONLY "stage speed; Enter starting speed $\mathrm{mm} / \mathrm{sec} ; "$ \$SPEED ;\$ZSTART=MSGINPUT DF_MSGBOX_OKONLY "Z-START POSITION;Enter ZStart Position/s.;"\$ZSTART

G90 G1 Z\$ZSTART F 20

G91

OPENSHUTTER

G1 X\$DISTX F\$SPEED

CLOSESHUTTER

G1 X-\$DISTX Y\$DISTY F10

ENDREPEAT

CLOSESHUTTER

G0 X0 Y0 F20

M2

; end of program 


\section{APPENDIX G: PROGRAM TO ABLATE LED}

DVAR \$SPEED

DVAR \$ZSTART

;starting Z

DVAR \$DISTX

;length of line in $\mathrm{X}$

DVAR \$DISTY

;step distance between lines

;DVAR \$DISTZ

DVAR \$NUMBER

;number of lines to do

DVAR \$INCREMENTNUMBER

;amount to increment stage speed by

DVAR \$DISTY1

$\$$ SPEED $=80$

\$ZSTART $=80.05$

$\$$ DISTX $=10$

$\$ \mathrm{DISTY}=0.004$

;\$DISTZ $=0.1$

$\$ N U M B E R=51$

\$INCREMENTNUMBER $=0.5$

\$DISTY $1=0.370$

ENABLE X Y Z

;HOME A B

DISABLE A B

G71

;\$DISTX=MSGINPUT DF_MSGBOX_OKONLY "X movement;Enter line length (X-axis) in mm.;"\$DISTX

;\$DISTY=MSGINPUT DF_MSGBOX_OKONLY "Y movement;Enter Y-axis step between lines in mm.;"\$DISTY 
;\$DISTZ=MSGINPUT DF_MSGBOX_OKONLY "Z movement;Enter Z-axis step in mm.;"\$DISTZ

;\$NUMBER=MSGINPUT DF_MSGBOX_OKONLY "Number of holes;Enter No. of lines to be drilled.;"\$NUMBER

;\$INCREMENTNUMBER=MSGINPUT DF_MSGBOX_OKONLY "stage speed increment; Enter stage speed increment mm/sec;"\$INCREMENTNUMBER

;M0 ; cycle to

continue

G92 X0 Y0

G91

REPEAT \$NUMBER

;CLOSESHUTTER

;M0 ; cycle to continue

;G4 F.5 ; wait for $0.5 \mathrm{sec}$ before next command ;\$SPEED=MSGINPUT DF_MSGBOX_OKONLY "stage speed; Enter starting speed $\mathrm{mm} / \mathrm{sec} ; "$ SPEED

;\$ZSTART=MSGINPUT DF_MSGBOX_OKONLY "Z-START POSITION;Enter Z-Start Position/s.;"\$ZSTART

G90 G1 Z\$ZSTART F 20

G91

OPENSHUTTER

G1 X\$DISTX F\$SPEED

;CLOSESHUTTER

G1 Y\$DISTY F10

G1 X-\$DISTX F\$SPEED

ENDREPEAT

CLOSESHUTTER

G0 X0 Y0 F20

G1 Y\$DISTY1

M2

;end of program 


\section{APPENDIX H: PROTOCOL FOR HCI CLEANING}

1) In a glass beaker mix $50 \% \mathrm{HCl}$ with water.

2) Secure the Gallium Nitride sample with plastic tweezers.

3) Immerse sample in the $50 \%$ dilute $\mathrm{HCl}$ solution for 10 minutes.

4) Rinse the sample by dipping in de ionized water for five minutes.

5) Blow dry sample in Nitrogen gas.

6) Dispose $\mathrm{HCl}$ solution through Aspirator and rinse both $\mathrm{HCl}$ beaker and rinse jar under a continuous stream of DI water for 10 minutes. 


\section{APPENDIX I: PROTOCOL FOR BUFFERED OXIDE ETCH FOR ETCHING SILICON DIOXIDE.}

1) Mix in a Nalgene beaker mix $70 \%$ Buffered Oxide Etch with ultra pure De ionized water.

2) Secure the sample in plastic tweezers.

3) Immerse in the Buffered Oxide Etchant. The etchant was found to have an approximate etch rate of $200 \mathrm{~nm} /$ minute at room temperature, therefore the sample is kept immersed accordingly.

4) The sample is then rinsed by immersing in a rinse jar filled with de ionized water and dried with Nitrogen.

5) Upon completion, the Buffered Oxide Etchant is disposed through the Aspirator.

6) The Nalgene beaker and the rinse jar are cleaned by rinsing under a continuous flow of de ionized water for 10 minutes. 


\section{APPENDIX J: PROTOCOL FOR TREATING LASER ABLATED GaN WITH TRANSETCH-n}

1) The region of the ablated Gallium Nitride which is not desired to be treated by the etchant is masked with a sample of silicon. About $200 \mathrm{~nm}$ of Silicon Dioxide is grown on the remaining are of the sample in a Plasma Enhanced Chemical Vapor Deposition System. A five minute growth is performed in order to achieve this thickness.

2) The Transetch-n is heated in a glass beaker to 180 degrees centigrade.

3) The sample is immersed in the etchant and allowed to react for 10 minutes. Plastic tweezers were found to be unsuitable at such high temperatures and metal tweezers were required to extract the sample from the beaker.

4) The sample is rinsed in de ionized water.

5) The rinsed sample is then treated with the Buffered Oxide Etchant, in order to remove the deposited Silicon Dioxide.

6) The cleaned sample is cleaned with the standard cleaning procedures and a dehydration bake is done for half an hour at 100 degrees centrigrade.

7) The sample is then ready to have contacts deposited on it. 


\section{APPENDIX K: ETCH RATES OF SILICON DIOXIDE AND PHOTORESIST UNDER DIFFERENT CONDITIONS}

Table 13: Etch rates of $\mathrm{SiO}_{2}$ and Photoresist under $\mathrm{RF}=220 \mathrm{~W} ; \mathrm{t}=2 \mathrm{~min} ; \mathrm{p}=10 \mathrm{mT}$;

$\mathrm{FR}=65 \mathrm{sccm}$

\begin{tabular}{|c|c|c|}
\hline ESiO2(nm/min) & EPR(nm/min) & ICP(Watts) \\
\hline 179.1667 & 140.909 & 153 \\
\hline 198.0357 & 354.318 & 170 \\
\hline 209.6154 & 307.5 & 193 \\
\hline 221.25 & 571.25 & 236 \\
\hline
\end{tabular}

Table 14: Etch rates of $\mathrm{SiO}_{2}$ and Photoresist under $\mathrm{RF}=220 \mathrm{~W} ; \mathrm{ICP}=250 \mathrm{~W} ; \mathrm{t}=2 \mathrm{~min}$; $\mathrm{FR}=40 \mathrm{sccm}$

\begin{tabular}{|c|c|c|}
\hline ESiO2(nm/min) & EPR(nm/min) & Pressure(mT) \\
\hline 167.8571 & 856.786 & 30 \\
\hline 153.9583 & 371.25 & 35 \\
\hline 153.125 & 572.083 & 40 \\
\hline 120.714 & 344.063 & 45 \\
\hline
\end{tabular}

Table 15: Etch rates of $\mathrm{SiO}_{2}$ and Photoresist under $\mathrm{RF}=220 \mathrm{~W} ; \mathrm{ICP}=250 \mathrm{~W} ; \mathrm{t}=2 \mathrm{~min}$; $\mathrm{FR}=65 \mathrm{sccm}$

\begin{tabular}{|c|c|c|}
\hline ESiO2(nm/min) & EPR(nm/min) & Pressure(mT) \\
\hline 221.25 & 571.25 & 10 \\
\hline 162.22 & 308.438 & 30 \\
\hline 107.3529 & 110.833 & 50 \\
\hline 122.3611 & 386.667 & 55 \\
\hline
\end{tabular}

Table 16: Etch rates of $\mathrm{SiO}_{2}$ and Photoresist under $\mathrm{RF}=220 \mathrm{~W} ; \mathrm{ICP}=250 \mathrm{~W} ; \mathrm{t}=2 \mathrm{~min}$; $\mathrm{p}=30 \mathrm{mT}$

\begin{tabular}{|c|c|c|}
\hline ESiO2(nm/min) & EPR(nm/min) & Flow Rate (sccm) \\
\hline 162.9545 & 550.938 & 29.8 \\
\hline 170.2083 & 856.786 & 40 \\
\hline 165.75 & 230.5 & 59.7 \\
\hline
\end{tabular}




\begin{tabular}{|l|l|l|}
\hline 163.5 & 301.25 & 77.8 \\
\hline
\end{tabular}

Table 17: Etch rates of $\mathrm{SiO}_{2}$ and Photoresist under $\mathrm{RF}=220 \mathrm{~W}$; ICP=250W; $\mathrm{t}=2 \mathrm{~min}$; $\mathrm{p}=10 \mathrm{mT}$

\begin{tabular}{|c|c|c|}
\hline ESiO2(nm/min) & EPR(nm/min) & Flow Rate (sccm) \\
\hline 232.314 & 802 & 60 \\
\hline 221.25 & 571.25 & 65 \\
\hline 223.25 & 547.25 & 68 \\
\hline 197.64 & 612.5 & 78 \\
\hline
\end{tabular}




\section{APPENDIX L: TABLE 13 SPECIFIC CONTACT RESISTIVITY AND SHEET RESISTANCE OBTAINED FOR DIFFERENT SAMPLES}

Table 18: Specific Contact Resistivity and Sheet Resistance obtained for GaN samples under different conditions

\begin{tabular}{|c|c|c|}
\hline \multicolumn{3}{|c|}{ 1. Unablated Gallium Nitride } \\
\hline GaN Sample \#. & Specific Contact Resistivity & Sheet Resistance \\
\hline 34 & $1.30 \mathrm{E}-04$ & 4077.123 \\
\hline 81 & $2.60 \mathrm{E}-03$ & 2239.635 \\
\hline 86 & $1.20 \mathrm{E}-03$ & 1632.165 \\
\hline \multicolumn{3}{|c|}{ 2. Ablated Gallium Nitride } \\
\hline GaN Sample \#. & Specific Contact Resistivity & Sheet Resistance \\
\hline 34 & $6.66 \mathrm{E}-04$ & 2395.184 \\
\hline 81 & $2.24 \mathrm{E}-04$ & 287.273 \\
\hline 86 & $1.60 \mathrm{E}-03$ & 1323.51 \\
\hline \multicolumn{3}{|c|}{3. Pre Annealed Gallium Nitride } \\
\hline GaN Sample \#. & Specific Contact Resistivity & Sheet Resistance \\
\hline 34 & $6.86 \mathrm{E}-04$ & 2141.324 \\
\hline 81 & $8.29 \mathrm{E}-03$ & 209.06 \\
\hline 86 & $7.30 \mathrm{E}-04$ & 1430.612 \\
\hline \multicolumn{3}{|c|}{4. Transene-n treated Gallium Nitride } \\
\hline GaN Sample \#. & Specific Contact Resistivity & Sheet Resistance \\
\hline 34 & $1.12 \mathrm{E}-03$ & 1237.624 \\
\hline 81 & $2.60 \mathrm{E}-03$ & 2239.635 \\
\hline 86 & $1.44 \mathrm{E}-03$ & 153.39 \\
\hline
\end{tabular}

